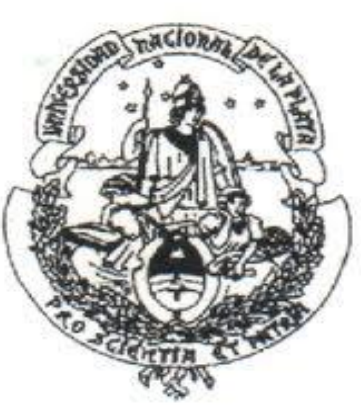

Universidad Nacional de La Plata

Facultad de Humanidades y Ciencias de la Educación

Secretaría de Posgrado

Departamento de Ciencias de la Educación

Maestría en Escritura y Alfabetización

\title{
Las creencias de futuros profesores de educación primaria sobre la ortografía y su enseñanza: estudio de caso
}

\author{
Tesis presentada por Mónica Viviana Ricca como requisito \\ para la obtención del grado de Magister en Escritura y Alfabetización
}

Dirección: Dr. Xavier Fontich Codirección: Dra. Anna Camps

La Plata

Diciembre de 2015 
Agradecimientos

En primer lugar, agradezco al Dr. Xavier Fontich y a la Dra. Anna Camps la generosidad que han tenido para aceptar la dirección de esta tesis de maestría. Sus comentarios y orientaciones han encauzado este trabajo y me han permitido realizar la investigación. Destaco mi agradecimiento a Xavier por haber sido asesor, director, maestro, psicólogo, compañero, amigo... Muchas gracias.

En segundo lugar, quiero agradecer a la Profesora Regina Usandizaga por su generosa ayuda y la predisposición para compartir su conocimiento y construir una temática para producir esta tesis.

En tercer lugar, toda mi gratitud a la Dra. Mirta Castedo y al excelente cuerpo de profesores de los seminarios, especialmente, a quien ha esclarecido el proceso de construcción de la escritura, la Dra. Emilia Ferreiro.

En cuarto lugar, también quiero recordar a mis compañeras y compañeros de cursado con los que hemos compartido largas jornadas de estudio, especialmente, a unas compañeras increíbles: Mariana Bianchi y Jorgelina Preciado.

En quinto lugar, reconozco a una persona muy especial, que me marcó un camino cuando cursé la escuela secundaria, la Profesora Marta Stonner de Cassano.

En sexto lugar, agradezco especialmente la formación y el acompañamiento de las Profesoras María del Pilar Vila y Juana Porro, que me impulsaron en la carrera docente y en la investigación. Es necesario también dedicar un cariño especial a mis compañeras del Departamento de Lengua, Literatura y Comunicación -Centro Universitario Regional Zona Atlántica de la Universidad Nacional del Comahue.

En séptimo lugar, distingo a quienes han sido mis MAESTRAS en el estudio de la lengua, las Profesoras Nelda Pilia de Assunçao y Elsa Biojout de Oliveras. Ambas han estado presentes en momentos muy significativos y me han formado como alumna.

Por último, agradezco la generosidad y el afecto de la Directora del Instituto Superior de Formación Docente y Técnica N² 25, Profesora María Angélica Balda; de mis compañeros profesores; de mis alumnos de formación docente y de los alumnos de las escuelas primarias asociadas por haberme permitido realizar esta investigación y aprender juntos en este camino que hemos recorrido. 
"Si tú tienes una propuesta no tienes que quedarte callado, porque las ideas sin la libertad no existen. No sólo quejarse, se debe de hacer cosas, lo que sea, hay que hacer algo, cada uno lo que pueda, lo que quiera. Nadie va a morir de ortografía, ni de educación, pero la ortografía es un reflejo de la educación, y la educación está detrás de todos los problemas. Se me ocurrió tomar el acento como un símbolo, un pequeño manifiesto en cada acento pegado. Respeto por las letras, por nuestra lengua, por nuestra cultura y por las calles... es una manera de decir 'la calle es nuestra'. Escribir bien significa respeto al interlocutor, a quien estás hablando, a quien le diriges tu mensaje. Abrí un blog donde subían todas las fotos que yo tomaba de las correcciones, un proyecto de calle que se difundió en línea. La ortografía no es la perfección, ni una falta, ni dos, ni ninguna. LA ORTOGRAFÍA ES UNA ACTITUD”.

Pablo Zulaica Parra (2012. Disponible en http://josemanuelochoa.com/2012/10/10/la-ortografia-es-una-actitud/) 


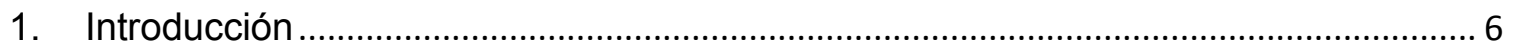

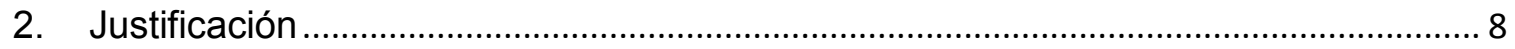

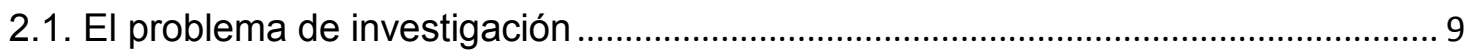

2.2. La necesidad de estudiar las creencias en las prácticas docentes ....................... 10

2.3. La enseñanza de la ortografía en el Diseño Curricular bonaerense ...................... 10

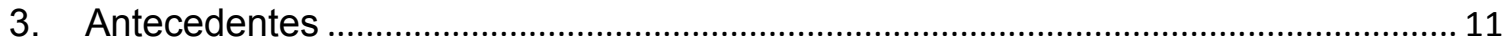

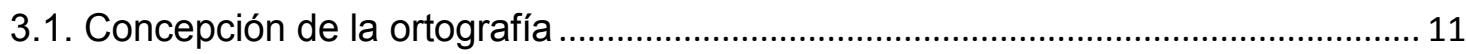

3.2. La enseñanza y el aprendizaje de la lengua escrita ............................................ 13

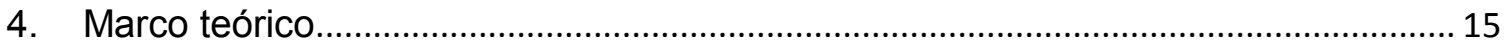

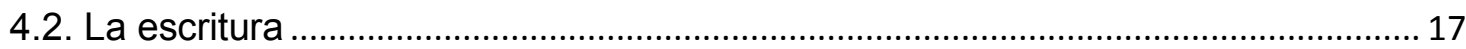

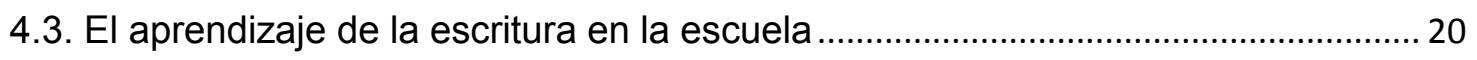

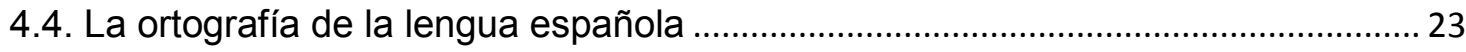

4.5. La reflexión metalingüística en el proceso de escritura ............................................ 28

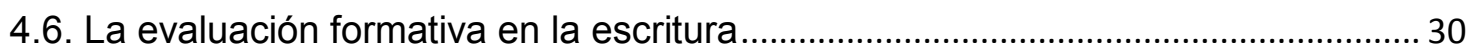

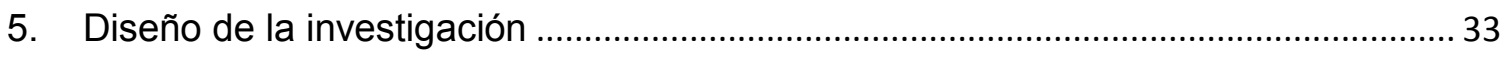

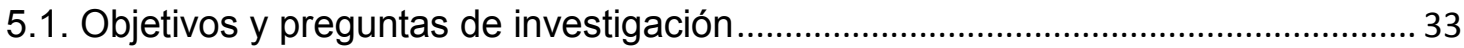

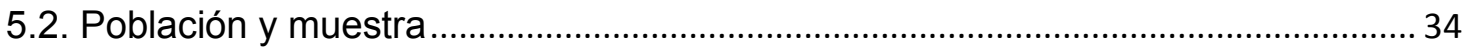

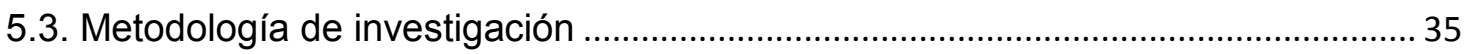

5.4. Procedimientos para recoger la información ........................................................ 37

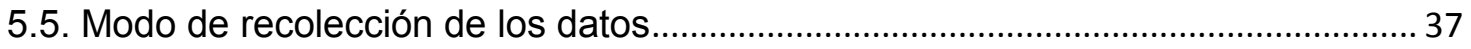

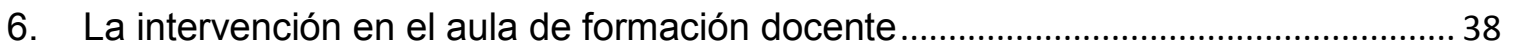

6.1. Antecedentes de la propuesta de intervención pedagógica en el aula...................39

6.2. Diseño e implementación de la secuencia didáctica................................................. 41

6.2.1. Primera fase: la preparación de la tarea.............................................................. 41

6.2.2. Segunda fase: la realización de la tarea.......................................................... 43

6.2.3. Tercera fase: la evaluación de la tarea .......................................................... 44

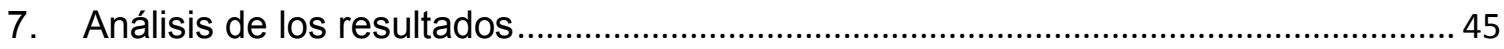

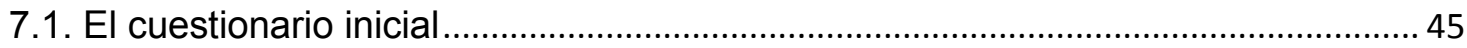

7.2. Análisis de las propuestas para enseñar ortografía ............................................. 50

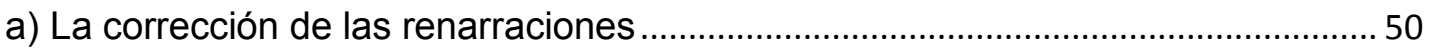

b) Formulación e implementación de secuencias didácticas en escuelas .................51 
c) Revisión de las propuestas sobre enseñanza de la ortografía..............................53

d) Autoevaluación de las propuestas sobre enseñanza de la ortografía....................55

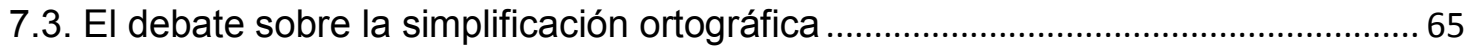

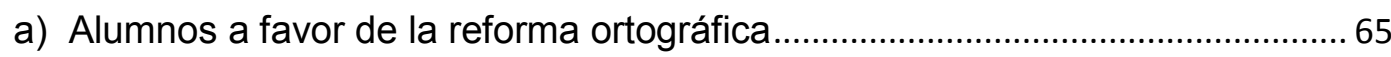

b) Alumnos en contra de la reforma ortográfica ..................................................66

c) Alumnos indecisos respecto de la simplificación ortográfica ..............................68

- Síntesis del análisis del debate sobre la reforma ortográfica .............................. 71

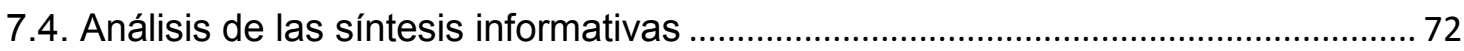

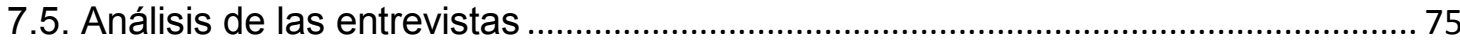

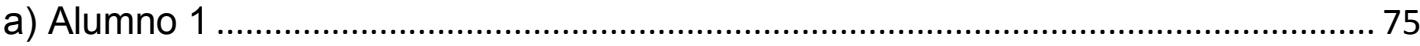

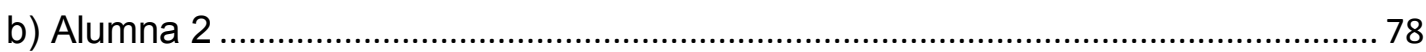

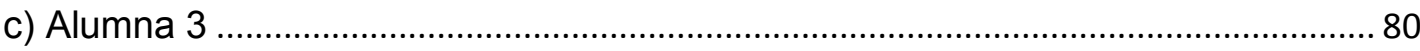

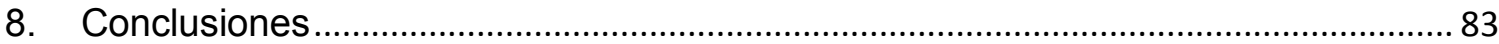

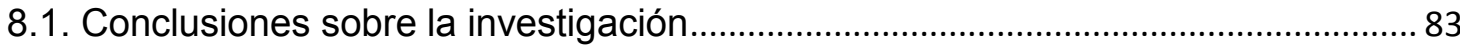

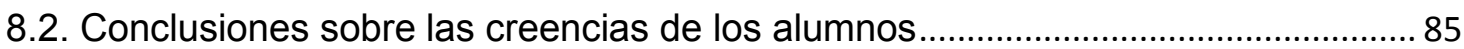

8.3. Conclusiones sobre la reflexión metalingüística ................................................... 87

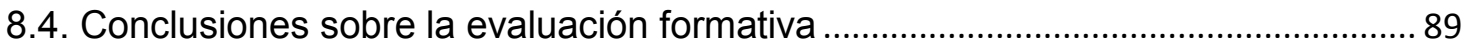

8.5. Implicaciones de esta investigación hacia el futuro ................................................. 90

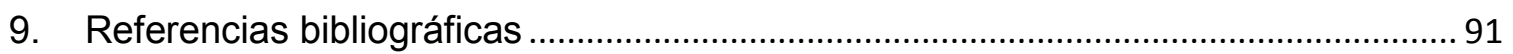




\section{Introducción}

El tema de este trabajo es la enseñanza de la ortografía en la formación del profesorado. La ortografía tiene una trascendencia social que no tienen otros aspectos del lenguaje escrito. Se trata de un tema que es discutido por docentes, alumnos, padres y la comunidad en general. Se le otorga tal importancia que hasta es noticia de diarios en nuestro país y en el mundo ${ }^{1} \mathrm{y}$, en alguno de ellos, se afirma que "la ortografía es uno de los indicadores más confiables del nivel educacional que posee una persona" (véase Blanco, 2013) ${ }^{2}$. Si bien a lo largo de la historia de la lengua española y todavía en la actualidad se discute si se debe simplificar o reformar, lo que no se puede dejar de tener en cuenta es que cumple una función muy importante en la normalización y perdurabilidad de nuestra lengua.

Camps et al. (1990) explican que la ortografía constituye una norma que tiene como fin una transcripción gráfica única para garantizar un modelo convencional y socialmente aceptado de representación de la lengua. En un diasistema como es el español, con las diferencias sociales y geográficas que presentan los dialectos, es la ortografía la que permite la comunicación eficaz y sin ambigüedades en los diferentes textos escritos por personas de diferentes lugares de habla hispana. Autores como Antonio de Nebrija y Andrés Bello han resaltado que la ortografía es el pilar sobre el que se asienta la unidad de la lengua española (véanse Esteve Serrano, 1982; Martínez de Sousa, 1996; Martínez Alcalde, 1999; Narvaja de Arnoux, 2006, 2008).

En relación con la enseñanza y el aprendizaje lingüístico-discursivo, el último diseño curricular implementado en la provincia de Buenos Aires (2008) ha propuesto la enseñanza de las prácticas del lenguaje a lo largo de los diferentes niveles educativos inicial, primario, secundario y superior- y la enseñanza de la ortografía a partir de promover la reflexión metalingüística con los alumnos. Las reformas curriculares implican incertidumbre, ya que los docentes tienen una formación particular y una manera de poner

\footnotetext{
${ }^{1}$ Cuáles son las faltas de ortografía que no pudieron descubrir los universitarios. Diario Clarín, 16/09/2015. Disponible en http://www.clarin.com/sociedad/faltas-ortografia-universitarios 0 1432057167.html

Bochazo masivo en el Poder Judicial de Mendoza por faltas de ortografía.
http://www.infobae.com/2015/09/16/1755686-bochazo-masivo-el-poder-judicial-mendoza-faltas-ortografia El dictado o la vuelta a las esencias de la educación en Francia. Diario El País, 25/09/2015

La publicidad con faltas de ortografía, un (triste) éxito de marketing. Diario El País, 24/09/2015

La 'hortografia'. Diario El País, 25/08/2015

Angriman, M.A. ¿A quién le importa la ortografía? Diario Río Negro, 23/06/2011. http://www.infobae.com/2013/09/25/1511397-los-diez-problemas-ortografia-mas-comunes-los-jovenes

2 Blanco, D. (2013). "Los diez problemas de ortografías más comunes entre los jóvenes". Disponible en http://www.infobae.com/2013/09/25/1511397-los-diez-problemas-ortografia-mas-comunes-los-jovenes
} 
en práctica su actividad que ha sido concebida en otros paradigmas. Cuando se plantea un cambio curricular, explica Strong-Wilson, los docentes pondrán en práctica lo que ya sienten como afinidad (2008: 448), es decir, las prácticas del profesorado estarán fuertemente influenciadas por sus propias creencias y conocimientos acerca de la materia. Clandinin también advierte que las innovaciones curriculares serán un fracaso a menos que se consideren los conocimientos de los profesores (1985: 364).

Diferentes autores han planteado que las creencias de los docentes tienen incidencia en sus comportamientos en el aula y en sus prácticas pedagógicas y que los cambios curriculares tienden al fracaso si no se consideran las creencias de los profesores (véanse Nespor, 1987; Pajares, 1992; Watson, 2015). Sobre la enseñanza de los contenidos gramaticales, Watson (2015) señala que el estudio sobre las creencias de los profesores tiene una gran relevancia porque son especialmente importantes para enfrentar situaciones en las que los docentes tienen que considerar demandas y prioridades que presentan diferentes enfoques o perspectivas teóricas. Borg y Burns explican que los profesores basan sus decisiones para enseñar en sus propias teorías sobre la práctica (2008: 458). En definitiva, estos estudios destacan que se deben explorar las concepciones de los profesores y describir sus prácticas para desarrollar un modelo de intervención en el aula, donde la enseñanza gramatical incida en los usos escritos.

En función de que no he encontrado estudios acerca de las creencias de los futuros docentes sobre la enseñanza de la ortografía, he tomado la noción de actividad metalingüística, desarrollada por el grupo GREAL, y aplicada en la enseñanza de la gramática y la escritura, para diseñar una intervención en el aula de formación del profesorado. De acuerdo con Calderhead, el proceso de reflexión y discusión de las creencias es un aspecto importante de su desarrollo profesional y constituye una manera de ayudar a los docentes -en este caso a los alumnos futuros profesores- a adaptarse a la reforma educativa (1996: 721). Así, en un estudio de caso, participaron veintinueve alumnos que cursaban el tercer año del Profesorado en Educación Primaria, en el Instituto Superior de Formación Docente y Técnica $N^{\circ} 25$ de Carmen de Patagones. La intervención consistió en dieciséis sesiones de clase. Los datos analizados corresponden a entrevistas individuales, tareas escritas de los alumnos y notas de campo de la investigadora.

El objetivo general de esta intervención fue implementar una secuencia didáctica sobre la enseñanza de la ortografía para, por un lado, poder analizar qué piensan los 
alumnos de formación docente sobre la ortografía y su enseñanza; y, por otro lado, poder fundamentar un instrumento de formación de enseñanza de la ortografía a partir de la reflexión metalingüística. Estos objetivos se realizaron a partir del desarrollo de dos tipos de actividades: a) la actividad de aprendizaje, que surge de la evaluación diagnóstica de los contenidos gramaticales que hacen falta trabajar y aprender; y b) la actividad de búsqueda, que se relaciona con buscar información y descubrir algún aspecto del funcionamiento de la lengua. Estas actividades permiten que los alumnos puedan hablar, escuchar, leer y escribir para construir conocimientos (Fontich, 2011). De acuerdo con Camps, las situaciones interactivas que se realizan en el aula entre alumnos y el docente a lo largo del desarrollo de la secuencia didáctica para aprender gramática, "facilitan que el profesor intervenga en el proceso de construcción del conocimiento y que pueda ofrecer las ayudas necesarias" (2003: 4; apud Camps y Zayas, 2006: 51).

\section{Justificación}

En la sociedad actual la enseñanza de la ortografía es un tema que genera incertidumbre porque no se sabe de qué manera debe abordarse. Suelen presentarse debates en los que se discute la conveniencia o no de reformarla. De hecho, el prestigioso escritor G. García Márquez propuso “jubilar la ortografía” (1997). Así, por un lado, están los que proponen una simplificación del sistema escrito, que intentan que haya una correspondencia biunívoca entre el fonema y la letra; y, por otro lado, se ubican los que defienden la evolución y las particularidades de la lengua. Desde los estudios gramaticales se destaca la función que cumple la ortografía en la normalización y en la perdurabilidad de la lengua.

La realidad es que nos encontramos con estudiantes y graduados de nivel superior que presentan dificultades ortográficas (véanse Padilla de Zerdán, 2003; Piacente y Tittarelli, 2006; Arnoux, Nogueira y Silvestri, 2007; Florit y Alochis, 2007; Teobaldo y Melgar, 2009; entre otros). Podemos observar en las redes sociales que se ocupan de aclarar cuándo escribir con determinadas letras. En diferentes grupos sociales se puede escuchar el cuestionamiento que se hace a la escuela primaria actual por no enseñar a escribir correctamente y por hacer que los alumnos pasen de año sin aprender lo básico y elemental. Frente a esta realidad, son muchos los que plantean volver a los métodos tradicionales de enseñanza, a los límites, a la repitencia escolar si no se sabe leer y escribir. Por otra parte, se repite que los alumnos ya no escriben, que el lenguaje escrito 
ha sido desplazado por la nueva tecnología y que la escuela debe ponerle un fin a esta situación.

\subsection{El problema de investigación}

En mi trabajo como docente formadora de futuros profesores de nivel primario recibo, con frecuencia, consultas de otros docentes y de los propios estudiantes acerca de cómo enseñar ortografía. Los alumnos que se están formando como futuros docentes presentan dificultades para escribir que los alejan de la convención ortográfica de la lengua. Otros aspectos de la lengua escrita no son tan cuestionados como las faltas ortográficas, tanto por parte de los propios alumnos como de los docentes que los forman (véanse Grande (h) y Jiménez Grotter, 2008; Vázquez, 2010; Frausin, Samoluk y Salas, 2012; Rondelli y Di Masso, 2014).

Mi problema fue pensar de qué manera abordar la enseñanza de la ortografía, especialmente con estudiantes de la formación inicial que deberán enseñarla más adelante a los alumnos de nivel primario. Recurrir a los manuales tradicionales fue encontrarme con ejercicios repetitivos de reglas ortográficas que poco explican sobre la construcción del conocimiento ortográfico.

Por otra parte, la consulta a otros docentes que enseñan la Didáctica de las Prácticas del Lenguaje y la Literatura -como se denomina la materia a partir de la última reforma curricular de 2008- me llevó a discutir sobre la necesidad de revisar cómo enfocamos la enseñanza de la lengua los docentes que estamos a cargo de la formación inicial de profesores. He observado que los docentes no sabemos cómo enfrentar esta formación. Pareciera que antes bastaba con que los alumnos se prepararan para leer y realizar ejercicios de análisis y reflexión gramatical. En cambio, en la actualidad, el nuevo diseño curricular (2008) incorporó una propuesta pedagógica más amplia que considera la revolución producida en los últimos cuarenta años sobre el estudio de las disciplinas que estudian el lenguaje, enfocadas desde la Didáctica de la lengua.

$\mathrm{Si}$ bien desde el discurso los profesores somos capaces de pensar que los contenidos gramaticales deben ser enseñados en el marco de la producción de textos, cuando enfrentamos la enseñanza en el aula no sabemos de qué manera hacerlo y lo primero que emerge son los modos de enseñanza con los que aprendimos. El hecho de haber formado parte de una enseñanza de la lengua desde un enfoque comunicativo, en el que se discutió y prácticamente se decretó la nulidad de la enseñanza gramatical en el aula, implica que se piense en volver a las formas tradicionales de enseñanza. A partir de las propuestas enmarcadas en la Didáctica de la lengua, que son superadoras del 
formalismo en el estudio de la lengua, es necesario que la educación lingüística revise sus prácticas en el aula.

\subsection{La necesidad de estudiar las creencias en las prácticas docentes}

La investigación en la enseñanza de la L1 ha explorado las creencias de los profesores, en campos como la educación multilingüe, la relación entre gramática y escritura, o la formación inicial del profesorado. Diferentes autores han planteado que las creencias de los docentes tienen incidencia en sus comportamientos en el aula y en sus prácticas pedagógicas (véanse Nespor, 1987; Pajares, 1992; Watson, 2015). De acuerdo con Calderhead, las creencias influyen en que los profesores puedan 'interpretar y simplificar' la información (1996: 719). Además, funcionan como un filtro a través del cual emergen los juicios sobre la enseñanza y constituyen la guía para tomar decisiones (Fang, 1996: 51).

En relación con la enseñanza de los contenidos gramaticales, como he indicado Watson (2015) señala que el estudio sobre las creencias de los profesores tiene una gran relevancia porque son especialmente importantes para enfrentar situaciones en las que los docentes tienen que considerar demandas y prioridades que presentan diferentes enfoques. Borg explica que los profesores basan sus decisiones para enseñar en sus propias teorías sobre la práctica (2008: 458). En definitiva, estos estudios destacan que se deben explorar las concepciones de los profesores y describir sus prácticas para desarrollar un modelo de intervención en el aula, donde la enseñanza gramatical incida en los usos escritos.

\subsection{La enseñanza de la ortografía en el Diseño Curricular bonaerense}

El último diseño curricular implementado en la provincia de Buenos Aires (2008) ha propuesto la enseñanza de las prácticas del lenguaje a lo largo de los diferentes niveles educativos -inicial, primario, secundario y superior-. Las define como diferentes formas de relación social que se realizan a través, en interacción y a partir del lenguaje. No se trata de enseñar contenidos de lengua aislados de sus usos, sino que el objeto de enseñanza son las prácticas sociales del lenguaje en los quehaceres del hablante, del lector y del escritor. Las prácticas del lenguaje ponen en juego acciones comunicativas, donde hacer -es decir, actuar en intercambios comunicativos orales y escritos- presupone una competencia comunicativa (un saber hacer, un poder hacer). Ese saber se va construyendo en una reflexión constante sobre aquello que se dice, lee, escribe, escucha, 
ya que se plantea que no hay "un saber" anterior al uso de la lengua que lo garantice, sino que se aprende a medida que se la usa.

En relación con la ortografía, el actual Diseño Curricular indica que forma parte de la reflexión sobre el lenguaje. Es natural que cuando los estudiantes escriban surjan dudas acerca de cómo escribir determinadas palabras, dado que la variedad de español que se emplea presenta diversos grafemas para representar un fonema y viceversa. Así, el conocimiento ortográfico es necesario para que las escrituras puedan ser comprensibles. Para abordar la enseñanza de la ortografía se propone que se puedan construir las reglas a partir de la observación y, cuando no se pueden hacer generalizaciones, provocar la reflexión metalingüística sobre el propio uso de la norma discursiva.

Por otra parte, al investigar sobre la relación entre las creencias de los futuros docentes, los materiales bibliográficos sobre la ortografía y su enseñanza, y la práctica pedagógica en un estudio de caso es posible analizar cuáles son los factores que obstaculizan o favorecen la enseñanza y el aprendizaje de la ortografía. Puede haber factores contextuales, externos, que limitan la enseñanza -como pueden ser los marcos teóricos y las propuestas para enseñar- y factores internos como las creencias. A continuación, explico brevemente cuáles son las diferencias entre los modos de concebir la ortografía y su enseñanza en dos marcos teóricos diferentes.

\section{Antecedentes}

Una de las dificultades que observo en algunas propuestas de enseñanza que se han difundido en los últimos veinte años en Argentina es la consideración de que la lengua española presenta una ortografía transparente. A partir de la hipótesis de la profundidad ortográfica (véase Katz y Frost, 1992) se formulan propuestas de enseñanza de la ortografía basadas en que los niños tienden a dominar más tempranamente y a emplear de manera privilegiada los mecanismos fonológicos de las lenguas de ortografía transparente. Esto implica que el uso de reglas de correspondencia grafema-fonema que son relativamente simples, según estos trabajos, les permite a los alumnos acceder a la pronunciación de las palabras sin necesidad de recurrir a otras fuentes de conocimiento.

\subsection{Concepción de la ortografía}

En función de revisar no solo las ideas de los alumnos sino mi propia concepción de ortografía, recurrí a la lectura de materiales que se han difundido en los últimos veinte años sobre la enseñanza y el aprendizaje de la lengua escrita. Estos trabajos presentan 
dos posturas diferentes frente a la temática: por un lado, están los que se preocupan por los métodos de enseñanza, conciben que la manera es enseñando la transcripción de la lengua oral y que la ortografía del español es transparente (véanse Cuetos, 1989; Borzone de Manrique, 1999; Borzone de Manrique y Diuk, 2001; Signorini y Piacente, 2001; Pujol Llop, 2001; Borzone y Diuk, 2003; Marín, Cuadro y Pagán, 2007; Ferroni, Sánchez Abchi, Diuk y Borzone, 2008; Diuk, Borzone, Sánchez Abchi y Ferroni, 2009; Carratalá Teruel, 2013; Ferroni, Diuk y Mena, 2015); y, por otro lado, en el marco de la psicogénesis se analiza la construcción del sistema de escritura, teniendo en cuenta las características del objeto de conocimiento -la escritura no consiste en la transcripción de la lengua y la ortografía del español no es totalmente transparente- y al alumno como sujeto cognoscente (véanse Díaz Argüero, 2004; Ferreiro, 2013).

En el caso del primer grupo de trabajos, pude observar que resaltan que en el aprendizaje de la lectura y la escritura el componente fonológico o conocimiento y uso de las correspondencias escritura-sonido tiene un papel fundamental. En relación con la ortografía, explican que en las lenguas más transparentes -como supuestamente el español-, observan en la formación de representaciones ortográficas mentales de las palabras un alto desempeño en lectura y escritura fonológica que se sustenta en el empleo de estrategias fonológicas (véanse Cuetos, 1989; Borzone de Manrique, 1999; Borzone de Manrique y Diuk, 2001; Signorini y Piacente, 2001; Pujol Llop, 2001; Borzone y Diuk, 2003; Marín, Cuadro y Pagán, 2007; Ferroni, Sánchez Abchi, Diuk y Borzone, 2008; Diuk, Borzone, Sánchez Abchi y Ferroni, 2009; Ferroni, Diuk y Mena, 2015). Por su parte, Pujol Llop también enfatiza que la ortografía del castellano es superficial y que los hablantes nativos tienden a emplear la vía fonológica. Esto implica para este autor que la ruta fonológica es la que permitiría la escritura correcta de las palabras una vez que el individuo identifica el fonema y aplica las reglas de conversión fono-ortográficas (2001: 70). En un sentido similar, Carratalá Teruel explica que

en el ámbito de la ortografía preventiva se inscribe el aprendizaje de los vocablos por medio del método viso-audio-motor-gnósico, que garantiza una alta rentabilidad léxico-ortográfica; y que combina los aspectos físicos del significante (las palabras han de ser vistas), con dificultades; con aquellos elementos ortográficos debidamente resaltados que puedan encerrar dificultades; pronunciadas con perfecta ortología, una vez se posea una correcta imagen auditiva de las mismas; y escritas con la atención debida, para completar, así, con una imagen cinética cuanto que afecta al ámbito polisensorial con los aspectos de naturaleza inmaterial (denotativos y connotativos) del significado; lo cual implica la inclusión de las palabras en contextos apropiados (2013: 21. La cursiva es mía). 
En cambio, un conjunto de trabajos no menor discrepa de la idea según la cual la ortografía del español es transparente (véanse Camps et al., 1990, Díaz Argüero, 2004; Kaufman, 2005; Kaufman y Rodríguez, 2008; Ferreiro, 2013). Enfocan además el trabajo de enseñanza de la ortografía incorporando al sujeto de aprendizaje como alguien que piensa y construye conocimiento. Los errores se analizan para entender los procesos psicolingüísticos involucrados en la construcción del conocimiento ortográfico de una lengua española que no es transparente en la correspondencia grafo-fónica y la enseñanza se propone en el estudio contextualizado de la ortografía mientras se escribe. Esto implica que no se proponga el aprendizaje de la ortografía como la repetición memorística de reglas y, así, se evite la sobrecarga de la memoria y la aplicación mecánica de ejercicios repetitivos y descontextualizados de situaciones reales de escritura.

\subsection{La enseñanza y el aprendizaje de la lengua escrita}

El presente trabajo, a partir de lo expuesto anteriormente, parte de dos cuestiones que se relacionan en el proceso de enseñanza y aprendizaje de la lengua escrita. La primera se relaciona con los trabajos de investigación realizados en los últimos años por el Grupo de Enseñanza y Aprendizaje de Lenguas (GREAL) sobre la importancia y la necesidad de realizar con los alumnos una reflexión metalingüística en el aprendizaje de la lengua para que logren el dominio de determinadas nociones gramaticales. En tanto que la segunda cuestión está relacionada con un modelo de enseñanza de los contenidos gramaticales implementado en las investigaciones del GREAL, que guían la intervención en el aula y exploran los procesos que se desencadenan a partir de esa intervención.

En tal sentido, los resultados de las investigaciones desarrolladas por el GREAL muestran que se puede explorar un modelo de enseñanza y aprendizaje de contenidos gramaticales que, a su vez, constituye un marco para la investigación sobre la enseñanza de la gramática que se inspira en los planteamientos de la investigación-acción. A partir de la investigación-acción se puede comprender mejor la práctica, dado que se consiguen sistematizar los resultados y, a partir de ellos, entender mejor el proceso de enseñanzaaprendizaje en el aula, renovando los procesos y ajustándolos a las características y necesidades de los alumnos. El uso del lenguaje en el aula posibilita el análisis de los productos en relación con los contextos en los que se producen y también con los procesos de enseñanza-aprendizaje de la lengua. El trabajo que proponemos realizar en esta investigación se ubica en el marco de las investigaciones de la didáctica de la lengua que, a partir de la perspectiva que ofrecen los conocimientos teóricos, intenta comprender 
los productos realizados en el aula con el propósito de renovar las prácticas de enseñanza.

Cabe destacar que la enseñanza de la gramática es un problema que ya tiene un largo recorrido, pero que todavía no ha sido resuelto (Camps, 2014). Esta problemática se basa en la división entre gramática implícita -que es adquirida en los primeros años de vida y que permite a los hablantes usar su propia lengua- versus la gramática explícita que es el conocimiento que permite reflexionar sobre la propia lengua y sobre las que se aprenden y, además, posibilita regular el uso en cualquiera de ellas-. Esta dicotomía entre gramática implícita y gramática explícita pasó a un segundo plano en la década del 80 , cuando se focalizó la enseñanza de la lengua desde una perspectiva comunicativa. No obstante, en la misma época surgió una propuesta renovadora al plantear en el contexto de la Didáctica de la Lengua, como la emergencia de un nuevo campo científico y un área de conocimiento específico, la necesidad de incluir la gramática como contenido de enseñanza a partir de reformular las finalidades, los fundamentos y las metodologías (Camps, 2009, 2014; Camps y Zayas, 2006; Fontich, 2006; Fontich y Camps, 2015).

En este contexto, la renovación de la enseñanza de la gramática se aborda desde el análisis de: (i) los contenidos de enseñanza, (ii) los modelos de enseñanza, (iii) el papel de los estudiantes. En relación con los contenidos de enseñanza, se destaca la necesidad de una gramática pedagógica que reformule los contenidos morfológicos y sintácticos en función de priorizar las dimensiones semántica y pragmática (Camps, 2014). Sobre los modelos de enseñanza se propone un aprendizaje basado en la reflexión generada en el aula a partir de la interacción entre los alumnos y con el docente y en la relación entre gramática y escritura, que promueve la reflexión metalingüística (Camps \& Milian, 2000). Esto implica que los alumnos puedan reflexionar sobre los contenidos gramaticales para lograr la abstracción, la generalización y la sistematización de los conceptos lingüísticos y su papel en la escritura. Si bien se han realizado estudios con alumnos de escuelas secundarias (Fontich, 2006; Watson, 2015), las creencias de los futuros profesores han sido poco exploradas (Fontich, 2010).

En los últimos años se han realizado investigaciones para construir nuevos conocimientos sobre la enseñanza de la lengua en la formación de maestros a partir de la observación de las prácticas en el aula, con el propósito de que puedan recuperarse en la formación del profesorado (Fontich, 2010; Dolz, 2009). Dolz explica que existen cinco desafíos relacionados con la formación lingüística del profesorado: a) la preparación lingüística necesaria para poder ejercer la profesión docente, b) la formación de un 
profesorado capaz de evaluar las capacidades y dificultades de los alumnos para orientar sus intervenciones en función de sus necesidades, c) la elaboración conjunta, con los profesores, de situaciones de comunicación que promuevan los aprendizajes lingüísticos, d) la puesta en práctica de la enseñanza, experimentando los principales gestos profesionales del profesor, y d) la articulación entre la formación y la investigación (2009: 2-3, la cursiva pertenece al original.). Si bien estos trabajos sugieren la importancia de estudiar las creencias de los estudiantes en formación -por ejemplo en relación con la escritura y la lectura-, como he indicado un aspecto poco explorado a pesar de su enorme relevancia social son las creencias en torno a la ortografía.

\section{Marco teórico}

Antes de abordar la investigación propiamente dicha es necesario delimitar su campo de estudio. En este apartado presento la perspectiva que he adoptado para abordar la ortografía y su enseñanza: a) los estudios sobre creencias de los docentes, b) los estudios sobre la escritura y sobre el aprendizaje de la lengua escrita en la escuela, c) la ortografía, d) la reflexión metalingüística, y e) la evaluación formativa. Considero necesario incluir la concepción de escritura y su aprendizaje porque tienen relación con el desarrollo del conocimiento ortográfico. Además, incluyo la actividad metalingüística y la evaluación formativa en la enseñanza de la lengua escrita, a partir del marco teórico de la enseñanza de la lengua escrita y la gramática propuesta por los investigadores del GREAL (Camps \& Milian, 2000; Camps y Fontich, 2015), para reflexionar sobre las creencias de los alumnos futuros docentes frente a la falta de ortografía y de qué manera abordarla.

\subsection{Los estudios sobre creencias de los docentes y su formación inicial}

En las investigaciones sobre la formación inicial de docentes se ha planteado la necesidad de analizar las creencias que tienen los alumnos cuando estudian una carrera docente. Una de las dificultades que se presentan cuando se proponen estudiar las creencias es precisar qué se entiende por 'creencia'. Borg señala que se trata de un concepto que presenta "ambigüedad conceptual" (2003: 352) y Pajares (1992) la describe como un constructo desordenado. De acuerdo con Van Dijk, las creencias "son productos o propiedades del pensamiento" y pueden definirse como "unidades de información y de procesamiento de la información, así como también pueden ser consideradas como 
productos del pensamiento, o, ciertamente, como las condiciones y consecuencias (mentales) del discurso y la interacción social" (1999: 35-38).

En relación con las creencias de los docentes, Kagan explica que se refieren a los pensamientos que se generan cuando se planifica la situación didáctica, a los que surgen durante la interacción mientras se desarrolla el proceso de enseñanza y aprendizaje, a las ideas implícitas sobre los estudiantes y el aprendizaje, a las reflexiones sobre su propio desempeño docente, a las actividades y rutinas automatizadas que forman parte de su repertorio al enseñar, y la autoconciencia sobre los procedimientos que se emplean en el aula para resolver problemas (1990: 420). Es importante aclarar que se incluyen entre estos elementos tanto los conscientes -que pueden ser explicitados- como los inconscientes o automatizados -que quedan de manera implícita-.

Existen diferentes perspectivas de análisis sobre las creencias de los docentes, entendidas como preconceptos o premisas que los sujetos consideran como verdaderas. De acuerdo con Marcelo y Vaillant (2009), las creencias difieren del conocimiento proposicional porque no requieren una condición de verdad para contrastar su validez. Además, según Richardson (1996; apud Marcelo y Vaillant, 2009: 66), las creencias cumplen dos funciones básicas: a) intervienen en la manera en que los futuros profesores aprenden, y b) influyen en los procesos de cambio que los docentes puedan protagonizar.

Otros autores hacen referencia al 'conocimiento práctico' de los docentes (Elbaz, 1983) o el 'conocimiento práctico personal' (Connelly y Clandinin, 1985) para explicar cómo funcionan los conocimientos, los valores, las experiencias y las creencias en las que se basan las decisiones que toman los docentes en sus prácticas áulicas. Estas dos maneras de conceptualizar las 'creencias de los docentes' involucran lo que Calderhead denomina los procesos mentales encubiertos que guían las conductas de los docentes (1987: 184) o la dimensión cognitiva de la enseñanza a partir del análisis de lo que los profesores saben, creen y piensan (Borg, 2003: 81).

Las creencias se han caracterizado por estar construidas por diferentes elementos:

- Elementos cognitivos, en tanto las creencias forman parte del pensamiento del profesor (Calderhead, 1987: 183);

- Elementos afectivos, dado que las creencias incluyen aspectos de emoción (Clandinin, 1985: 362; Nespor, 1987: 318);

- Elementos evaluativos, en función de que las creencias implican juicios (Clandinin, 1985: 362; Nespor, 1987: 318; Pajares, 1992: 325); 
- Elementos episódicos, constituidos por eventos particulares o episodios que les dan forma a las creencias (Nespor, 1987: 320; Pajares, 1992: 325); $y$

- Elementos ontológicos o existenciales, que son las creencias que guían la visión de lo que se percibe como real o realidad (Nespor, 1987: 318; Braithwaite, 1999).

Si bien entre los diferentes abordajes sobre las creencias de los profesores se pueden encontrar diversas formas de denominación y de perspectivas, existe una zona de acuerdo en que se deben abordar estas creencias en las reformas curriculares y para analizar las prácticas de enseñanza. De acuerdo con los estudios, se trata de una construcción realizada a través de un proceso de enculturación social (Pajares, 1992: 316), que ha sido modelada por la experiencia (Nespor, 1987: 318) y que forman un filtro o una lente a partir de la cual los docentes orientan sus acciones educativas.

Por otra parte, los resultados de las investigaciones sobre la formación inicial del profesorado señalan que las creencias que los estudiantes tienen incorporadas cuando comienzan los estudios de una carrera docente afectan de forma directa la interpretación y la valoración que realizan de su aprendizaje. Se trata de un aprendizaje que no se produce de manera intencionada, sino que impregna las estructuras cognitivas y emocionales de los futuros docentes inconscientemente, y puede crear expectativas y creencias difíciles de modificar (Marcelo y Vaillant, 2009: 66).

En este trabajo recupero el aporte de Borg, quien explica que los sistemas pedagógicos personales están formados por las creencias, el conocimiento, las teorías, las suposiciones y las actitudes que los profesores tienen acerca de su trabajo (1998: 9). De acuerdo con Borg, se trata de un modelo de cognición docente, que relaciona las creencias con las prácticas a partir de estudiar lo que saben los maestros -lo que piensan y creen- y cómo se relacionan estas creencias y saberes con lo que hacen en el aula (Borg y Burns, 2008: 457). Por otra parte, Pajares ha afirmado que las investigaciones de las creencias deben incluir observaciones de sus prácticas y entrevistas con el fin de considerar la relación entre los maestros 'dicen' y 'hacen' (1992: 327).

\subsection{La escritura}

De acuerdo con Ferreiro (1997), la escritura es un sistema de representación del lenguaje, que involucra un proceso de diferenciación entre los elementos y las relaciones reconocidas en el objeto representado y una selección de elementos y relaciones que son 
retenidos en la representación. Explica la autora que si un sistema $(X)$ constituye una representación adecuada de una cierta realidad $(R)$, se unen dos condiciones que parecieran ser contradictorias:

- $(X)$ posee algunas de las propiedades y relaciones propias a $(R)$;

- (X) excluye algunas de las propiedades y relaciones propias a (R).

Así, la construcción de un sistema de representación $(X)$ adecuado a $(R)$ puede generarse a partir de vincularse de manera arbitraria -como es el caso del lenguaje- o de manera analógica. Ferreiro establece la diferencia entre sistemas de representación creados como la escritura y los alternativos. Explica que "en el caso de la creación de una representación ni los elementos ni las relaciones están pre-determinados" (1997: 14, la cursiva corresponde al original); mientras que los sistemas de representación alternativos de uno que ya fue creado -como la transcripción de las letras del alfabeto en código telegráfico, la transcripción de la escritura en código Morse, entre otros- constituyen códigos de transcripción alternativa que se basan en una representación ya elaborada (el sistema alfabético del lenguaje o el sistema ideográfico de los números). La diferencia esencial es que en los códigos o la codificación tanto los elementos como sus relaciones ya están predeterminados; en cambio, en la construcción de una primera forma de representación adecuada -es decir, por ejemplo, el caso particular de la representación del lenguaje escrito- el proceso es una larga evolución histórica que logra una forma de uso colectivo (1997: 14-15).

En otras palabras, la escritura capta, registra o representa con relativa facilidad las formas verbales, es decir, el léxico y la sintaxis de una lengua. Es importante considerar que la escritura solo puede conservar los elementos verbales -léxico y relaciones sintácticas- de un enunciado, pero no puede representar otros aspectos relacionados con el significado como la expresión de determinados acentos al hablar, la entonación, el tono de voz, que se pierden en el paso de la oralidad a la representación gráfica. Compartimos con Olson que

La escritura requiere que estas propiedades sean representadas gráficamente a través de la puntuación, o léxicamente por medios como los verbos "suponer", "inferir", "sugerir", etc., si no se quiere que las expresiones estén sujetas a interpretación. La creación de representaciones exige no sólo una comprensión de estas diferencias, sino también un control conceptual y léxico de ellas a través de la indicación de cómo deben ser tomadas (proveer indicaciones implícitas sobre si se intenta amenazar o prometer, si se está hablando literal o metafóricamente, si se trata de un hecho o de una conjetura, etc.) (1999: 218).

En tal sentido, Olson (1999) explica que existen creencias sobre la lengua escrita que han originado débiles prácticas educativas y frágiles políticas sociales. Estas 
creencias se basan en considerar que a) la escritura es una forma de transcripción del lenguaje oral o del habla, b) la escritura es superior a la oralidad, en función de que se considera que el habla es imprecisa y desordenada y que la escritura es un instrumento de precisión y poder, c) el sistema alfabético de escritura tiene una superioridad tecnológica, d) la escritura es un órgano de progreso social, e) la cultura escrita constituye un instrumento de desarrollo cultural y científico, f) la escritura, así como es protagonista del desarrollo cultural, es un instrumento de desarrollo cognitivo, dado que las habilidades para leer y escribir constituyen las vías de acceso al conocimiento.

Comparto con Olson (1999) que, para poder comprender las consecuencias cognitivas que tiene la escritura, se debe partir de que la escritura no es una transcripción de la oralidad, sino que constituye un sistema de representación con sus rasgos específicos. Destaca que la escritura tiene una importante función epistémica, cuando afirma que

La magia de la escritura proviene no tanto del hecho de que sirva como nuevo dispositivo mnemónico, como ayuda para la memoria, sino más bien de su importante función epistemológica. La escritura no sólo nos ayuda a recordar lo pensado y lo dicho: también nos invita a ver lo pensado y lo dicho de una manera diferente. Es un clisé decir que escribir es más que el abecé, y que el alfabetismo es más que la capacidad para descodificar palabras y oraciones. El problema consiste en aprehender ese "más" (1999: 16).

Considero que ese "más" al que hace referencia Olson está relacionado con el desarrollo de la reflexión metalingüística. En tal sentido, este autor afirma que lejos de ser una transcripción del habla, la escritura provee un modelo conceptual para el estudio del habla y los modelos de lengua que brinda la escritura no solo son los que se adquieren en la lectura y en la escritura sino, principalmente, el hecho de pensar acerca de la lengua. En otras palabras, la escritura es metalingüística (véase 1999: 114). Así, de acuerdo con Olson, al utilizar el lenguaje escrito a través de la lectura o de la escritura, los seres humanos tomamos conciencia de manera simultánea de dos cuestiones importantes: el mundo y el lenguaje. Según este autor, hay cuatro niveles de análisis: (i) el mundo de los objetos, (ii) el lenguaje oral que se produce a partir de tomar al mundo como objeto y construye una forma lingüística de conciencia del mundo, (iii) la escritura que produce una conciencia lingüística desde que toma al lenguaje oral como objeto de análisis, y (iv) el metalenguaje oral que se genera al tomar la escritura o algún elemento de un texto escrito como objeto y produce una conciencia metalingüística.

Aprender a leer y a escribir en la escuela el sistema alfabético de escritura del español implica que los niños puedan vincular la lengua escrita con la lengua oral. De 
acuerdo con Quinteros (2004), para descubrir el principio alfabético y relacionar una letra con un sonido es necesario comprender cómo opera nuestro sistema de escritura. A partir de las investigaciones psicolingüísticas que han explicado la evolución de la construcción del sistema de escritura en los niños (véanse los trabajos de Ferreiro y sus colaboradores), se ha mostrado que una de las dificultades de los niños en la alfabetización inicial es descubrir el principio alfabético. Explica Quinteros (2004) que antes de comprender este principio alfabético, los niños logran darse cuenta de una noción básica de nuestro sistema de escritura: que se trata de un sistema de representación y que es un objeto simbólico.

Gracias a las investigaciones realizadas en el marco teórico de la psicogénesis, Ferreiro (1997, entre otros) ha esclarecido que las ortografías que inventan los niños, mientras están construyendo el sistema de escritura, presentan regularidades diferentes que responden al nivel de conceptualización de la escritura -escrituras silábicas, escrituras silábico-alfabéticas y alfabéticas-. Antes de que construyan el principio alfabético, los niños logran descubrir que la escritura representa sonidos de la palabra oral. Desde este momento, los niños comienzan a agregar letras a las escrituras generalmente, las consonantes que acompañan a los núcleos vocálicos de la sílaba-. A partir de este momento de la construcción del sistema de escritura, el logro es que pueden analizar la palabra oral en segmentos menores, que comienzan en la sílaba continúan con los componentes intrasilábicos y terminan en los fonemas (véase Quinteros, 2004).

\subsection{El aprendizaje de la escritura en la escuela}

De acuerdo con Quinteros, la importancia de estudiar el pasaje del período silábico al alfabético radica en la necesidad de comprender cómo se re-estructura lo 'oral' a medida que el niño re-estructura lo 'escrito' cuando aborda el sistema de escritura como un subsistema lingüístico que tiene su propia especificidad. Concebir el aprendizaje de la lengua escrita como la manera de comprender la escritura, en tanto sistema de representación, implica la comprensión acerca de por qué hay elementos de la oralidad que no se representan en la escritura -como la entonación, los modos que incluyen la ironía, etc.-, por qué todas las palabras se tratan como equivalentes en la representación, aunque formen parte de clases diferentes; por qué se dejan de lado las semejanzas en el significado y se enfatizan las semejanzas sonoras; etc. Explica, en tal sentido, la autora que 
la actividad cognitiva de los niños no sólo se dirige a organizar las unidades gráficas del sistema de escritura (sus repertorios de letras) sino que dicho esfuerzo se coordina con la necesidad de comprender la manera como este sistema opera (modo de producción), las reglas que lo rigen y su naturaleza (cuál es la relación entre lenguaje escrito y lenguaje oral y qué clase de unidades del lenguaje oral son representadas por nuestro sistema). Tales son los aspectos involucrados en la adquisición del principio alfabético (2004: 281).

Ferreiro (1997) explica que, cuando los niños han llegado a construir la hipótesis alfabética, han comprendido la naturaleza intrínseca del sistema alfabético de escritura, pero todavía no pueden abordar los rasgos ortográficos específicos de la lengua escrita signos de puntuación, espacios en blanco, representación poligráfica de fonemas, usos de mayúsculas y de minúsculas, etc.-. Así, una vez que comprendieron que la similitud sonora implica similitud de letras y las diferencias entre ellas incluyen letras diferentes, dado que no pueden asumir de manera inmediata todas las particularidades gráficas del sistema alfabético, intentan eliminar las irregularidades ortográficas.

A partir de la noción de 'conocimiento ortográfico' propuesta por Cassar y Treiman, Ferreiro propone que es más conveniente emplear la denominación 'conocimiento gráfico', en función de que los niños pequeños podrían manifestar en sus escrituras y en sus elecciones interpretativas un conocimiento de las combinaciones de letras posibles o imposibles, sin que tuvieran todavía el conocimiento de las alternancias en un punto dado de una cadena gráfica. Así, de acuerdo con Ferreiro,

puede haber un conocimiento de las secuencias como tales (eje sintagmático) sin que las correspondencias grafemas-fonemas estén consolidadas $y$, sobre todo, sin que las alternativas en el eje paradigmático estén organizadas (o sea, los lugares de alternancia gráfica en una secuencia dada). Ese conocimiento gráfico seguramente es reorganizado a medida que progresa el conocimiento ortográfico, pero no hay razón para pensar que desaparece. Hay que tener en cuenta que los requerimientos de cantidad mínima y variedad interna (Ferreiro y Teberosky, 1979; Ferreiro, 2000) están sólidamente establecidos mucho antes de las correspondencias fonema-grafema, lo cual sugiere una atención precoz a las secuencias de letras como tales (2013: 171, la cursiva corresponde al original).

Conocer y considerar la evolución psicológica de la construcción del sistema de escritura en los niños es importante para valorar lo que habitualmente en las prácticas conductistas se señala como errores y para rechazar esas prácticas que reducen el lenguaje escrito a actividades escolares en que la lengua se convierte en un código. Pero este conocimiento no es suficiente si los docentes o futuros docentes esperan y solicitan métodos y materiales de enseñanza a través de los cuales puedan controlar el proceso de 
aprendizaje. Tampoco este conocimiento implica que los docentes se queden esperando que los niños arriben al siguiente nivel, sino que se deben organizar experiencias con la lengua escrita para que los alumnos puedan apropiarse del lenguaje escrito en el marco del uso social. Comparto con Teberosky que el marco teórico constructivista que aporta la perspectiva psicogenética de conceptualización de la escritura plantea algunas cuestiones que la diferencian de la visión en componentes:

desde el punto de vista evolutivo ningún aprendizaje es estable, aislado e
independiente de otros aprendizajes sobre el sistema de escritura. Los nuevos
aprendizajes se apoyan en aprendizajes anteriores que se reorganizan, no de forma
inmediata sino a lo largo del proceso. Por ejemplo, la posibilidad de ir más allá de la
sílaba en el análisis de las palabras, el conocimiento de las letras y la
conceptualización sobre lo escrito entran en relación recíproca con los avances en la
escritura (Vernon, 1998; apud Teberosky, 2011: 4).

Asumo, de acuerdo con Teberosky (2011) que la escritura no sólo es un sistema que representa unidades fonológicas o morfológicas, sino que constituye un sistema complejo de formas y géneros que crean sus propias unidades. Así, la letra, la palabra, la frase, el parágrafo, el género y el texto son unidades que están producidas por las propias convenciones del uso del lenguaje escrito.

En tal sentido, Teberosky (2011) explica que la distinción sintagmáticaparadigmática en el campo lexical se produce hacia los 6 o 7 años, a partir de la influencia de la escolaridad y particularmente por el aprendizaje de la lectura y la escritura, que estimula un cambio conceptual y lingüístico. Al principio, cuando se les pide a los niños pequeños que asocien palabras, ofrecen asociaciones sintagmáticas, por una combinación mental que evoca el mismo escenario o porque asocian con la primera palabra que se les viene en mente. En cambio, cuando son más grandes, los niños formulan palabras dentro del mismo paradigma y de la misma clase gramatical en relaciones semánticas opuestas, coordinadas o sinónimas.

Para explicar el cambio sintagmático-paradigmático que se produce en el campo gráfico y ortográfico, Ferreiro explica que los niños inicialmente consideran las secuencias de letras, antes de tomar las relaciones fonográficas. De esta forma, prestan atención al aspecto sintagmático -en cuanto a la cantidad y variedad de letras que pueden ir juntasantes de considerar la correspondencia entre grafema y fonema, que corresponde a la relación paradigmática. El conocimiento acerca de las letras que van juntas es de tipo gráfico y, si bien no desaparece posteriormente, se reorganiza con la incorporación del conocimiento ortográfico, que es de naturaleza paradigmática (2002; apud Teberosky, 2011: 6-7). 
Otro cambio que se produce, de acuerdo con Teberosky (2011) es el desarrollo de la competencia metalingüística a partir de las relaciones con los textos y las actividades de lectura. Según la autora, el aprendizaje de la escritura no solo pone en juego la representación de aspectos fonológicos o morfológicos, sino que también se aprende sobre la manera en que se representa el lenguaje en los textos escritos. Por ello, la autora recomienda que se desarrollen diferentes tipos y niveles de conciencia metalingüística en las actividades de lectura y de escritura. Sostiene que la reflexión en los diferentes niveles debe generar:

- Conciencia enunciativa, a partir del análisis de las situaciones de enunciación presentes en los textos -mensaje, comentario, repetición, citación, etc.-;

- Conciencia analítica, generada por la reflexión de las unidades del lenguaje escrito -letras y sonidos, palabra, frase, parágrafo, texto o género;

- Conciencia metalingüística, que se desarrolla a través del empleo de un metalenguaje;

- Conciencia autonímica, surgida a partir de emplear el lenguaje para referirse a sí mismo, en oposición al uso referencial del lenguaje propio de la conversación. Esta conciencia requiere del desarrollo de la conciencia metalingüística (2011: 7-8).

La escritura, al ser gráfica y visual, permite que el lenguaje tenga permanencia y posibilita la lectura, la relectura para que los lectores puedan analizar, corregir, interpretar, reinterpretar, diseñar, escribir, rediseñar y reescribir un texto. Por otro lado, la circulación hace a la independencia de los textos que pueden ser leídos, releídos, reinterpretados y, también, repetidos, memorizados, parafraseados, comentados, citados, etc. En el siguiente apartado, abordo el desarrollo de la capacidad para reflexionar sobre los textos.

\subsection{La ortografía de la lengua española}

La ortografía, de acuerdo con la Real Academia Española y la Asociación de Academias de la Lengua Española (2011), es un conjunto de normas y una disciplina lingüística. En primer lugar, se explica que la escritura está constituida por el conjunto de signos convencionales que se emplean para representar gráficamente el lenguaje y que son necesarias las normas que regulan cuándo y cómo deben utilizarse estos signos. Así, la palabra ortografía, cuya definición etimológica hace referencia a la 'recta escritura', designa el conjunto de normas que determinan la escritura correcta de la lengua. En 
segundo lugar, se refiere a la ortografía como disciplina lingüística que se encarga de "describir y explicar cuáles son los elementos constitutivos de la escritura de una lengua y las convenciones normativas de su uso en cada caso, así como los principios y criterios que guían tanto la fijación de las reglas como sus modificaciones" (2011: 9).

Es importante analizar el alcance que tiene la concepción de la ortografía que presenta el diccionario de la Real Academia de la Lengua Española, cuando la define como "parte de la gramática, que enseña a escribir correctamente por el acertado empleo de las letras y de los signos auxiliares de la escritura" (1970; apud Camps et al., 1990: 7). De acuerdo con esta definición, no solamente se trata de las relaciones entre letras y sonidos, sino que también se incluye la representación del nivel suprasegmental. Camps advierte $^{\circ}$ que "la noción de corrección presupone la existencia de una norma que regula la transcripción gráfica y que es aceptada por todos los hablantes de una lengua" (1990: 7). La norma se establece a partir del principio de convencionalidad, a partir de un acuerdo aceptado por los usuarios de la lengua.

Mientras que la lengua oral es la que más experimenta cambios, el sistema de escritura se mantiene más regular y favorece la comunicación en un diasistema como es el español. Un aspecto relevante es que en la lengua escrita no hay arbitrariedad, dado que se anula con la regularidad que justifica muchas de las soluciones gráficas. En la relación del sistema gráfico con los diferentes niveles lingüístico-gramaticales -fonológico, morfológico, sintáctico, léxico, prosódico y también pragmático-, es necesario que los sujetos descubran las regularidades en lugar de aprender de memoria las normas y sus excepciones. Como afirman Camps et al., "la ortografía es una convención necesaria para todos los miembros de una comunidad lingüística; el dominio de esta técnica consolida, en los individuos, la pertenencia al grupo y, a la vez, es un signo de cultura del entorno" (1990: 9).

En la actividad ortográfica se debe tener en cuenta el uso que los sujetos realizan del sistema grafemático cuando escriben. Esto implica vincular el sistema fonológico con el grafemático. De acuerdo con Kaufman y Rodríguez (2008), la relación entre los grafemas y fonemas del español se rige por cuatro tipos diferentes de restricciones:

- Restricciones directas: esta restricción indica la relación biunívoca entre el grafema y el fonema. Hace referencia al caso de la alfabeticidad estricta -un único grafema para un único fonema-, que en el caso del español son nada más que seis las letras que cumplen con esta restricción: $a, e, o, f, t, l$. 
- Restricciones posicionales: se refiere al uso de determinadas letras según su posición en la palabra. Por ejemplo el uso de $m$ antes de $p$ o de $b$; el empleo de $n$ antes de $v$; la inclusión de $u$ para que la $g$ suene suave en guitarra o en Miguel; la inserción de $b$ (y no $v$ ) antes de cualquier otra consonante; el uso de $b$ en todas las palabras que comiencen con bu, bus, bur; el sonido fuerte de $r$ cuando está en el inicio de la palabra (reja) frente al suave cuando está en una posición intersilábica (oreja), y el empleo de doble $r$ para que suene fuerte en posición intersilábica (véase carro frente a caro). Este tipo de restricción solo considera la posición de la letra y su relación con el fonema en la palabra.

- Restricciones morfológicas: este tipo de restricción unifica semejanzas morfosintácticas (por ejemplo, las desinencias verbales terminadas en -aba se escriben con $b$; las terminaciones de -ivo, -iva de los adjetivos se escriben con $v$, etc.). También se incluyen en estas restricciones los casos de las palabras que pertenecen a una misma familia de palabras que, cuando comparten la raíz, comparten la escritura.

- Restricciones particulares o léxicas: con este tipo de restricción se vinculan las palabras homófonas (arrollo, arroyo; asta, hasta, etc.). Se trata de restricciones particulares que rigen casos particulares y se vinculan con razones etimológicas.

Aunque se plantea que el español es una lengua transparente, que se puede escribir estableciendo las correspondencias entre fonemas y grafemas, es necesario observar y analizar que el español es un diasistema con variaciones en los diferentes lugares donde se habla. Si uno hace un listado de los grafemas del español que mantienen una relación unívoca con los fonemas, puede observar que el número de grafemas es muy pequeño. Por ejemplo, en el español rioplatense:

$>$ no presentan relación unívoca los fonemas y grafemas de $b / v, c / s / z, g / j$, $k / q, h, j / x, i / y$ porque comparten la sonoridad;

$>$ otras pueden remitir a más de un sonido como $c, g$;

$>$ el sonido de la $r$ varía según su posición -inicial o en el interior de la palabra-;

$>$ la $h$ no tiene sonido cuando precede a una vocal pero sí tiene una sonoridad diferente cuando forma parte del dígrafo ch;

$>$ la $u$ tiene una restricción posicional, ya que no tiene sonido en guerra o guinda y sí lo tiene en vergüenza; 
la $d$ final en palabras como ciudad, igualdad no suele ser pronunciada en el habla coloquial; lo mismo sucede con la $s$ final en algunos sectores de la comunidad de hablantes;

$>$ la $p$ suele compartir sonoridad con la $b$ cuando precede a determinadas consonantes (por ejemplo, en optativo y obtuso);

$>$ la $c$ a veces comparte sonoridad con la $p$ frente a determinadas consonantes (por ejemplo, en aptitud y actitud), etc.

En definitiva, las letras que tienen una relación univoca con el fonema son: $a, e, o$, $f, t$, I. Lo que subyace a esta ilusión de la transparencia en la relación unívoca grafemafonema del español, son dos problemas teóricos: 1) la escritura es una técnica de transcripción de sonidos en letras, es decir, constituye un código, y 2) el método de enseñanza se elabora independientemente de los sujetos que aprenden. Un código sí presenta una relación unívoca de los elementos que lo componen, por ejemplo, el sistema ASCII, el sistema Braille, el código Morse, que son construcciones individuales denominadas por el nombre de su creador en algunos casos. En los códigos hay relaciones estables entre un signo y su interpretación, no hay signos ambiguos.

Ahora bien, ninguno de estos códigos tiene ortografía, mientras que la escritura sí la tiene. La escritura es una construcción colectiva, resultado de siglos de desarrollo y de múltiples y variadas situaciones de comunicación por parte de los usuarios. En esas situaciones, los usuarios han dejado sus marcas en los signos gráficos. Los sistemas de escritura de uso social son el producto histórico y, precisamente, porque presentan aspectos socioculturales de la evolución histórica, son radicalmente diferentes de los códigos racionalmente construidos y utilizados por un número limitado de especialistas.

Para resumir, el actual sistema ortográfico de la lengua española es el producto de un largo proceso a través del cual se han planteado ciertas reglas de escritura. Es importante marcar que la ortografía no constituye un simple artificio que pueda anularse o cambiarse con facilidad, sino que es un elemento esencial para mantener la unidad de una lengua hablada por muchas personas oriundas de diferentes países. Es un imprescindible elemento de unión porque mantiene la unidad de la lengua por encima de las variantes en la pronunciación gracias a la unificación de criterios y usos para escribir. La importancia otorgada a la ortografía aparece ya en el Discurso proemial de la orthographía de la lengua castellana, incluido en el primer tomo del Diccionario de autoridades (1726): "Una de las principales calidades, que no solo adornan, sino componen cualquier idioma, es la ortografía, porque sin ella no se puede comprender bien 
lo que se escribe, ni se puede percibir con la claridad conveniente lo que se quiere dar a entender".

La fijación de nuestra ortografía es el resultado de un largo proceso de constantes ajustes y reajustes entre la pronunciación y la etimología, gobernado por la costumbre lingüística. Entre ortografía y pronunciación existen, en consecuencia, desajustes motivados por la evolución fonética del idioma, por sus variedades dialectales (el español se extiende por más de veinte países) y por la misma tradición ortográfica. Así, en nuestro sistema gráfico se encuentran casos de fonemas representados por un dígrafo o grupo de dos letras, letras que pueden representar más de un fonema, fonemas que pueden ser representados por varias letras, una letra que representa un grupo de fonemas y otra que no representa ningún fonema.

En este trabajo asumo que la lengua escrita es un sistema de notación, producto de una construcción histórica para representar el lenguaje, que se caracteriza por ser arbitrario y convencional. Alegría Izcoa y Carrillo Gallego (2014), en un estudio sobre cuáles son los mecanismos cognitivos implicados en la escritura de palabras en castellano, explican que para clasificar los sistemas ortográficos distinguen dos criterios: la consistencia de las correspondencias fonema-grafema y grafema-fonema y la profundidad del sistema. La primera distinción, según estos autores, les permite clasificar los sistemas de escritura en transparentes -porque tienen un alto grado de consistencia- y en opacos -porque son poco consistentes-. En función de aplicar la noción de consistencia, evalúan estos estudiosos que "el castellano y el finlandés, por ejemplo, son más transparentes que el francés y el danés" (2014: 50).

Con la dimensión de profundidad Alegría Izcoa y Carrillo Gallego (2014) hacen referencia a las unidades lingüísticas que se representan en la ortografía y clasifican a los sistemas de escritura en superficiales o profundos. En relación con sistema del castellano, explican que el respeto por la morfología es relativamente limitado, dado que, por ejemplo, los verbos que terminan en 'ger' y en 'gir' cambian la $g$ de la raíz por una $j$ cuando va acompañada de vocales como $a, o, u$; o se transforma una $c$ en qu cuando se pasa de vaca a vaquero, o de saco a saquito. Estas modificaciones muestran un mayor respeto por la fonología que por la morfología. Para estos autores, el castellano se caracteriza por ser un sistema transparente-superficial y, mientras que si el inglés o el francés se escribieran fonema por fonema producirian textos muy difíciles de leer por la ausencia de información morfológica y semántica importante,

el castellano puede permitirse ese lujo porque su fonología superficial, la que sale de la boca del hablante, puede ser traducida ortográficamente fonema a fonema sin 
perder información morfológica ni semántica. Esto tiene consecuencias a nivel del aprendizaje de la lengua escrita. Es obvio que adquirir un sistema con pocas unidades de correspondencia es más fácil y más rápido que un sistema con muchas unidades (2014: 52).

\subsection{La reflexión metalingüística en el proceso de escritura}

Los estudios que se han realizado en los últimos años enfatizan la importancia que tiene incidir en el proceso de composición escrita y destacan la necesidad de que los alumnos interactúen entre sí y con el docente mientras están escribiendo. Las interacciones entre pares y con el profesor favorecen la resolución de actividades metalingüísticas. Camps y Ribas (2000) incorporan en esta interacción una modalidad de evaluación formativa (que expongo en el siguiente apartado V.6), en función de que consideran que regular de manera consciente el proceso de redacción a través de este modo de evaluación permite la construcción de conocimientos en la revisión de las características lingüísticas, discursivas, textuales, etc., de los textos.

En la actualidad, en el marco de la enseñanza y aprendizaje de la lengua, se emplean las denominaciones metalenguaje, actividad o capacidad o reflexión metalingüística. Se trata de que el lenguaje se puede emplear de manera reflexiva para hacer referencia a sí mismo en el uso, tal como ha planteado Jakobson (1963) cuando formuló el circuito de comunicación y las funciones del lenguaje, entre ellas, la metalingüística. Camps y Ribas (2000) realizan la distinción entre: (i) hablar del lenguaje cotidiano, y (ii) hacer referencia al lenguaje como objeto de conocimiento específico de las ciencias del lenguaje, es decir, el empleo de un metalenguaje o de metalenguajes provenientes de los marcos teóricos de estudio de la lengua.

En el marco teórico sociocultural, a partir de los trabajos de Vigotsky sobre el doble proceso de descontextualización que se produce en la situación enunciativa y en la correspondiente contextualización en el uso de signos lingüísticos, se plantea que los usos elaborados del lenguaje escrito corresponden a una reconstrucción que los niños pueden hacer en un segundo nivel del lenguaje, gracias a lo que aprendieron en los intercambios orales anteriores. Desde este planteo se analiza que ciertos elementos lingüísticos tendrían una función metalingüística. En tal sentido, Schneuwly (1985; apud Camps y Ribas, 2000: 79) considera que las unidades lingüísticas que forman parte de un contexto creado lingüísticamente -modalizadores, mecanismos de conexión y de cohesión, correlación de tiempos verbales, etc.- actúan como mediadores que imponen una relación más distante y más reflexiva sobre el uso del lenguaje en la producción de textos. 
Si bien Camps y Ribas (2000) reconocen la polémica acerca de la incidencia o no que tendría el aprendizaje de la escritura en el desarrollo del pensamiento, consideran que un proceso de enseñanza y aprendizaje que lleve a los alumnos a analizar la representación del sistema de escritura -signos gráficos en letras, a partir de sonidosfonemas que se corresponden con ciertas letras; palabras que se separan por espacios en blanco; oraciones o construcciones sintácticas más extensas, donde se emplean signos de puntuación; partes de un texto que se distribuyen gráficamente en párrafos con títulos y subtítulos, etc.- seguramente influirá en la conceptualización de la lengua y en promover la capacidad de tomarla como objeto de estudio y análisis, que es la base de la reflexión metalingüística.

De esta manera, la reflexión metalingüística junto con la evaluación formativa permiten comenzar a comprender cómo se construyen los conocimientos en la comprensión y en la producción de la lengua escrita, qué intervenciones favorecen su aprendizaje, cuáles son los factores que dificultan o bloquean los procesos de construcción, de qué manera surgen y se emplean los conocimientos en la reflexión metalingüística, en qué niveles, etc. Los trabajos de investigación desarrollados por Camps resaltan el proceso de escritura y la diversidad de operaciones que forman parte de la actividad de escribir y, al tenerlas en cuenta, se pueden organizar situaciones de enseñanza y aprendizaje que permitan focalizar los conocimientos que se emplean en la construcción del discurso escrito.

La reflexión metalingüística durante el proceso de redacción del texto posibilita que los alumnos construyan conocimientos sobre cómo mejorar la construcción discursiva y también enseña a los alumnos que escribir es una tarea ardua de construcción y reconstrucción textual. El aprendizaje de la escritura incluye aprender a usar la lengua escrita de manera adecuada a la situación, al contexto de comunicación y no se puede desarrollar esta capacidad si se realiza como una práctica alejada de un contexto real de producción. Por ello, el modelo de enseñanza de la composición escrita que promueven Camps y sus colaboradores es una reformulación de la propuesta de la teoría de la actividad de Leontiev, que permite interrelacionar dos tipos diferentes de actividades: (a) una tarea de producción textual enmarcada en una situación comunicativa real para que salga del ambiente de ficción del aula, donde se escribe por escribir y el profesor es el que corrige; y (b) una actividad de enseñanza y aprendizaje de contenidos discursivos y textuales específicos del texto a producir. 


\subsection{La evaluación formativa en la escritura}

Camps y Ribas recuperan los planteos de autores que proponen nuevas formas de evaluación (véanse Scriven, 1967; Bloom, 1971; Allal, 1979; apud Camps y Ribas, 2000) y desarrollan la práctica de la evaluación formativa en el proceso de escritura con los alumnos, cuya función es adaptar los mecanismos empleados por el profesorado a las necesidades de los alumnos de una manera individualizada y lograr que el máximo número de alumnos consiga alcanzar los objetivos que se han fijado en el inicio del proceso de enseñanza y aprendizaje. Las autoras critican el paradigma neoconductista porque le da mucho valor a los datos objetivos que se recogen de los comportamientos de los alumnos y se miden con métodos cuantitativos para ponderar el resultado; en cambio, desde un marco cognitivo los datos a considerar son cualitativos: cuestionarios, observación de la actuación de los alumnos en el desarrollo de la tarea, valoración de sus reflexiones en voz alta y por escrito, interacciones en el seno de los pequeños grupos, con sus pares y con el/la docente. Otro elemento importante es que la información no solo se emplea para apreciar el grado en que se logra cada objetivo, a partir de la aplicación de unos criterios preestablecidos, sino que se focaliza en las estrategias que va desarrollando el alumno mientras escribe o desarrolla su tarea. El propósito de este tipo de evaluación es que se orienta a analizar el proceso para descubrir los aspectos positivos y negativos en el desarrollo de la tarea e introducir las modificaciones necesarias en función de construir una estrategia de enseñanza más adecuada al proceso de enseñanza y aprendizaje.

En el marco de la evaluación formativa, Camps et al. (1990) proponen no sobrecargar la memoria de los alumnos con tanta cantidad de datos, sino descubrir con ellos constantes o regularidades de acuerdo con lo que recuperan de Read, quien sostiene que

Si (regularidad) significa solamente expresar un tipo de unidad lingüística en una correspondencia de uno a uno, existen muy pocos sistemas lingüísticos que podamos considerar regulares $y$, en ese sentido, la mayoría son extremadamente e inexplicablemente irregulares. Si establecemos representaciones en más de un nivel, la regularidad se convierte en una noción realmente compleja [...] Se plantea asimismo el problema de qué tipo de regularidad puede facilitar la lectura; y cuál, la escritura, teniendo en cuenta que lo regular para el lector puede ser irregular para el escritor (apud Camps et al., 1990: 20).

En tal sentido, es necesario que los alumnos puedan descubrir y manipular las unidades lingüísticas como una forma clave de poder acceder al sistema. Así, el descubrimiento de las relaciones entre el conocimiento gráfico y el sistema de la lengua no depende exclusivamente de la estructura de la lengua, sino que es necesario 
desarrollar la conciencia (meta)lingüística del alumno, su conocimiento sobre la lengua, su capacidad analítica, su percepción. La evaluación formativa permite que se pueda analizar el contexto gráfico en el que se presentan las dificultades, abordar la etimología o la familia de palabras para poder construir reglas que ofrezcan la oportunidad de predecir.

Podemos observar que una de las particularidades de la evaluación formativa es que se amplía su objeto de análisis. La evaluación tradicional ha tenido en cuenta siempre los resultados; en cambio, la evaluación formativa incluye una nueva perspectiva basada en el análisis del proceso para explicar cómo se ha realizado la tarea, qué ha sucedido y qué se puede hacer para mejorar el proceso. La manera tradicional de evaluar se caracterizaba por focalizar en el texto que, generalmente, era producido por el alumno fuera de la escuela y, cuando se lo entregaba al profesor, la evaluación se basaba en señalar las faltas de ortografía, de léxico adecuado y de sintaxis de la frase. Si se empleaban otros criterios como la coherencia global del texto, la estructura o el contenido, en general el profesor hacía una mención aproximada. De esta manera, se enfatiza la corrección de la norma, tal vez por tener una referencia explícita y no se consideran los elementos que constituyen la globalidad del texto.

Por otro lado, en un enfoque que integra los aspectos cognitivo y psicosocial, Camps y Ribas recuperan de la propuesta de Allal y colaboradoras (1992, 1993; apud Camps y Ribas, 2000) un modelo que da cuenta de los diferentes tipos de regulación que se pueden generar en una situación didáctica. Esas regulaciones se ubican en tres ámbitos diferentes: (a) las que se producen a partir de la actuación del docente en la clase, a partir de la situación que establece en el aula, de los materiales que aporta, etc.; (b) las que se generan entre el profesor y el alumno, o entre alumnos de una manera individualizada, a partir de la iniciativa de uno de ellos; y (c) las autorregulaciones que realiza el propio alumno y que son las que provocan el aprendizaje. En tal sentido, no es tan relevante que el alumno se apropie de un conocimiento sino que tome conciencia acerca de cómo apropiarse de él y que pueda realizar un retorno reflexivo sobre el propio proceso de aprendizaje.

En el caso particular del proceso de enseñanza y aprendizaje de la producción escrita, el objeto de la evaluación formativa se compone de: (i) el texto que el alumno produjo, generalmente acompañado de sus borradores o versiones anteriores; (ii) el proceso de composición escrita, en el que se ponen en juego un conjunto de operaciones y conocimientos que se actualizan cuando se desarrolla el proceso; y (iii) el proceso de 
aprendizaje, que hace que la composición escrita se convierta en una actividad de construcción de conocimientos procedimentales y conceptuales sobre la escritura.

La propuesta de articular la actividad metalingüística explícita con la evaluación formativa en las aulas donde se enseña y se aprende lengua se basa, de acuerdo con Camps y Ribas, en que:

(i) la actividad de producción y comprensión del lenguaje vaya acompañada de procesos de control, lo que implica el desarrollo de cierta capacidad de análisis del mismo lenguaje que se usa;

(ii) estas representaciones se construyen, del mismo modo que se construye el lenguaje, en la interacción social y su evolución es el resultado de las situaciones interactivas;

(iii) el objetivo específico de la clase de lengua es desarrollar el conocimiento de los usos de la lengua y de los conceptos que se asocian cultural y socialmente a la concepción de lo que implica saber lengua;

(iv) el empleo del lenguaje escrito, especialmente en situaciones de enseñanza y aprendizaje de la composición escrita basadas en actividades de producción que se ubican en contextos que les dan sentido, provocan una importante actividad metalingüística y, en este contexto, el trabajo colaborativo se convierte en una situación privilegiada para ello;

(v) la actividad metalingüística explícita en la interacción social puede poner en práctica el empleo de metalenguajes específicos;

(vi) los cambios de una palabra por otra o la comparación de términos cuando se escribe implican una actividad metalingüística no explícita (2000: 83-84).

En definitiva, el propósito de la evaluación formativa es evaluar el proceso y mejorar el aprendizaje de los alumnos. Para ello, el profesor debe implementar los elementos que le permitan recabar información sobre la manera en que los alumnos participan del proceso de enseñanza y aprendizaje. Esa información permite que se puedan planificar actividades de aprendizaje de los conocimientos que necesiten los alumnos para aprender, analizar la evolución del grupo total y de los alumnos de manera individual y retroalimentar la comunicación con los alumnos sobre el proceso para que no solo se consideren los resultados de los productos, sino que puedan ser explicados y comprendidos por los participantes de la actividad áulica. Camps y Ribas (2000) explican, en tal sentido, que la evaluación formativa en el proceso de enseñanza y aprendizaje de la lengua escrita encontró su lugar en la Didáctica de la Lengua. 


\section{Diseño de la investigación}

En este apartado presento los objetivos y las preguntas de esta investigación, cuyo propósito es analizar qué resultados se obtienen cuando se aborda con los alumnos de formación del profesorado la enseñanza de la ortografía a partir de la reflexión metalingüística -también denominada 'actividad metalingüística'-. En tal sentido, el tipo de investigación que me he propuesto no se cuestiona de una manera neutra qué se hace en el aula cuando se enseña y aprende ortografía y cómo es la manera en que los alumnos de la formación docente aprenden, sino que el marco teórico seleccionado orienta un modelo hipotético de enseñanza de la escritura y de la gramática que permiten desarrollar unas intervenciones en el aula para responder las preguntas planteadas. De esta manera, las actividades que se proponen están organizadas en una secuencia didáctica y se fundamentan en la concepción de la psicología sociocultural y en la teoría de la actividad (Camps, 2001 y 2012).

Este trabajo se desarrolló en el ámbito educativo, concretamente con alumnos que estaban cursando el anteúltimo año de la carrera Profesorado en Educación Primaria en el Instituto Superior de Formación Docente y Técnica № 25 de Carmen de Patagones. El análisis se centra en lo que sucedió en el aula mientras implementé una intervención pedagógica y, posteriormente, en la recuperación de lo realizado a través de entrevistas semiestructuradas. Así, el análisis de los discursos orales y escritos tiene una especial relevancia para comprender los resultados de la propuesta de intervención pedagógica en la relación que me he planteado entre enseñanza de la ortografía y las creencias iniciales de los alumnos.

\subsection{Objetivos y preguntas de investigación}

El objetivo general de este trabajo de investigación es:

- abordar la enseñanza de la ortografía en la formación inicial de docentes a través de la implementación de una secuencia didáctica que sobre la base de la actividad metalingüística permita confrontar las creencias de los alumnos futuros profesores con los materiales teóricos sobre la ortografía, su enseñanza y la polémica sobre simplificarla o no.

El objetivo general de esta investigación incluye los siguientes objetivos específicos:

a) Relevar los aciertos y dificultades que se producen en la implementación de una secuencia didáctica sobre la ortografía y su enseñanza en el aula de formación inicial del profesorado de Educación Primaria. 
b) Analizar las creencias iniciales que los alumnos futuros docentes tienen sobre la ortografía y su enseñanza

c) conocer si se producen cambios en las concepciones de estos alumnos después de la implementación de la secuencia didáctica.

Las siguientes preguntas de investigación surgen de los objetivos -general y específicos- presentados:

La pregunta para los objetivos a) y b) que he formulado es:

- ¿Qué creencias tienen los alumnos de formación del profesorado -que están a punto de terminar su carrera- sobre la ortografía, su enseñanza y su aprendizaje en el marco de la implementación de una secuencia didáctica que tiene como objetivo promover la reflexión de los alumnos sobre esta temática?

La pregunta para el objetivo c) es:

- ¿Qué resultados se obtienen a partir de implementar la reflexión metalingüística sobre ortografía y su enseñanza?

El contexto de investigación que desarrollamos constó de tres fases: una de preparación (en la que se conformó una representación de la tarea que los estudiantes de formación del profesorado debían realizar), otra de puesta en práctica (que consistió en la ejecución de un conjunto de actividades puntuales con el fin de dominar los aspectos programados) y una final de "recuperación metacognitiva que permitirá a los alumnos tomar conciencia de lo que se ha estado trabajando, con un control que monitoriza todo el proceso, entendiendo la evaluación como un instrumento regulador del aprendizaje" (Fontich, 2006: 30-31).

\subsection{Población y muestra}

Los alumnos futuros docentes con los que llevé a cabo esta experiencia de investigación pertenecían a dos grupos de tercer año de la carrera Profesorado en Educación Primaria, que estudiaron en el Instituto Superior de Formación Docente y Técnica N²5 de Carmen de Patagones, Provincia de Buenos Aires, República Argentina. Uno de los grupos cursaba su carrera en el turno diurno -de 13 a 17.15 horas- y el segundo lo hacía en el turno vespertino - de 18.15 a 22.30 horas.

Es importante considerar que, en el marco de su formación, estos alumnos cursaron en el primer año de su carrera un Taller de lectura, escritura y oralidad, orientado a reconocer capacidades y mejorar su comprensión lectora y su producción escrita y oral; mientras que en el segundo año reciben la formación específica sobre la alfabetización inicial y el estudio del Diseño Curricular para la Educación Primaria en la materia 
Didáctica de las Prácticas del Lenguaje y la Literatura I. Las dos asignaturas son anuales y la segunda tiene continuidad en el tercer año con Didáctica de las Prácticas del Lenguaje y la Literatura II, donde se profundizan los temas y culmina en el último año de la carrera -cuarto- con el Ateneo de Prácticas del lenguaje.

El primer curso, que asistía a clases en el horario diurno, se formaba con catorce alumnas de entre 20 y 25 años. En cambio, el segundo grupo estaba compuesto por quince alumnos, un varón y catorce mujeres, cuyas edades oscilaban entre los 20 y 22 años. Solamente una de las estudiantes tenía más edad, ya que contaba con 32 años. Se eligió trabajar con los dos cursos porque, por cuestiones organizativas con la escuela destino, el grupo diurno hizo sus observaciones y prácticas de clase en el Segundo Ciclo del Nivel Primario; mientras que los alumnos que asistían al turno vespertino lo hicieron en el Primer Ciclo del mismo nivel de educación. Esto nos permitió poder abordar la experiencia en todos los años de la escuela primaria.

\subsection{Metodología de investigación}

La metodología de investigación seleccionada para este trabajo se basó en la observación y el análisis cualitativo de los discursos que se generaron en el aula de formación inicial de docentes, mientras los alumnos participaron en la implementación de una secuencia didáctica, y en lo que pudieron manifestar posteriormente en una entrevista individual semiestructurada.

Las investigaciones que han desarrollado los miembros del GREAL focalizan el análisis de las actividades de escritura mientras se escribe en situaciones de aprendizaje. En estos trabajos se ha constatado que las actividades de escritura son complejas y diversas, y que es necesario tomar el contexto no solo como situación comunicativa, sino como un espacio social en el que los alumnos puedan asumir roles diversos y compartir conocimientos y discursos. Esta participación implica que los alumnos puedan asumir un rol en una comunidad de discurso (véanse Fish, 1980; Resnick, 1991; apud Ruiz Bikandi, 2006), o en otras palabras, que puedan formar parte de grupos sociales que comparten intereses, historias, maneras de decir, instrumentos y formas de escolaridad. Así, las actividades que se realizan a través de la participación en "las comunidades de discurso proveen de los instrumentos cognitivos -ideas, teorías y conceptos-, pero también de los modos discursivos y de las prácticas sociales que es preciso dominar para intervenir en ellas como miembros de esa comunidad" (Ruiz Bikandi, 2006: 223).

La particularidad de esta investigación de tipo etnográfico estuvo dada por mi participación como docente del grupo de alumnos y como investigadora. Pude asumir el 
rol de investigadora y que los alumnos pudieran ser los protagonistas del trabajo en una secuencia didáctica con mi participación como observadora, lo que me permitió detenerme a escuchar las ideas que los futuros docentes expresaron de la ortografía y su enseñanza. La aplicación de una metodología cualitativa me permitió percibir de una manera especial el desarrollo de la secuencia didáctica, porque fue diferente la manera en que me ubiqué para replantear, sintetizar y sistematizar las ideas que los estudiantes expresaron cuando realizaban la actividad.

En función de precisar el tipo de metodología que he escogido para este trabajo, sintetizaré qué es la investigación cualitativa. Se trata de un método de análisis que es empleado para poder explicar la realidad tal como es experimentada por los sujetos involucrados en una acción particular. En tal sentido, su objetivo es comprender el comportamiento de las personas, considerando el contexto de realización de la actividad a través de una actitud interpretativa que intenta describir el proceso desarrollado y se orienta a explicar las decisiones que los participantes tomaron, a responder preguntas, a plantearse nuevos interrogantes.

En función de que el objetivo de mi trabajo es comprender la enseñanza de la ortografía y la relación que tiene el proceso de aprendizaje con las creencias que dos grupos de alumnos futuros docentes tienen sobre ella, es necesario aplicar una metodología cualitativa para el análisis de los datos de investigación porque permite "establecer una comprensión empática para el lector, mediante la descripción, a veces la descripción densa, transmitiendo al lector aquello que la experiencia misma transmite" (véase Stake, 1999: 43). Por otra parte, Taylor y Bogdan afirman que la metodología cualitativa "se refiere en su más amplio sentido a la investigación que produce datos descriptivos: las propias declaraciones de las personas, habladas o escritas, y la conducta observable" (1998: 19).

En tal sentido, la metodología cualitativa permite que, en una propuesta de intervención pedagógica como es la implementación de una secuencia didáctica en el aula de formación inicial de docentes, se puedan analizar las concepciones que estos alumnos tienen sobre la ortografía y su enseñanza. A partir de la aplicación del método cualitativo, he podido estudiar e interpretar el discurso que se genera en el aula y de qué manera se inicia un proceso de construcción de conocimiento mientras discuten sobre la temática y se exponen las creencias de los alumnos futuros docentes sobre la ortografía y su enseñanza. 


\subsection{Procedimientos para recoger la información}

La información se basa en la documentación que generó la implementación de la secuencia didáctica en el aula de formación de docentes, teniendo en cuenta los puntos de vista de los actores participantes para asegurar la validez del trabajo. A partir de preguntarse qué es la ortografía y cómo se enseña se generaron diferentes actividades discursivas que son el centro de mi interés, dado que analizo las interacciones orales entre los estudiantes, las producciones escritas, las interacciones entre los alumnos y conmigo. Además, las entrevistas individuales semiestructuradas tienen el objetivo de poder recuperar con los alumnos el trabajo realizado, de evaluar si se registran cambios en el pensamiento después de haber participado de la experiencia, y de reflexionar sobre el desarrollo de los aprendizajes logrados.

El método de investigación cualitativa me permitió analizar la aplicación de una propuesta basada en una secuencia didáctica sobre la enseñanza de la ortografía. Dado que el método cualitativo es apropiado para analizar la dinámica de la comunicación cuando se participa de una secuencia didáctica, he empleado diferentes procedimientos para poder obtener la información necesaria. A continuación, explico la manera en que recogí esta información y en un apartado posterior abordo los procedimientos empleados para su tratamiento y su análisis.

\subsection{Modo de recolección de los datos}

Dado que se trató de una investigación cualitativa, el modo de recolección de los datos estuvo directamente relacionado con las acciones que se llevaron a cabo en la intervención didáctica en el aula de formación inicial de profesores. He partido de la observación realizada del entorno y de la participación de los futuros docentes en clase. Posteriormente, he recuperado de manera individual con los alumnos de formación docente la recapitulación de lo realizado en clase a través de entrevistas individuales. Los elementos empleados para recolectar los datos en la participación de los alumnos en la secuencia didáctica fueron:

Un cuestionario inicial, realizado a los veintinueve participantes.

La presentación de las propuestas que los alumnos construyeron inicialmente para enseñar ortografía en las escuelas primarias, teniendo en cuenta el Diseño Curricular y las renarraciones de la fábula que habían escrito los alumnos de las escuelas primarias. Estas propuestas fueron realizadas por parejas pedagógicas, con lo que resultaron quince planificaciones. 
Datos registrados de la observación en las clases y las anotaciones que he realizado cuando los alumnos futuros docentes debatieron sobre la reforma ortográfica

Las relatorías -síntesis informativas- de aprendizaje que produjeron los veintinueve alumnos.

Las entrevistas semiestructuradas a tres de los alumnos participantes.

Dado que esta investigación se ha basado en la puesta en práctica en el aula de una secuencia didáctica con los alumnos de la formación docente, se han obtenido muchos datos que surgen del proceso de observación e intervención en el aula. Estos datos fueron analizados e interpretados.

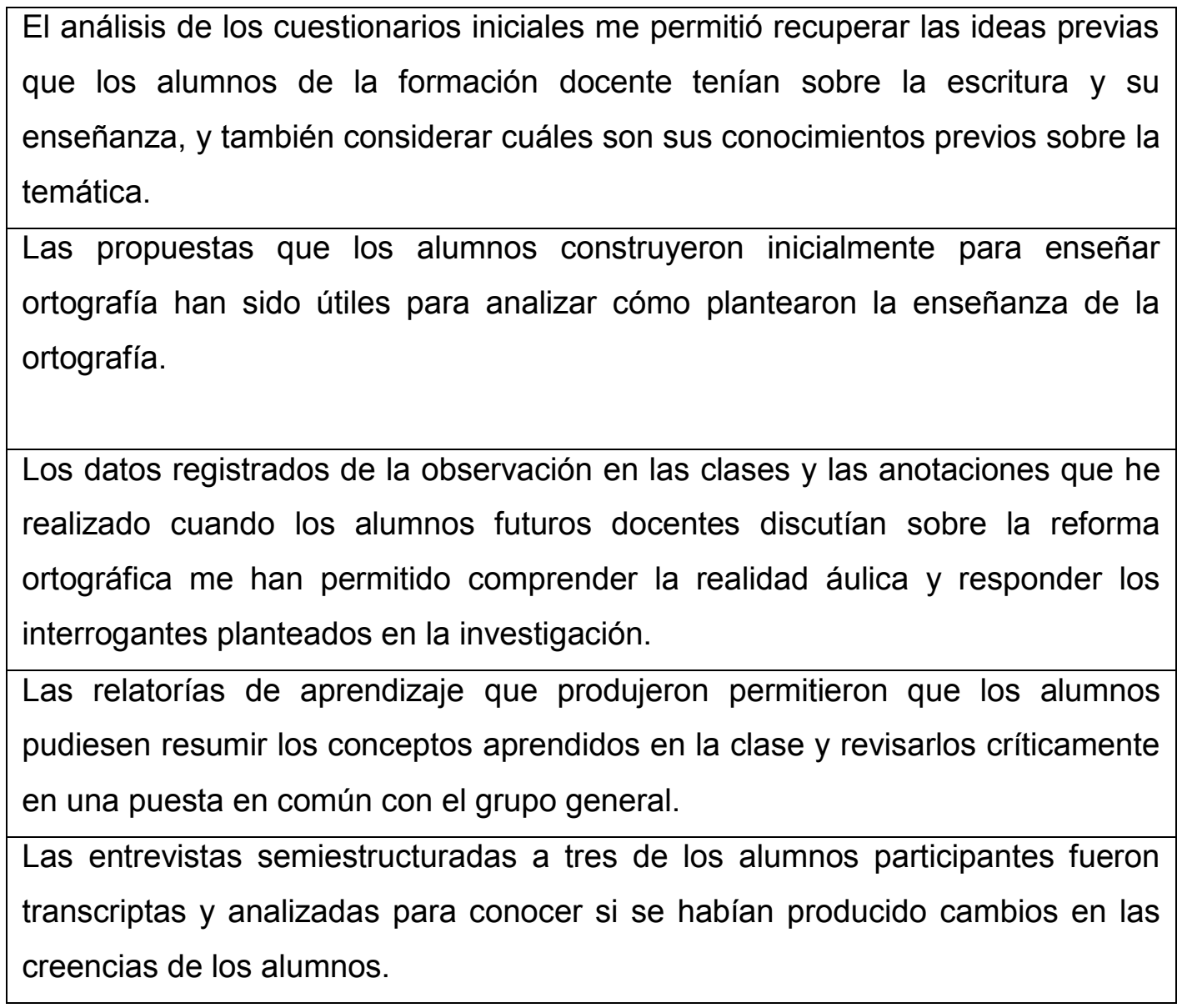

\section{La intervención en el aula de formación docente}

En este apartado presento los antecedentes que dieron origen a esta propuesta de intervención pedagógica en el aula de formación docente inicial y explico en qué se basó 
la secuencia didáctica que implementé con los alumnos del profesorado sobre la ortografía y su enseñanza.

\subsection{Antecedentes de la propuesta de intervención pedagógica en el aula}

Fontich y Camps (2015) enfatizan la necesidad de reflexionar sobre la función que tienen los contenidos gramaticales en la formación lingüística de los estudiantes de diferentes niveles educativos. Destacan los investigadores el papel que tiene la gramática en la enseñanza y el aprendizaje de lenguas, especialmente en la escritura, a partir de considerar el lenguaje en el marco de las perspectivas de sus usos reales y de los contextos en los que se producen las prácticas discursivas. Los estudios de este grupo de investigación sobre la actividad metalingüística que subyace a las producciones verbales muestran que la reflexión y la conciencia sobre el lenguaje y su funcionamiento son imprescindibles.

Cambra, Fons, Palou y Civera (2008) explican que los procesos formativos deben ubicar el análisis y la reconfiguración de las creencias, representaciones y saberes de los participantes -docentes, en su estudio; futuros docentes en mi investigación- en un lugar preeminente para dejar al descubierto las resistencias que se presentan frente a los procesos de innovación y de mejora de la práctica docente. Se pueden desestabilizar estas creencias cuando se fomenta la reflexión sobre la acción, sobre la práctica y sobre los marcos teóricos que abordan la didáctica y los procesos de enseñanza y aprendizaje. Por ello, los docentes formadores deben promover, estimular y enmarcar la reflexión a partir de un apoyo conceptual y personal. En tal sentido, "la palabra escrita (memorias, diarios de maestros, actas, etc.) y la palabra oral (debates, entrevistas, comentarios ante situaciones de aula, etc.) ayudan a la reconstrucción de significados (Bucheton y otros, 2004; Vanhulle, 2004)" (Cambra, Fons, Palou y Civera, 2008: 58).

En particular, las secuencias didácticas para aprender gramática (véase Camps, 2006) tienen el objetivo de abordar los contenidos gramaticales como objeto de enseñanza y aprendizaje. De acuerdo con la autora, en el contexto de los propósitos fundamentales de la educación lingüística orientados al aprendizaje de los usos verbales, es necesario afrontar el conocimiento explícito de los niveles de organización de la lengua -enunciativo, pragmático, textual, sintáctico y morfológico- y también en las relaciones que establecen estos elementos en los diferentes géneros discursivos que son objeto de aprendizaje. Comparto con la autora que el hecho de abordar los aspectos formales de la lengua en un proceso de enseñanza y aprendizaje implica que se plantee la manera de incorporarlos a partid de dos cuestiones fundamentales: 
- Cómo se puede dar sentido a la actividad de aprendizaje de estos aspectos más allá de los ejercicios puntuales,

- Cómo se les puede dar coherencia y no presentarlos de manera ocasional, de acuerdo con su aparición en los textos que se leen o con su necesidad para los textos que se escriben (Camps, 2006: 31).

Es importante considerar que esta propuesta de trabajo presenta una evaluación de tipo formativa, que focaliza el proceso y que se entiende como regulación de los procesos de aprendizaje. Camps destaca tres aspectos de la evaluación en la implementación de estas secuencias:

- La necesidad de establecer claramente, y por lo tanto compartir, los objetivos de la tarea. Para ello es necesario hablar y explicitar qué se pretende hacer, sobre qué tema, qué se aprenderá haciendo la tarea, etc. Estas situaciones iniciales aportan (o pueden aportar) al profesor conocimiento de los conceptos y del saber hacer del alumnado sobre la cuestión que se quiere trabajar, sobre experiencias anteriores, etc.

- Durante el proceso de trabajo, la interacción en grupo y la resolución de tareas parciales son fuente de información de las dificultades que se presentan y ofrecen la posibilidad de intervenir en ellas para no llegar al final arrastrándolas.

- En la tercera fase es relevante la importancia de la síntesis final, del informe, para dar coherencia significativa a los contenidos trabajados y para hacerlos funcionales respecto de situaciones futuras. Se destaca la función de la recuperación metacognitiva de todos los contenidos, conceptuales y procedimentales, implicados en la secuencia didáctica (2006: 36).

En resumen, el grupo GREAL ha desarrollado investigaciones que relacionan la actividad metalingüística (i) con el aprendizaje de la escritura, (ii) con el rol que en ella juega los conocimientos gramaticales, (iii) con la construcción de los conceptos gramaticales, (v) con el espacio que tiene la reflexión y la actividad metalingüística en la formación permanente del profesorado en relación a la escritura y la gramática. Este grupo ha trabajado materiales para la enseñanza de la ortografía que promueven la actividad metalingüística y ha desarrollado algunos trabajos en los que aparecen referencias a la ortografía en la reflexión de los alumnos. Sin embargo no ha trabajado la relación entre (i) ortografía y su enseñanza y aprendizaje, (ii) la actividad metalingüística, (iii) las creencias de los alumnos de formación inicial del profesorado, que constituyen el eje de mi trabajo. 


\subsection{Diseño e implementación de la secuencia didáctica}

La presente experiencia tenía como propósito que los estudiantes participaran en una metodología de investigación en el aula que se apoya en la reflexión en y sobre la acción llevada a cabo, a través de la cual expusieran sus creencias. Compartimos con Fontich que "la formación inicial puede encontrar en la práctica reflexiva a partir del estudio de caso y en el énfasis en la comunidad de discurso las vías para modular progresivamente el conocimiento" (2010: 1). Según este autor, el proceso de formación debería ser presentado como un conjunto de procedimientos de reflexión colectiva y no como el acceso a un conocimiento "acabado" y netamente teórico o práctico.

La experiencia se desarrolló durante la última semana de agosto, el mes de septiembre y la primera quincena de octubre de 2012, en las instalaciones del Instituto Superior de Formación Docente y Técnica $N^{\circ} 25$ y de la Escuela Primaria Básica $N^{\circ} 2$ "Bartolomé Mitre", la Escuela Primaria Básica N 14 "Mariano Zambonini" -escuelas asociadas, destino de las prácticas de los alumnos de formación docente-, todos sitos en Carmen de Patagones, Provincia de Buenos Aires, República Argentina. Cada clase de la formación docente tenía una duración de dos módulos - dos horas reloj- y se llevaban a cabo los días martes -en el horario de 13 a 15 con el grupo de tercer año que cursaba en el turno diurno y en el horario de 20.30 a 22.30 con el grupo del vespertino-. Se eligió este período de tiempo en función de que los alumnos iniciaban sus observaciones y, posteriormente, sus prácticas en la escuela primaria destino.

El contexto de la investigación que desarrollo constó de tres fases: una de preparación (en la que se conformó una representación de la tarea que los estudiantes de formación del profesorado debían realizar), otra de puesta en práctica (que consistió en la ejecución de un conjunto de actividades puntuales con el fin de dominar los aspectos programados) y una final de "recuperación metacognitiva que permitirá a los alumnos tomar conciencia de lo que se ha estado trabajando, con un control que monitoriza todo el proceso, entendiendo la evaluación como un instrumento regulador del aprendizaje" (Fontich, 2006: 30-31).

\subsubsection{Primera fase: la preparación de la tarea}

En la fase de preparación, asumiendo mi lugar de docente-investigadora expliqué el tema a los alumnos -futuros docentes de Educación Primaria- y les informé que 
realizaríamos una investigación ${ }^{3}$. El objetivo de esta presentación fue explicar y determinar las tareas que se efectuarían en el marco de esta investigación. Posteriormente, solicité a los alumnos que respondieran un cuestionario escrito en forma individual, que presentaba las siguientes preguntas:

a) ¿Qué es la ortografía?

b) ¿Qué conocimientos debe tener un futuro docente sobre ortografía?

c) ¿Cómo se enseña y se aprende la ortografía?

d) ¿Para qué sirve la ortografía?

Además, en función de que los alumnos en el tercer año de su carrera comienzan a realizar prácticas en escuelas primarias, les propuse que leyeran una fábula -por ser un texto narrativo breve- a los alumnos de nivel primario y les pidieran una renarración por escrito. La actividad propuesta tenía la finalidad de que los alumnos de la formación docente, organizados en parejas pedagógicas -que es la modalidad instituida para realizar las prácticas docentes- pudiesen tener un diagnóstico de las dificultades de escritura de las palabras a partir de la producción escrita del grupo de alumnos con los que iniciaban su experiencia de práctica. El texto seleccionado para leerles a los alumnos de la escuela primaria es el siguiente:

\section{LAS MULAS Y LOS LADRONES}

Dos mulas bien cargadas con paquetes andaban con dificultad por el camino. Una cargaba sacos con dinero, y la otra llevaba granos. La mula que llevaba el dinero andaba con la cabeza erguida, como si supiera del valor de su carga, y movía de arriba abajo las campanas sonoras sujetadas a su cuello. Su compañera seguía con el paso tranquilo y silencioso.

De repente unos ladrones se precipitaron sobre ellas desde sus escondrijos, y en la riña con sus dueños, la mula que llevaba el dinero fue herida con una espada, y avariciosamente tomaron el dinero sin hacer caso del grano. La mula que había sido robada y herida se lamentó sus desgracias. La otra contestó:

- Estoy en efecto muy contenta de que fui despreciada, pues no he perdido nada, y tampoco me hicieron daño con herida alguna. -

Moraleja:

La ostentación bulliciosa de la riqueza sólo trae desventuras.

De Fábulas de Esopo

${ }^{3}$ Esta investigación se realizó en el marco de un Programa de la Dirección de Nivel Superior de la Dirección General de Cultura y Educación de la Provincia de Buenos Aires y de la Maestría en Escritura y Alfabetización, que se dicta en la Facultad de Humanidades y Ciencias de la Educación de la Universidad Nacional de La Plata. 
Posteriormente, en el espacio de la formación docente analizamos los "errores" ortográficos que presentaban las renarraciones, focalizando solamente la escritura de las palabras y sin tener en cuenta el uso de los signos de puntuación. La decisión de dejar de lado la puntuación se debe a que presenta una complejidad diferente a la escritura de palabras, que se corresponde con conocimientos sintácticos, con elementos prosódicos y también estilos retóricos particulares. Para buscar soluciones posibles a las dificultades que los alumnos del Nivel Primario presentaban en sus textos escritos, solicité a los futuros docentes que diseñaran una secuencia didáctica sobre ortografía para aplicarlas con ellos en la escuela primaria destino.

\subsubsection{Segunda fase: la realización de la tarea}

En la fase de exploración les propuse un ejercicio de autoevaluación del trabajo realizado en la primera fase. La puesta en común de la autoevaluación constituyó la base para la construcción de un taller sobre la ortografía y su enseñanza. Así, una vez que obtuve los resultados iniciales de la investigación -respuestas a los cuestionarios iniciales, la corrección de las renarraciones y las propuestas para enseñar ortografía en las escuelas primarias-, realizamos con los alumnos una revisión teórica de los materiales bibliográficos sobre enseñanza y aprendizaje de la lengua escrita (Ferreiro, 1997, 2013; Teberosky, 1998, 2011), sobre la enseñanza y el aprendizaje de la ortografía (Camps et al., 1990; Kaufman, 2005; Kaufman y Rodríguez, 2008). Además, exploramos textos que planteaban diferentes posturas sobre la ortografía, con el objetivo de que los alumnos pudiesen observar la ortografía como objeto cambiante, que tiene un desarrollo histórico $y$, al mismo tiempo, pudieran reflexionar sobre las ventajas o desventajas que tiene el hecho de tener una ortografía unificada entre los países hispanohablantes. También se consultaron los manuales destinados a los alumnos de nivel primario, diccionarios y gramáticas para observar cuáles son las propuestas para enseñar ortografía. Esta actividad estuvo orientada a que analizaran cuál es la concepción de lengua escrita que subyace en las propuestas de enseñanza de la ortografía y a que realizaran síntesis de los materiales teóricos. Se trató de que fueran tomando posturas en relación con la escritura y con la enseñanza de la lengua escrita.

Dado que mi interés está centrado en analizar las creencias y la reflexión metalingüística que los alumnos futuros docentes realicen sobre la ortografía y su enseñanza, grabé los diálogos que sostuvieron los grupos de trabajo. Para ello, los alumnos habían formado tres grupos - dos de cinco alumnos y uno de cuatro en el curso que asistía al turno diurno y tres grupos de cinco con los alumnos que cursaban en el 
turno vespertino- y cada uno tenía un secretario encargado de grabar en audio la actividad que realizaban ${ }^{4}$.

Después de la lectura y el análisis de los materiales -que también incluyeron los textos sobre alfabetización-, los alumnos futuros docentes tenían que escribir un borrador de texto argumentativo que identificara un destinatario, explicitara su postura y representara globalmente la situación polémica sobre la conveniencia o no de la simplificación ortográfica. Además, la consigna planteaba que construyeran los argumentos teniendo en cuenta las posibles respuestas de quienes estaban en contra. Posteriormente, en la clase de formación docente cada uno expuso las ideas que había desarrollado sobre la temática. El objetivo era que pudiesen presentar, en forma individual, cómo habían construido su texto argumentativo y compartirlo con los demás para enriquecer las posturas a partir de escuchar a los compañeros

\subsubsection{Tercera fase: la evaluación de la tarea}

La tercera fase consistió en la realización de una síntesis informativa de lo trabajado en clase y de la realización de una entrevista semiestructurada a tres alumnos participantes de la formación docente. Es muy importante esta fase final, tanto para los alumnos como para el profesor, ya que es el momento en que finalizó el proceso y, entonces, permite tomar conciencia de las metas alcanzadas como también reconsiderar la selección de los materiales empleados para mejorar un diseño de secuencia futuro. Fue el momento de hacer el balance y hacer consciente los procesos metacognitivos puestos en marcha y de valorar los resultados y los conocimientos obtenidos.

\footnotetext{
${ }^{4}$ Para transcribir las grabaciones he empleado el código que proponen Calsamiglia y Tusón:

a) las cifras a la izquierda del texto indican el número de la toma de palabra,

b) las iniciales en mayúscula identifican a cada participante,

c) | || y ||| indican pausas de diferente duración - de mayor a menor-,

d) ¿? Marca la entonación interrogativa,

e) (??) simboliza un fragmento cuyo contenido es ininteligible -los enunciados entre paréntesis recogen el contenido aproximado-,

f) : indican alargamiento silábico,

g) - indica truncamiento de palabra,

h) > al comienzo de una toma de palabra indica que el locutor hace una pausa o se solape su intervención con la de otro hablante,

i) [ ] alrededor de un fragmento indica que esa secuencia se solapa con las palabras de otro participante -que se reproducen también entre corchetes-,

$\mathrm{j})==$ al comienzo de una toma de palabra indica que no existe pausa entre esa toma y la anterior (2001: 360)
} 


\section{Análisis de los resultados}

\subsection{El cuestionario inicial}

Tal como explicité en el apartado sobre diseño de la secuencia didáctica (véase 6.2.1.), las preguntas para el cuestionario inicial eran:

a) ¿Qué es la ortografía?

b) ¿Qué conocimientos debe tener un futuro docente sobre ortografía?

c) ¿Cómo se enseña y se aprende la ortografía?

d) ¿Para qué sirve la ortografía?

A continuación, presento el análisis de las respuestas que formularon los alumnos.

\section{a) ¿Qué es la ortografía?: Concepción de ortografía}

El $78 \%$ de las respuestas coinciden en que la ortografía se basa en escribir bien. Explican que escribir bien incluye la escritura correcta de las letras, tener en cuenta los acentos y el empleo adecuado de las mayúsculas. El $22 \%$ restante señala que una buena pronunciación lleva a no confundir las letras cuando se va a escribir. Escribir implica considerar las condiciones de la situación comunicativa y dominar una serie de actividades cognitivas complejas que se relacionan con el contexto sociocultural en el que se produce el texto, sin embargo una de las cuestiones que surgen es que los alumnos futuros docentes plantean la ortografía como un elemento básico para el dominio del lenguaje escrito ("La ortografía es la base de una buena escritura. Se debe enseñar a los alumnos y alumnas que no deben confundir $\mathrm{b} / \mathrm{v} 0 \mathrm{c} / \mathrm{s} / \mathrm{z}$, que pongan bien los acentos en las palabras y que usen bien las mayúsculas cuando escriben nombres propios.").

Por otra parte, existe una idea que, en general se mantiene en el ámbito educativo, relacionada con la corrección de la escritura ("La ortografía es el uso correcto de las letras al escribir. Por ejemplo, saber las reglas de que antes de ' $p$ ' o de 'b' se escribe ' $m$ '. Tambien ay que incluir los acentos para escribir sin errores.", aunque en este ejemplo a la alumna se le escape la "corrección"). Por ser uno de los elementos que está en la superficie textual o el más evidente, las faltas ortográficas es lo que primero se corrige y la ortografía ha sido el conocimiento al que se le ha prestado más atención en la enseñanza de la lengua. Además, la corrección se ha relacionado en la enseñanza con las reglas ortográficas, que es lo que en el ejemplo la alumna recupera. Otra de las definiciones que se plantea en el mismo sentido es el conocimiento que tienen los escritores, entendiendo por definición a los que tienen el dominio de la lengua escrita, sobre el uso de algunas normas ("La ortografía es la escritura correcta de las palabras. Los escritores que saben 
escribir conocen el uso de las letras, de los acentos y de las mayúsculas para escribir bien.").

Otro problema, además de considerar la corrección vinculada con la ortografía, es presuponer que la lengua escrita es la transcripción de la lengua oral. Entonces, si se atiende a la correcta pronunciación del sonido, la ortografía estará garantizada (“La ortografía es la correcta escritura de las palabras. Uno tiene que saber poner acentos, conocer las reglas de mayúsculas y las letras que van bien en el texto. A veces, el problema es que se habla mal y los alumnos no escuchan bien, por eso escriben mal. Si se pronuncian bien las palabras, los chicos las escriben bien."// "La ortografía se compone de reglas para escribir correctamente. Al leer los textos, el docente tiene que pronunciar bien las palabras para que los alumnos puedan escribirlas. A veces hay tanto ruido en el aula que no escuchan bien y terminan escribiendo cualquier cosa. Igual no les importa mucho, total se los corrije el maestro.").

b) ¿Qué conocimientos debe tener un futuro docente sobre ortografía?: Enseñanza de la ortografía

En relación con la enseñanza de la ortografía, la totalidad de los alumnos expresan que no saben de qué manera realizarla ("Enseñar ortografía debe ser muy difícil. La verdad, no sé. Son tantas las reglas y hay que acordarse de las palabras que no entran en cada regla. Tiene que existir una manera nueva de enseñar."). Es importante que esta alumna reconozca que se produce una saturación de la memoria, si se intenta que los alumnos sepan de memoria las reglas y sus excepciones. Pero llama la atención que, a pesar de haber estudiado en el año anterior de su carrera la noción y la construcción del sistema de escritura desde la perspectiva psicogenética, no se cuestione de qué manera aprenden los alumnos a escribir y cómo se construye el conocimiento ortográfico. Plantea que debe existir una manera nueva de enseñar, como suele esperarse en el ámbito educativo una receta que dé una solución mágica. El nuevo Diseño Curricular incorpora la reflexión metalingüística para abordar y construir el conocimiento ortográfico, sin embargo, no lo menciona en su respuesta.

Algunos futuros docentes recuperan recuerdos de las etapas educativas anteriores, especialmente del nivel primario ("La verdad es que no se como se enseña ortografía ahora. En mi escuela primaria aprendíamos trabajando con un cuaderno aparte para repetir los errores que cometíamos."). Tal vez mencionen su práctica en la escuela primaria y no la de la escuela secundaria por el hecho de que la ortografía ha dejado de 
enseñarse -así como la gramática en los diferentes niveles educativos- a partir de enseñar lengua desde un enfoque comunicativo, que dejó fuera los contenidos gramaticales. En una de las respuestas se plantea la necesidad de enseñar las reglas, como si se pudiera reducir la enseñanza de la ortografía a una mecánica de reconocimiento de elementos mínimos de la lengua escrita que se relacionan con otros elementos mínimos de la lengua oral ("Una idea muy buena es tener un cuaderno para hacer borradores y escribir palabras nuevas y las que los chicos escriben con errores. Como enseñar la ortografía es un problema porque hay mucha gente recibida que escribe con errores, hasta maestras. Falta enseñar las reglas y que escriban más.”).

Otros señalan que es importante que haya una corrección en los textos a través de la revisión con los compañeros y con el docente ("Los textos sobre escritura explican que la corrección se hace entre compañeros. En el Diseño Curricular también se indica que deben corregirse los textos y no que los corrija solamente el maestro. Con el enfoque comunicativo se dejaron de enseñar las reglas y se tendría que empezar a practicar de a una, siempre con ejemplos."). Es importante partir del Diseño Curricular y buscar la manera de ubicar la ortografía en el contexto de la producción escrita, no como una actividad mecánica, sino como una construcción colectiva en función de lo que se escribe.

Por otra parte, se plantea la ortografía como un problema para resolver en la enseñanza, pero la solución para esta alumna pareciera que es dejar que las herramientas de la tecnología corrijan los errores ("La ortografía sigue siendo un problema. Nunca pude aprenderla y me parece que no hay manera de poder enseñarla. Los chicos se aburren y no quieren copiar dos renglones de la misma palabra. La escuela no tendría que perder tanto tiempo si ahora los celulares y las computadoras te marcan los errores en seguida. Apretan la opción correcta y listo."). Si bien puede ser una opción, debe considerarse que no siempre las computadoras reconocen las ambigüedades y pueden aceptar palabras que estén mal escritas o marcar algunas que no tienen falta. Es importante que el docente guíe a los alumnos hasta que puedan reflexionar por sí mismos sobre la escritura y su adecuación al contexto comunicativo. La noción de corrección implica la existencia de una norma que regula la escritura y que puede analizarse en función de construir con los niños las regularidades de la lengua.

\section{c) ¿Cómo se enseña y se aprende la ortografía?: Modo de aprendizaje de la ortografía}

Dado que el modo de aprender ortografía se relaciona con la enseñanza, la mayoría respondió no saber -“No sé”-. Hubo dos respuestas que propusieron la 
enseñanza de las reglas de manera reflexiva y la utilización de un cuaderno extra para que los alumnos pudieran ejercitar los errores. A pesar de que uno de los grupos de alumnos en el segundo año de su carrera estudiaron la perspectiva psicogenética de la construcción del sistema de escritura en el niño, no se planteó que el niño cuando aprende a escribir en la escuela aprende el sistema convencional gráfico de la lengua y que la construcción del sistema ortográfico se produce cuando el niño puede reflexionar sobre las dificultades que tiene cuando escribe para encontrar alguna solución. Por lo tanto, no se puede hablar de errores, sino de tanteos que va haciendo mientras construye el conocimiento sobre el funcionamiento de la lengua escrita y su convención social.

\section{d) ¿Para qué sirve la ortografía?: Importancia social de la ortografía}

Todos los alumnos resaltaron la importancia social que tiene la ortografía y en una de las respuestas se indica el valor en la comunicación escrita ("La ortografía es muy importante. Conocerla te da las normas para poder escribir bien." // "La práctica y el conocimiento de la ortografía es fundamental para encontrar un trabajo o para empezar a estudiar. Se puede expresar muy bien por escrito una solicitud de trabajo o la exposición de un tema cuando estudiamos."). Por otra parte, se plantea la necesidad de que se enseñe en el marco de la actividad de escribir en todas las materias ("La enseñanza de la ortografía tiene que plantearse en todas las materias. Así como dicen que todos los profesores tienen que enseñar a escribir, tendrían que incorporar la ortografía. El problema es cuando ellos no saben, porque yo he tenido profesores en el secundario que te corregían con errores de ortografía y escribían mal en el pizarrón. Una vergüenza."). Es importante que la ortografía sea enseñada en el marco de la actividad de escritura, ya que el niño podrá aprender a partir de situaciones en las que tiene que resolver problemas para lograr un texto adecuado a sus propósitos comunicativos. En el contexto real de uso, el alumno podrá reconocer y darle valor a la norma como una convención social necesaria para la perdurabilidad de la lengua escrita.

\section{- Reflexiones sobre los cuestionarios iniciales}

Una vez que sistematicé las respuestas, hice una presentación en diapositivas para observar las semejanzas y diferencias que había en lo que habían respondido y empezamos a contrastarlas con las definiciones que se presentan en los manuales sobre ortografía y en los libros de Ortografía de la Real Academia Española. Aunque los futuros docentes presuponían que todos compartíamos una misma idea sobre las preguntas, 
compartimos con los alumnos que el concepto presenta una dinámica que se ha ido modificando a lo largo del transcurso del tiempo.

Las respuestas al cuestionario inicial indican que los alumnos consideran que la enseñanza y aprendizaje de la ortografía constituye un problema. De acuerdo con las palabras que emplean para hacer referencia a la ortografía -error, corrección, reglas, etc.puedo observar que la relacionan con prácticas de enseñanza tradicional en las que se sanciona el error y se busca enseñar la ortografía a partir de las reglas impuestas por la norma. Reducen el conocimiento ortográfico al uso correcto de las letras, de las mayúsculas y de los acentos. En ningún caso consideran que la puntuación forma parte del conocimiento ortográfico.

La noción de lengua escrita que se desprende de las respuestas es la que habitualmente se le asigna a la escuela: los docentes deben enseñar la relación grafofónica y cuestiones elementales relacionadas con la ortografía -como el empleo de las mayúsculas-. Una vez que los alumnos logran este conocimiento, estamos en condiciones de afirmar que ya saben leer y escribir. Pero, cuando los alumnos llegan a la escuela secundaria o a cursar estudios en el nivel superior, los docentes nos quejamos porque no saben escribir bien un texto. Durante años se redujo la escritura a la transcripción de un código y para escribir un texto se les ofreció un modelo que los alumnos copiaron, en una actividad totalmente descontextualizada de una situación comunicativa real o simulada que exija que el alumno pueda aprender realmente a escribir.

Lo que los alumnos representan con sus respuestas es que consideran que escribir bien depende del conocimiento de las reglas ortográficas -saber qué letra corresponde, cuándo emplear correctamente las mayúsculas y los acentos- y que, tradicionalmente, esto se ha enseñado a partir de la memorización de reglas y de la corrección del docente y la posterior repetición de las palabras que el alumno debía realizar para fijar la norma. No consideran la producción escrita como una actividad compleja que requiere el conocimiento de diferentes niveles lingüístico-discursivos que confluyen en el entramado de un texto y la ortografía aparece como un conjunto de reglas a memorizar, sin tener en cuenta las relaciones que tienen los elementos entre sí.

Otra cuestión es que el papel protagónico lo tienen el docente y el objeto de conocimiento, pero no se considera el alumno como sujeto cognoscente y la elaboración que puede hacer de ese conocimiento de acuerdo con su edad. Tampoco aparece el contacto con textos escritos o instrumentos de consulta que pudieran ayudar al alumno a construir el conocimiento ortográfico. Si no es el docente el que corrige los textos y señala 
las faltas, el poder lo tiene la tecnología, ya que tanto la computadora como el celular tienen posibilidades de corregir los errores.

\subsection{Análisis de las propuestas para enseñar ortografía}

Los alumnos futuros docentes fueron a las escuelas primarias asociadas, que habían sido asignadas en acuerdo con el instituto de formación docente para realizar sus prácticas, y les solicitaron a los estudiantes de nivel primario que renarraran en forma escrita la fábula de Esopo. El trabajo en las escuelas primarias se realizó por parejas pedagógicas y hubo un solo caso en que trabajaron tres alumnos juntos con el mismo grupo de nivel primario. Esto se debió a que la modalidad de la carrera de formación docente contempla las prácticas en parejas pedagógicas $\mathrm{y}$, dado que eran veintinueve alumnos, uno quedaba solo.

La actividad posterior al ejercicio implementado en las escuelas primarias se basaba en:

a) la corrección de las renarraciones de los alumnos de escuelas primarias,

b) la formulación e implementación de secuencias didácticas para enseñar ortografía,

c) revisión de las propuestas sobre enseñanza de la ortografía,

d) autoevaluación de las propuestas sobre enseñanza de la ortografía.

Presento, a continuación, los resultados y el análisis de esta actividad.

\section{a) La corrección de las renarraciones}

Una vez que tuvieron las renarraciones que los estudiantes de escuelas primarias habían realizado por escrito de la fábula de Esopo, los alumnos futuros docentes realizaron las correcciones de los textos. Focalizaron sus correcciones en la ortografía de las palabras y no tuvieron en cuenta otros aspectos del texto como la correlación de los tiempos verbales, los mecanismos de cohesión, el tipo de narrador, la forma de incluir otras secuencias textuales en la narración, la construcción de oraciones y párrafos, etc.

En ninguno de los casos observé que tuvieran en cuenta los aspectos positivos de los textos, sino que focalizaron los errores. Después de que compartieron con el resto de las parejas pedagógicas los textos corregidos, la reflexión de la mayoría fue que en los últimos años el nivel educativo ha descendido. Justificaron su posición al considerar que con el enfoque comunicativo dejó de enseñarse ortografía y gramática y que los resultados se ven en los problemas que los alumnos tienen para escribir. Además, 
incluyeron el efecto negativo que tiene la tecnología en la escritura de los textos escolares, ya que los alumnos escriben como quieren y van deformando la lengua escrita.

\section{b) Formulación e implementación de secuencias didácticas en escuelas}

En función de abordar la enseñanza de la ortografía con los alumnos de las escuelas primarias, después de haber corregido los textos, los futuros profesores debían formular una secuencia didáctica organizados en parejas pedagógicas. En los cuestionarios iniciales, la respuesta generalizada a cómo enseñar ortografía fue no saber de qué manera podían hacerlo. Esta situación quedó al descubierto, dado que las secuencias que produjeron fueron realizadas a partir de copiar actividades para ejercitar las reglas ortográficas que se proponen en manuales para el nivel primario o en libros que se destinan específicamente a la ortografía (véase en el Anexo). En ningún caso se planteó abordar la enseñanza de la ortografía a partir de los textos que los alumnos del nivel primario habían elaborado. Tampoco se tuvieron en cuenta las orientaciones didácticas que sugiere el Diseño Curricular actual de la Provincia de Buenos Aires.

Los futuros docentes debieron presentar las propuestas de secuencias didácticas que habían formulado a sus compañeros y uno de los integrantes de las parejas debía explicar cómo la habían realizado. Cuando realizamos la puesta en común de los trabajos, los alumnos explicitaron haber tomado los materiales bibliográficos sobre ejercicios de ortografía ("Fuimos a la Biblioteca de la escuela y sacamos lo que había para enseñar y, como algunos ejercicios nos parecían difíciles, adaptamos a las actividades que pueden hacer los chicos"). Así esta pareja pedagógica presentó la regla sobre el uso de la $b$ para las desinencias del pretérito imperfecto y, a continuación, una lista de verbos conjugados en ese tiempo para que los estudiantes colocaran la letra correspondiente. La cuestión es que si no se presentan desafíos, los alumnos sabrán que tienen que repetir la misma letra en todos los casos. No es lo mismo que tengan que elegir cuál de las letras $-b \circ v$ corresponde a la palabra escrita.

Otra de las propuestas incluía el reconocimiento de un listado de palabras en una sopa de letras y pintar las letras que podían confundir los alumnos "por su sonido parecido". Las palabras eran caza-caza, casador-cazador, asta-hasta, paja-paga, hallahaya, sierra-cierra, seso-ceso, abano-habano, ablando-hablando, acecho-asecho, arrolloarroyo, bote-vote. Las alumnas explicaron que habían consultado un manual en el que se abordaba la escritura de palabras homófonas ("Nos pareció importante darle una sopa de letras, como para que lo vinculen con una actividad de juego, y con palabras que tienen el 
mismo sonido pero las letras son diferentes, para que los alumnos pudieran diferenciar bien la escritura correcta").

En el caso de la tercera propuesta, se había focalizado en el uso de mayúsculas. Se presentaban una serie de dibujos para que los alumnos tuviesen que escribir el nombre debajo de cada dibujo. Además, se incluía el uso de la mayúscula a partir de un ejercicio que presentaba oraciones simples, en las que faltaba la letra de la primera palabra y los alumnos debían completarla. Las alumnas esperaban que los alumnos escribieran los nombres de los dibujos con la mayúscula inicial, pero no se trataba de sustantivos propios, por lo que no era seguro que el ejercicio resultara como esperaban. Por otra parte, hubiese sido más recomendable que tomaran un párrafo para ejemplificar el uso de la mayúscula después del punto, como lo explicitaban entre los usos que habían detallado en el comienzo de la actividad propuesta ("Tomamos la mayúscula porque es un problema para los chicos. Siempre se equivocan. Intentamos hacer un ejercicio que fuera interesante para ellos, poniéndoles dibujos en colores").

Hubo cinco propuestas que eran las fotocopias de libros. Algunas de ellas presentaban primero las reglas $\mathrm{y}$, a continuación, una actividad para que pudieran resolver los estudiantes. La justificación de los alumnos para presentar esas fotocopias se basó en que no sabían cómo formular una actividad para enseñar ortografía ("Tomamos el libro que nos prestó la maestra de la escuela y lo fotocopiamos por las imágenes que presenta. No sabíamos de qué manera proponer una actividad que sea sencilla para que los chicos resuelvan y que trabaje la ortografía" // "En nuestro caso, como no estábamos seguras de hacer algo que estuvieran bien y por los tiempos, armamos con las fotocopias. Teníamos en cuenta que no estaba bien hacerlos escribir a los alumnos dos o tres renglones de cada palabra que se habían equivocado" // "Tomamos los libros porque nos pareció que estaba trabajar con materiales bibliográficos auténticos. Como había actividades un poco difíciles para los alumnos, seleccionamos una parte del trabajo").

Las secuencias didácticas restantes -siete en total- también incluyeron actividades de libros para enseñar ortografía. En lugar de presentar fotocopias, los alumnos las transcribieron y las adaptaron a un trabajo que pudiesen llevar a cabo los estudiantes. Incluían el reconocimiento de $m p, m b, n v$ en uno de los casos, y las restantes ofrecían distinguir entre el uso de $b-v, j-g, s-c-z$. Los alumnos justificaron sus propuestas a partir de plantear que es necesario abordar las letras que más conflicto les ofrecen ("Nuestro trabajo toma las letras que traen más dificultades a los alumnos. Sacamos las fotocopias para que ellos tuvieran que completar la letra que falta y no copiaran todo. Cuando hay 
que copiar mucho, les lleva mucho tiempo y se atrasan unos cuantos cuando hay que borrar el pizarrón" // "Para nosotros también fue importante trabajar con las letras que tienen más dificultades $\mathrm{y}$, como también a nuestro grado les cuesta mucho copiar, preferimos sacarles y llevarles las fotocopias").

Después de haber discutido sobre la formulación de las secuencias, dos parejas pedagógicas decidieron llevarla a la práctica en las escuelas primarias donde habían iniciado sus prácticas. Así, pude observar la implementación de las secuencias en dos aulas de las escuelas primarias, una correspondiente al Primer Ciclo -tercer año- y la otra, al Segundo Ciclo -sexto año-. En el primer caso, las futuras docentes distribuyeron las fotocopias de las actividades para que los alumnos completaran los ejercicios. Al principio, preguntaban qué letras debían colocar en cada ejercicio y las futuras docentes respondieron un par de veces. Les dijeron que podían consultar el diccionario. Varios alumnos fueron resolviendo la tarea con la ayuda del diccionario y muchos fueron copiando lo que habían escrito sus compañeros.

En el aula de sexto año las alumnas futuras docentes repartieron las fotocopias, organizaron a los alumnos en grupos de cuatro y fueron asistiéndolos mientras hacían la tarea. Cuando los estudiantes preguntaban, las futuras docentes remitían la pregunta a la clase para que pudieran responderla. Si no podían, los orientaban o terminaban dándoles las respuestas.

\section{c) Revisión de las propuestas sobre enseñanza de la ortografía}

Posteriormente a la actividad de aplicación de las secuencias didácticas sobre ortografía en las aulas de escuelas primarias, en función de poder reconceptualizar la enseñanza de la lengua escrita, especialmente, de la ortografía, les propuse a las alumnas que solicitaran a los alumnos de sexto que produjeran una reseña. El propósito de la reseña fue que pudieran compartir con los alumnos que asisten a la Biblioteca del establecimiento la lectura de cuentos. La secuencia se inició con la lectura de reseñas en diferentes soportes textuales: páginas web de revistas de literatura infantil, de editoriales y librerías, de diarios y revistas en papel. Luego se compartió en el grupo total las características que tienen las reseñas de obras literarias y se acordó qué características tendría la que construirían en el grupo. Volvieron a leer los cuentos y a focalizar en el contenido, en los personajes y en la descripción, ya que eran cuentos de terror.

Una vez que tuvieron las notas, comenzaron a dictarle a la futura docente lo que querían que dijera la reseña de uno de los cuentos. La alumna de formación docente inició su escritura en afiches. Cuando terminó de escribir, leyeron lo que tenían escrito y 
surgieron discusiones entre los alumnos sobre si era conveniente describir más el lugar y qué impacto causaría en los futuros lectores o si estaba bien que emplearan ciertos términos, etc. Recuperaron los apuntes que habían tomado sobre las reseñas para ver si se hacía mención a todos los personajes o a algunos, si se contaban todos los hechos o si se generaba cierto suspenso. Releyeron el contenido de su reseña e hicieron algunas modificaciones sobre no contar todo lo que pasaba en el cuento. Cuando tuvieron listo el nuevo borrador, focalizaron la atención en la ortografía. Consultaron el diccionario y el cuento leído para revisar y corregir la ortografía.

Fue importante para las alumnas participar de esta actividad, de acuerdo con lo que pudieron manifestar en el aula de formación docente al compartir la experiencia con sus compañeros futuros docentes ("Los alumnos se concentraron en revisar los textos. Es increíble cómo participaron en buscar en el diccionario para corregir las palabras mal escritas, hasta los que estaban siempre más callados participaron." // "Sí. Yo también me di cuenta de la participación de los alumnos. Chicos que antes no preguntaban empezaron a preguntar y a interesarse por corregir. $Y$ lo bueno es ver que revisan teniendo en cuenta los materiales escritos, no en cómo se pronuncian las palabras.").

En tal sentido, en el aula de formación docente compartimos la experiencia realizada para discutir acerca de la necesidad de considerar que la revisión y corrección de un texto no solo implica corregir ortografía, sino que es necesario atender a aspectos léxicos, a aspectos de construcción gramatical y aspectos textuales. Tuvieron la oportunidad de comparar, a partir de las observaciones que ya habían hecho de las clases anteriormente y de la participación en esta secuencia, que no es lo mismo para los alumnos escribir cuando saben que habrá lectores reales que si lo hacen solo para una práctica áulica ("Escribir entre todos y poder discutir nos llevó a pensar a nosotras también la importancia que tiene la escritura en grupo. Es una manera diferente de aprender a escribir. El chico que no puede escribir solo se queda con la hoja en blanco o se copia del compañero. En cambio, así, es un aprendizaje para todos, porque pensamos entre todos qué escribir y cómo lo habíamos escrito. Hasta nosotras tuvimos que consultar. Aunque nos daba cosa tener que preguntar, es una manera de hacerles ver a los alumnos que hay que revisar lo que se escribe para mejorarlo." // "Es impresionante ver cómo se preocupan para escribir bien cuando saben que se hará una presentación del texto. Además, es cierto que ayuda mucho pensar qué escribir y cómo escribirlo. Los chicos participaron, opinaron, corrigieron y nosotras también pudimos compartir con ellos."). 
Posteriormente, en el aula de formación docente, repetí la misma actividad pero con los alumnos futuros profesores. Mi propósito fue que pudieran participar de una situación de enseñanza y aprendizaje de la ortografía a partir de la reflexión metalingüística. En lugar de abordar las reglas ortográficas, se promovió el análisis de las faltas, se recurrió a diccionarios para consultar y se fueron construyendo conocimientos sobre el origen etimológico, el uso, aspectos morfológicos, etc. Se trató de una actividad de enseñanza y aprendizaje de la ortografía y de la acción de escribir en una situación grupal con un claro objetivo de aprendizaje, en la que los participantes se involucraron en una tarea de construcción de la lengua escrita en un género discursivo particular. La revisión constituyó un momento importante porque se pudieron construir pautas para analizar de qué manera plantear una evaluación formativa de la producción escrita.

\section{d) Autoevaluación de las propuestas sobre enseñanza de la ortografía}

Como indiqué en la sección introductoria, en este trabajo de tesis me interesa analizar las creencias de los futuros docentes sobre la ortografía y su enseñanza y también abordar cómo emerge el contenido metalingüístico en los alumnos cuando resuelven actividades. Así, en función de que pudiésemos reconceptualizar la ortografía, les propuse a los alumnos de la formación docente revisar nuevamente las renarraciones de los alumnos de las escuelas primarias e investigar materiales para producir propuestas sobre su enseñanza. A partir de la investigación en los materiales -en los que tenían como lecturas obligatorias a Camps et al. (1990), Díaz Argüero (2004), Quinteros (2004), Vernon (2004), Zamudio Mesa (2004), Ferreiro (2013)-, debían explicar qué es la ortografía y cómo se puede enseñar.

Dado que el diálogo entre los alumnos cobra una relevancia fundamental en la construcción del aprendizaje y su análisis, y además, nos permite abordar la reflexión metalingüística, a continuación presento las interacciones entre los alumnos. Es necesario aclarar que los alumnos conformaron grupos de cuatro o cinco alumnos cada uno y que los turnos que he seleccionado responden a los momentos en que surge reflexión metalingüística en cada uno de los intercambios en estos grupos - dos grupos de cinco y uno de cuatro alumnos en el tercer año que cursaba el turno diurno, y tres grupos de cinco alumnos del turno vespertino-. En cada uno de los grupos, uno de los alumnos ocupa el rol de secretario para grabar y tomar notas de lo que va sucediendo mientras llevan a cabo la tarea. 
a) Primera pregunta: ¿Qué relación hay entre la lengua oral, la lengua escrita y la ortografía?

Esta primera pregunta tiene el objetivo de que los alumnos compartan las respuestas que dan los autores seleccionados. Les aclaré que no evaluaría que la respuesta fuera única y correcta, sino que tenía la intención de que compartiéramos significados y se animaran a reflexionar colectivamente. Dado que es una temática que les resulta compleja, los invité a leer y discutir en clase:

\section{- Resultados}

El habla exploratoria está conformada por diferentes turnos de intercambio, en los que los alumnos proponen respuestas para la pregunta y se consultan sobre los materiales que están leyendo. Presentaré aquellos resultados que pudieron ser grabados en el transcurso de la actividad áulica, que se relacionan con el desarrollo de la reflexión metalingüística en los alumnos futuros docentes y su análisis para las dos preguntas formuladas.

- Alumnos de tercer año del turno diurno

\begin{tabular}{|c|c|}
\hline Transcripción de diálogo exploratorio & Análisis \\
\hline $\begin{array}{l}\text { 12. (R.E.) -Acá encontré algo que se relaciona } \\
\text { con la ortografía. \|l El principio alfabético, una } \\
\text { letra y un sonido, es una noción que se } \\
\text { construye al ubicar el punto de intersección } \\
\text { entre dos sistemas lingüísticos. ¿Por qué dice } \\
\text { que el lenguaje oral es natural y el gráfico es } \\
\text { artificial? } \\
\text { 13. (A.M.) - ¿Eso no se relaciona con lo de la } \\
\text { transcripción de un código? } \\
\text { 14. (C.F.) - Quinteros explica que el niño } \\
\text { necesita hacer todo un esfuerzo cognitivo para } \\
\text { poder analizar de manera aislada las } \\
\text { consonantes y las vocales. } \\
\text { 15. (J.A.) - Ferreiro acá dice que lo ortográfico } \\
\text { surge cuando hay posibles alternancias o } \\
\text { soluciones gráficas. } \\
\text { 16. (C.F.) - Yo marqué otra cosa \|l Zamudio } \\
\text { dice que las palabras ortográficas no se } \\
\text { centran exclusivamente en el sonido. }\end{array}$ & $\begin{array}{l}\text { Las alumnas se habían planteado la necesidad } \\
\text { de analizar la ortografía en relación con lo que } \\
\text { es el sistema de escritura. Como les sugerí la } \\
\text { lectura de algunos materiales obligatorios, } \\
\text { recurrieron a ellos para comprender por qué se } \\
\text { plantea la escritura como un sistema de } \\
\text { representación y no como la transcripción de la } \\
\text { oralidad. Las alumnas intentaban comprender } \\
\text { la diferencia entre el aprendizaje de la escritura } \\
\text { como una técnica o como un sistema gráfico } \\
\text { que tiene sus convenciones. Al principio, } \\
\text { cuestionaban que los fonemas tuviesen una } \\
\text { realidad psicológica discutible y que los chicos } \\
\text { pudiesen discriminarlos una vez que } \\
\text { aprendieran la escritura alfabética. Discutir en } \\
\text { el grupo total, cuando hicimos la puesta en } \\
\text { común, les permitió comprender que los niños } \\
\text { comienzan a establecer relaciones de } \\
\text { correspondencia entre las letras y los fonemas } \\
\text { cuando ya escriben de manera silábica. Por } \\
\text { otra parte, consideramos que no hay una } \\
\text { relación transparente entre la lengua oral y la } \\
\text { lengua escrita, sino que se basa en una } \\
\text { convención que ha sido aceptada por los } \\
\text { usuarios de la lengua. }\end{array}$ \\
\hline $\begin{array}{l}\text { 7. (R.B.) - Vernon dice que los niños } \\
\text { reestructuran el universo oral y gráfico | } \\
\text { porque la exigencia de producir e interpretar la }\end{array}$ & $\begin{array}{l}\text { A una de las alumnas le cuesta comprender la } \\
\text { relación entre grafema y fonema. Desde un } \\
\text { principio, quienes no habían profundizado en }\end{array}$ \\
\hline
\end{tabular}


palabra escrita es lo que les permite a los niños conceptualizar la palabra oral como un conjunto de unidades sonoras -consonantes y vocales- aislables, clasificables y como conjuntos de sonidos que son diferentes unos de otros.

8. (N.L.) - Sí. Pero, ¿no es que hay una letra para cada sonido?

9. (R.B.) - No. Acordate de los ejemplos de sandía, zapato y cielo. Las letras no son las mismas y el sonido de las tres es igual.

10. (A.O.) - Acá encontré que los sistemas alfabéticos aumentan las posibilidades de representación con un número reducido de signos. I|| Lo que no me queda muy claro son los criterios y las relaciones. ¿Le preguntamos a la profe?

23. (R.B.) - ¿O sea que las palabras, por ejemplo, que terminan con $z$ se escriben con $c$ en sus plurales? | ¿Y eso es por formar parte de una familia de palabras?

24. (A.O.) - ¿Pero qué tiene que ver la identidad de sonido? Acá sí se podría plantear que no haya dos letras para un mismo sonido.

25. (R.B.) - Pensá en la convención. México se ha escrito con $x$ y con $j$. ¿Eso es hasta que se normaliza una lengua, no?

28. (R.B.) - Por eso se plantea la relación con el contexto y con establecer las regularidades por pertenecer a una familia de palabras.

31. (N.L.) - El tema es el conocimiento gramatical que no tenemos. || Es fácil cuando empezamos a conocer sobre los niveles y la morfología más que nada.

3. (C.L.) - Sofía Vernon nos dice que aprender a leer y a escribir en español está relacionado con el sistema alfabético y que se relaciona con poder vincular la lengua escrita con la lengua oral.

4. (J.G.) - No es cualquier relación dijo la profesora. III Mirá que explica que la lengua escrita representa los sonidos de la lengua oral.

5. (K.D.) - ¿Pero no es eso lo que dijo la profe que estaba mal?

6. (F.F.) - Sí, porque no es una relación tan estricta. Tiene sus características. Porque no hay tanta consistencia con el principio alfabético. Los alumnos tienen que ir reconociendo patrones ortográficos para construir y hacer generalizaciones y saber cómo se pronuncian las letras en la escritura. Dice que no se pronuncia igual $\mathrm{la}\langle\mathrm{g}\rangle$ en gato los materiales, consideraban que existía una relación biunívoca entre grafía y sonido. En la medida en que fueron releyendo los materiales y discutiéndolos, pudieron encontrar algunas respuestas a la pregunta sobre la relación oralidad, escritura y ortografía. Uno de los alumnos plantea las relaciones entre ciertas letras y sus sonidos, con los criterios de pertenecer a una misma familia de palabras o de contexto gráfico. La relación entre la oralidad y la escritura es de (in)dependencia, ya que se deben analizar los diferentes niveles de organización y del funcionamiento de la lengua y no exclusivamente las correspondencias grafo-fónicas.
Estas alumnas comenzaron a discutir sobre la pregunta cuando iniciaron la lectura de los materiales. Si bien no habían leído todo, fue interesante que pudieran reflexionar acerca de la relación que se entabla entre la lengua escrita y la lengua oral. Se plantearon la correspondencia entre letra y sonido y pudieron reflexionar sobre la construcción de patrones ortográficos a partir de consultar lenguaje escrito. 
o en gigante.

7. (K.D.) - Ah... y con la $<\mathrm{g}>$, no es lo mismo 'guitarra' o 'Miguel'. Explica que no se pueden leer solamente a partir de la correspondencia entre los sonidos y las letras. Hay una letra más que no se lee.

8. (C.L.) - Es que antes dice / Les leo: el español es relativamente regular en su escritura. Hay patrones gráficos y ortográficos que no corresponden directamente a la aplicación del principio alfabético.

9. (J.G.) - ¿Y cómo entendemos el principio alfabético?

10. (K.D.) - Como el principio que conecta una letra con un sonido. Pero hay letras que no se conectan con sonidos en castellano como la ' $h$ '. Por eso es que tenemos que organizar patrones ortográficos.

11. (F.F.) - Por eso dice que los alumnos tienen que aprender a segmentar los sonidos y aislar los sonidos de su lengua.

12. (J.G.) - Es difícil poder aislar los sonidos. A mí me cuesta darme cuenta.

13. (K.D.) - Bueno. Imaginate los chicos. Les recuesta. Por eso es mejor usar soportes gráficos para que relacionen con las letras. $Y$ lo dice la autora, que es un hecho reconocido que identificar y operar al nivel de los sonidos menores a la sílaba es algo difícil de lograr.

- Alumnos de tercer año del turno vespertino

\begin{tabular}{|c|c|}
\hline Transcripción de diálogo exploratorio & Análisis \\
\hline $\begin{array}{l}\text { 11. (J.C.) - Vernon explica que la mayoría de } \\
\text { las personas piensan que la lengua escrita } \\
\text { representa, fundamentalmente, los sonidos de } \\
\text { la lengua oral. Esto tiene algo de consistente, } \\
\text { pero se relaciona con el aprendizaje de la } \\
\text { escritura y el dominio de la lengua escrita. } \\
\text { 12. (A.D.) - También Quinteros se plantea que } \\
\text { conocer la lengua escrita ha llevado a una } \\
\text { profunda reflexión sobre lo que es la lengua } \\
\text { escrita en sí misma y su relación con el } \\
\text { lenguaje oral. } \\
\text { 13. (C.L.) - Sí. Como no hay sistemas } \\
\text { alfabéticos puros, no se puede plantear que la } \\
\text { escritura sea una transcripción de lo oral, sino } \\
\text { que los modelos de escritura sirven para } \\
\text { analizar el habla. } \\
\text { 14. (C.R.) - Para la Psicogénesis, en el } \\
\text { proceso del desarrollo del principio alfabético, } \\
\text { los alumnos reestructuran el universo oral y } \\
\text { gráfico en la medida que lo transforman, }\end{array}$ & $\begin{array}{l}\text { Esta selección de turnos es relevante porque } \\
\text { permite observar de qué manera los alumnos } \\
\text { comenzaron a consultar los materiales y a } \\
\text { seleccionar las ideas que les parecían más } \\
\text { importantes. Han sido capaces de poder } \\
\text { cuestionarse la relación entre la lengua oral y la } \\
\text { escrita, junto con la posibilidad de pensar en la } \\
\text { ortografía de acuerdo con la concepción de } \\
\text { lengua escrita que se plantee. Además, se } \\
\text { incluye la necesidad de tener en cuenta la } \\
\text { manera en que los alumnos construyen y } \\
\text { piensan sobre lo escrito. }\end{array}$ \\
\hline
\end{tabular}




\begin{tabular}{|c|c|}
\hline 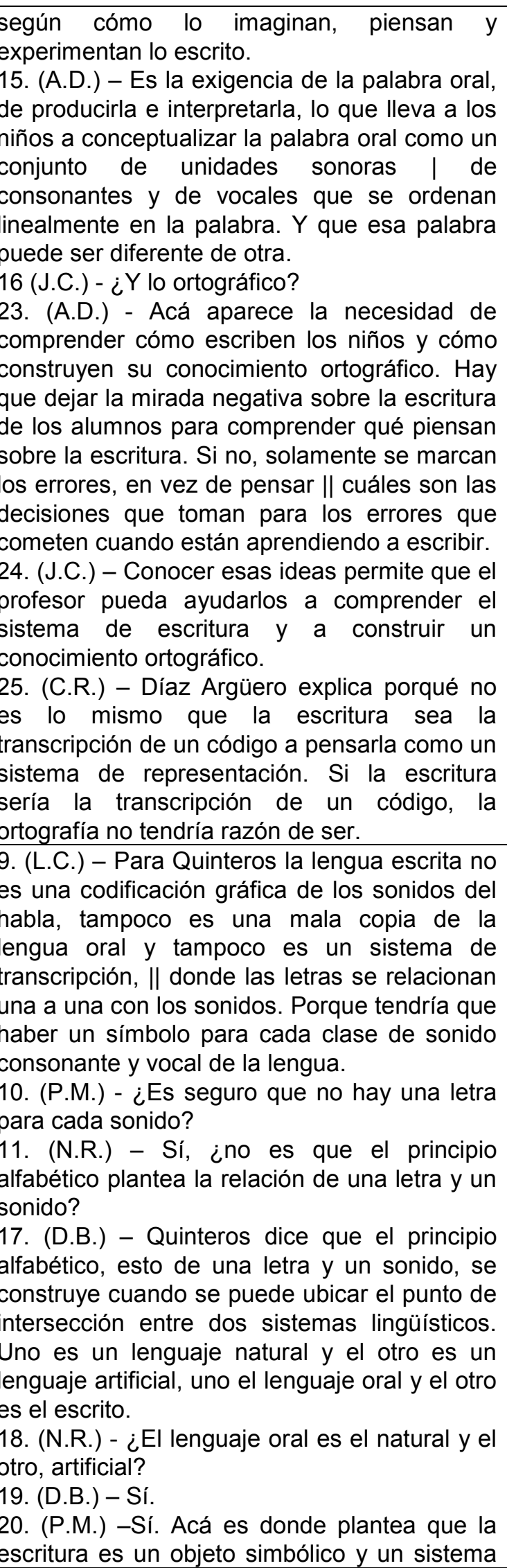 & $\begin{array}{l}\text { Estas intervenciones son valiosas para los } \\
\text { alumnos porque les permitió comenzar a } \\
\text { pensar sobre el sistema de escritura. No } \\
\text { solamente abordaron el momento en que se } \\
\text { inicia la fonetización de la escritura, sino que } \\
\text { también consideran la intervención del docente. }\end{array}$ \\
\hline
\end{tabular}


de representación.

21. (D.B.) - Cuando aparece el principio fonetizante de la escritura, los alumnos reorganizan su sistema gráfico. $Y$ es importante que si les permitimos actuar, tomar decisiones sobre la escritura, pueden transformar el sistema gráfico. El maestro tiene que intervenir para ubicarlos en los aspectos más relevantes del proceso. Acá me perdí.

22. (P.M.) - Pero les da seguridad para que escriban.

4. (A.G.) - Para Vernon, $\|$ aprender a leer y a escribir se relaciona con un sistema alfabético que está relacionado con poder vincular la lengua escrita con la lengua oral.

5. (H.C.) - Sí. Explica que la mayoría de las personas creen que la lengua escrita representa los sonidos de la lengua oral. Pero, para los niños poder segmentar las palabras en fonemas, depende del conocimiento de la lectura y la escritura.

6. (L.M.) - Para Quinteros no es la lengua escrita una codificación de la lengua oral, ni tampoco es una mala copia de ella, ni es un sistema de transcripción || porque no hay relación de un sonido es igual a una letra.

7. (A.G.) - La manera de comprender la relación entre oralidad y escritura resulta validada por el proceso de desarrollo que los niños siguen para poder comprender el modo de producción de la lengua escrita, de los principios que la rigen y de las unidades que forman el sistema alfabético.

8. (H.C.) - Es necesario ubicar la escritura como un objeto de conocimiento de carácter histórico y también ubicar al niño como un sujeto cognoscente y no únicamente como un aprendiz.

9. (A.G.) - Los niños analizan su propia palabra escrita y pueden transformar su forma de escucha y pensar el lenguaje oral para poder repensar la palabra escrita.

10. (L.M.) - De Camps. | Dice que la relación entre lengua escrita y oral no es transparente. Es el resultado de una convención aceptada por los usuarios de una lengua en un momento determinado de su historia. Una convención.

Las alumnas recuperan el marco teórico sobre la enseñanza de la lengua escrita a partir de reconsiderar la relación con la lengua oral y la manera en que los alumnos construyen el objeto de conocimiento. Recuperan que no hay una relación transparente entre la lengua oral y la lengua escrita y que la ortografía es producto del acuerdo entre los usuarios de la lengua y se trata de una convención. 
b) Segunda pregunta: ¿Cómo enseñar ortografía?

Esta segunda pregunta tiene el objetivo de que los alumnos compartan reflexiones sobre los materiales que orientan la enseñanza de la ortografía.

- Alumnos de tercer año del turno diurno

\begin{tabular}{|c|c|}
\hline Transcripción de diálogo exploratorio & Análisis \\
\hline $\begin{array}{l}\text { 4. (A.M.) - Lo ortográfico surge cuando hay } \\
\text { posibles alternancias gráficas para un mismo } \\
\text { fonema. Por ejemplo, Il de la } s \text { y la } z \text {, la } c \text { o la } \\
s \text {, la } j \text { y la g, la } v \text { y la b. Ill No son los únicos } \\
\text { pares posibles, pero sí son los que mejor } \\
\text { ejemplifican el problema ortográfico del } \\
\text { español. Esto es de Ferreiro y Díaz Argüero. } \\
\text { 5. (J.A.) - Sí, eso son los problemas de } \\
\text { siempre. Más los acentos. } \\
\text { 6. (C.F.) - ¿Qué dicen de enseñar? } \\
\text { 7. (R.E.) - Por ejemplo, que el problema de } \\
\text { fondo es cómo impartir la enseñanza, porque } \\
\text { reside en crear condiciones de aprendizaje } \\
\text { para que los esquemas de conocimiento que } \\
\text { construye el alumno evolucionen en un } \\
\text { sentido determinado. } \\
\text { 8. (J.A.) - ¿Qué leés? } \\
\text { 9. (R.E.) - Esto. } \\
\text { 14. (J.A.) - Esto está bueno. Facilitarles } \\
\text { situaciones reales de escritura, } \\
\text { proporcionarles instrumentos de apoyo, crear } \\
\text { situaciones de aprendizaje sistemático de los } \\
\text { aspectos regulares del sistema gráfico y } \\
\text { facilitarles instrumentos para la práctica de } \\
\text { determinados problemas. } \\
\text { 15. (C.F.) - ¿Qué son los instrumentos de } \\
\text { apoyo? } \\
\text { 16. (J.A.) - Mmmm. } \\
\text { 17. (R.E.) - Son materiales como diccionarios, } \\
\text { fichas de consultas, cuadernos de ortografía, } \\
\text { murales y otros materiales confeccionados por } \\
\text { los mismos alumnos. } \\
\text { 18. (J.A.) - Ah. Está bueno. Esto es para } \\
\text { profundizar. Marcá bien las páginas. }\end{array}$ & $\begin{array}{l}\text { La lectura y el análisis de los materiales les } \\
\text { permiten poder delimitar algunos problemas } \\
\text { que surgen en ciertas alternancias gráficas y } \\
\text { buscar soluciones para encontrar una manera } \\
\text { de resolverlos. Una cuestión relevante es que } \\
\text { consideren las condiciones que se deben } \\
\text { generar en el aula para revisar la ortografía } \\
\text { cuando se escribe y que incorporen situaciones } \\
\text { de escritura real y soportes para consultar. } \\
\text { Debido a la falta de tiempo, las alumnas } \\
\text { señalan las páginas para volver a leer el } \\
\text { material. }\end{array}$ \\
\hline $\begin{array}{l}\text { 9. (A.O.) - ¿Cuál es la función del maestro? } \\
\text { Tiene que darles oportunidades a los alumnos } \\
\text { para el uso del lenguaje escrito, para la } \\
\text { elaboración de hipótesis y para resolver los } \\
\text { conflictos que se le presenten entre sus } \\
\text { hipótesis y el uso social del lenguaje escrito, } \\
\text { con una práctica que le permita automatizar } \\
\text { los aprendizajes ortográficos. } \\
\text { 10. (R.B.) - Sí. Se deben crear situaciones } \\
\text { reales de escritura, tener instrumentos de } \\
\text { apoyo para consultar, que haya situaciones de } \\
\text { aprendizaje sistemático de los aspectos }\end{array}$ & $\begin{array}{l}\text { Los intercambios entre las alumnas posibilitan } \\
\text { que piensen en cuál es la función del maestro y } \\
\text { cuáles son las condiciones que debe generar } \\
\text { para que los alumnos puedan construir el } \\
\text { conocimiento ortográfico. Recuperan las } \\
\text { situaciones reales de escritura, la consulta a } \\
\text { materiales y, especialmente, la práctica en } \\
\text { lugar de hacerlos memorizar las reglas } \\
\text { ortográficas. }\end{array}$ \\
\hline
\end{tabular}




\begin{tabular}{|c|c|}
\hline 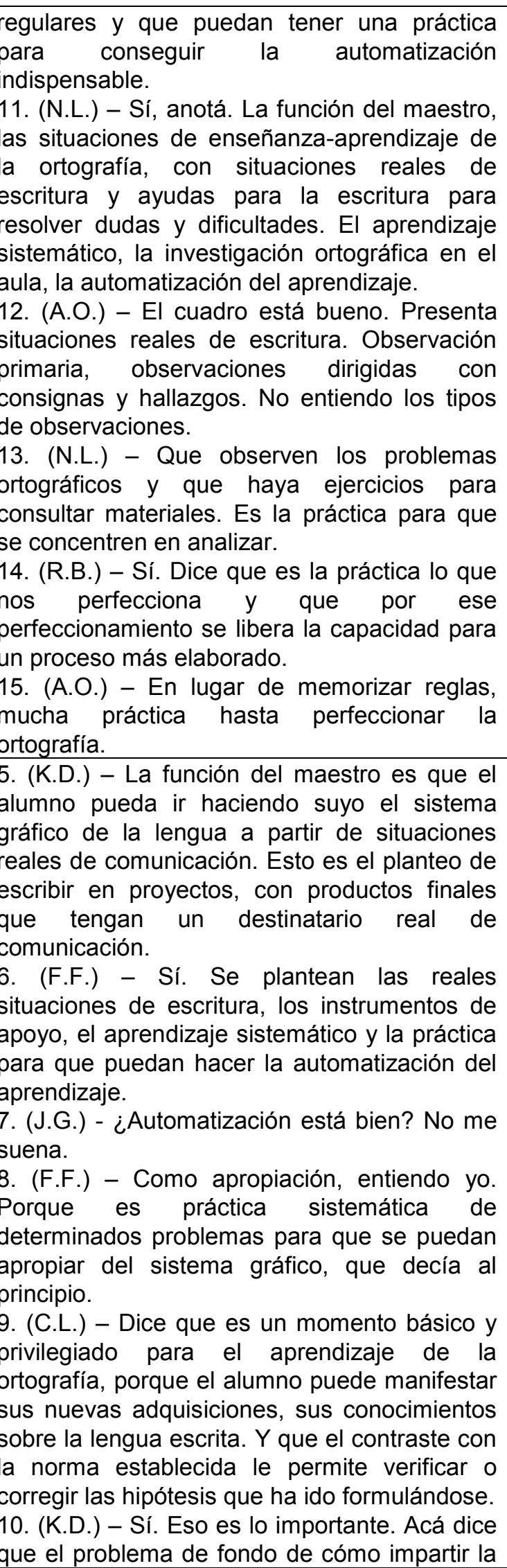 & $\begin{array}{l}\text { A través del intercambio se puede observar que } \\
\text { las alumnas tienen en cuenta la propuesta de } \\
\text { enseñanza de la ortografía en situaciones } \\
\text { reales de escritura. Además, es importante que } \\
\text { consideren para qué se usa la lengua escrita y } \\
\text { que el alumno es un sujeto cognoscente que } \\
\text { elabora hipótesis sobre el objeto de } \\
\text { conocimiento, que deben ser verificadas o } \\
\text { corregidas. Recuperan la importancia de la } \\
\text { práctica y de la construcción de materiales } \\
\text { construidos por los alumnos para reflexionar } \\
\text { sobre la convención ortográfica. }\end{array}$ \\
\hline
\end{tabular}


enseñanza reside en crear las condiciones de aprendizaje para que los esquemas de conocimiento puedan evolucionar. $Y$ la evolución se da a partir de verificar o de corregir las hipótesis.

11. (F.F.) - Para eso es importante que tenga escritura real, materiales construidos por el mismo alumno, y ejercicios para asimilar el uso de la lengua escrita.

12. (K.D.) - Se plantea el uso de la lengua escrita para aprender sobre la naturaleza, el mundo que lo rodea, para comunicarse, etc.

\section{- Alumnos de tercer año del turno vespertino}

\begin{tabular}{|l|}
\hline Transcripción de diálogo exploratorio \\
\hline 6. (H.C.) - Camps resalta que la enseñanza \\
de la ortografía debe hacerse en situaciones \\
reales de escritura. Los textos no tienen que \\
ser escritos para que los corrija el maestro o \\
para que después se hagan ejercicios \\
mecánicos y repetitivos. ¿Qué les parece? \\
7. (A.G.) - Yo no sé si siempre se puede \\
plantear la escritura de textos reales. La \\
profesora hablaba de proyectos. Ahí capaz \\
que sí.
\end{tabular}

8. (L.M.) - A mí me interesa el tema de la investigación ortográfica en el aula, además de la escritura de textos con propósitos comunicativos reales.

9. (H.C.) - Sí, a mí también me gusta la propuesta de investigar en libros y hacer como un juego. El inconveniente que veo es que el maestro debe ser siempre el guía. ¿Y si no sabe? ¿Cómo los guía?

10. (L.M.) - ¿Y si juega a que aprende con ellos?

11. (H.C.) - No me parece adecuado. Para mí tendríamos que resolver el problema de la ortografía, antes de ir a la escuela.

5. (A.D.) - Aparece la cuestión de la sobrecarga de la memoria en la escritura y la imposibilidad de poder tener en cuenta todas las variables a la hora de escribir. | Para mí es importante lo de la evaluación para aprender a escribir, que enseña y no es para poner una nota definitiva.

6. (C.R.) - Sí, estoy de acuerdo. Organizando un taller para revisar la ortografía es una buena medida para enseñar mientras se corrige el texto. $Y$ que los textos sean para una situación real de escritura, ubicados en un proyecto de trabajo para publicarlos o

Análisis

Las alumnas comienzan a revisar los materiales sobre la enseñanza del conocimiento ortográfico y a valorar las propuestas de escritura real, de que haya una situación comunicativa auténtica. Además, recuperan el trabajo de taller y la investigación aplicada a la enseñanza de la ortografía. Sin embargo, una de las alumnas presenta su postura de "resolver el conocimiento ortográfico" antes de dar clase; mientras que otra propone que el docente se incorpore a la investigación, como si participara del juego.

Estas alumnas trabajaron con los materiales sobre enseñanza de la ortografía y recuperaron la necesidad de considerar que escribir es una actividad compleja, que requiere el dominio de diferentes conocimientos en la producción de un texto. Otra cuestión importante es reconocer la necesidad de tener en cuenta que la escritura sea con fines comunicativos, para un destinatario real y no solo para el docente, y de implementar la evaluación formativa con talleres de revisión de la ortografía. 
exponerlos después.

7. (C.L.) - Sí. Hay un uso de las letras que uno no los tiene en cuenta. Por ejemplo ॥ cómo se pronuncian las $n \circ \mathrm{m}$ cuando están en una sílaba en el interior de la palabra. $\mathrm{O}$ el uso de la $r$, que para mí siempre se escribía doble cuando estaba en el medio de la palabra.

11. (N.R.) - El maestro tiene que permitir que el alumno construya progresivamente el conocimiento de la lengua escrita. Acá dice que no es solamente cultivar la espontaneidad del individuo, porque los seres humanos necesitamos aprender la negociación del diálogo.

12. (L.C.) - La comunicación también se plantea en proponer situaciones reales de escritura para que les interese a los chicos revisar los textos y corregirlos.

13. (P.M.) - Eso es importante. Se preocupan por corregir. Pero hay que proponérselos y ayudarlos.

14. (L.C.) - Acá está la ayuda con materiales de consulta, con diccionarios, con materiales que ellos hayan construido y que el maestro intervenga a lo largo del proceso, no en el final.

15. (D.B.) - Sí. El alumno necesita resolver dudas y el maestro tiene que estar atento. Las herramientas son los diccionarios, las fichas de consulta, los cuadernos de ortografía, los murales, y los materiales que hayan sido producidos por los mismos alumnos.

Este grupo también focalizó en la importancia que tiene la función del maestro en la organización de la práctica en el aula. Las alumnas recuperaron las situaciones reales de escritura, la intervención docente mientras se escribe, la consulta a materiales escritos y la producción de textos sobre la convención ortográfica con los alumnos.

Discutimos con los alumnos de la formación docente la importancia que tiene que la escuela les ofrezca a los niños y jóvenes estudiantes situaciones de lectura y escritura en las que puedan valorar el uso del lenguaje en la vida social. Si se focaliza exclusivamente en la ortografía, se reduce el lenguaje escrito a la notación gráfica. Además, la enseñanza de la norma a partir de la memorización de reglas ortográficas satura la memoria y no permite construir conocimiento sobre las excepciones. En tal sentido, fue importante que en los diferentes grupos pudieran rescatar la importancia de la escritura en situaciones reales de comunicación y en la intervención docente a lo largo del proceso de escritura. Por otra parte, también compartimos algo que habían destacado los grupos sobre los materiales de consulta, la construcción de la norma con los alumnos y la práctica sistemática para posibilitar la construcción del sistema gráfico. 


\subsection{El debate sobre la simplificación ortográfica}

Para que los alumnos pudieran debatir sobre la conveniencia o no de la simplificación ortográfica, seleccionamos la propuesta de reforma ortográfica realizada por gramáticos y escritores hispanoamericanos.

En la clase siguiente, los alumnos eligieron un moderador y debatieron acerca de la conveniencia o no de reformar la ortografía. A partir de los argumentos presentados, pudieron observarse tres posturas: la primera estaba de acuerdo con simplificar la ortografía, la segunda planteaba que no era conveniente modificarla y la tercera estaba compuesta de indecisos que no tenían claro qué hacer al respecto. A continuación, presento los resultados.

\section{a) Alumnos a favor de la reforma ortográfica}

Los alumnos que se manifiestan a favor de la reforma ortográfica consideran que los problemas de "errores" ortográficos tienen directa relación con la "decadencia de la escuela" y el avance de las nuevas tecnologías, como podemos observar en el siguiente argumento:

"El poco interés de los maestros y de los estudiantes, la falta de enseñanza de la ortografía, el abuso de la tecnología y la falta de lectura producen muchos errores ortográficos".

En este caso, también el alumno atribuye a la tecnología y a la falta de lectura que haya "errores" ortográficos. Si bien empleó en su discurso conceptos como aprendizaje significativo, construcción y reconstrucción del sistema de escritura, y consideró el valor del proceso de aprendizaje y la visión constructiva del error, no pudo diferenciar entre falta y error de ortografía. Se ha apropiado del discurso de clase pero, probablemente, le falté la lectura en profundidad de los materiales teóricos y la comprensión de la naturaleza de la lengua escrita como objeto de conocimiento.

En cambio, los argumentos que consignamos a continuación presentan una visión reduccionista de la lengua escrita. Se trata de valorar el aspecto fonético en desmedro de la construcción del lenguaje escrito:

"El conocimiento de la lengua y del lenguaje tiene una gran complejidad. Si se respeta la relación grafema-fonema, por lo menos habría un aspecto más fácil para abordar". 
"Tendría que favorecerse un sistema donde se escriba como se pronuncia. Así sería más fácil enseñar y aprender a escribir".

Un grupo pequeño de alumnos aportó que la práctica de enseñanza que centraliza el error no promueve que los estudiantes se cuestionen acerca de las variantes sociales, geográficas e históricas que determinan las reglas ortográficas.

Otro de los argumentos presentados es que

"El problema es que no hay recetas para enseñar. Todo depende del grupo de alumnos que se reciben".

Pudimos reflexionar con los alumnos que en el marco de las prácticas sociales del lenguaje, la reflexión es una actividad que cobra sentido en la planificación y revisión de lo que se produce, en la lectura compartida y en el intercambio de interpretaciones acerca de los textos. Una de las alumnas planteó que se trata, entonces, de un proceso de múltiples idas y vueltas entre el uso del lenguaje y su análisis. Por eso no puede descontextualizarse, postularse en la memorización de reglas o convertirse en un mero ejercicio de reconocimiento. Un grupo pequeño de futuros docentes explicó que los estudiantes deben aprender a analizar los recursos de los textos, comparando y evaluando sus significados y alcances durante la lectura, la escritura y la revisión de los mismos.

\section{b) Alumnos en contra de la reforma ortográfica}

Los alumnos que estuvieron en contra de la reforma ortográfica plantearon que no se puede simplificar la ortografía y afirmaron que la escritura es un sistema de representación del lenguaje, convencional y arbitrario, que ha requerido de un largo proceso histórico para adquirir una forma de uso colectivo. Sostuvieron, a partir de las lecturas y de lo que habíamos explicado en las clases, que el sistema ortográfico es central dentro de un idioma, dado que actúa como normalizador y fijador de la lengua y constituye un elemento medular en la cohesión y unidad del español. Incluyeron, a partir de la presentación realizada por Gutiérrez Ordóñez de la nueva Ortografía panhispánica de la RAE en conjunción con las diferentes asociaciones hispanoamericanas (2011), que la ortografía fue dejada de lado en el siglo XX y que ha comenzado a ser considerada en estos últimos años. Pusieron en consideración de los presentes que, como afirma Gutiérrez Ordóñez, "la lengua es la cultura” y que la ortografía debe concebirse como ciencia y debe convertirse en un ámbito de conocimiento y de investigación, ya que es en 
el sistema de la ortografía donde se observa la unidad de la lengua como en ningún otro y es eso lo que permite que podamos disfrutar de los textos literarios producidos por escritores de diferentes nacionalidades de habla española. En tal sentido, los alumnos argumentaron que

"La lengua es el producto de la evolución histórica. Es importante que se mantenga porque, al ser un producto de la convención de una comunidad, permite la comunicación".

"El problema de simplificar la ortografía es que acá en nuestro país se crearían diferentes idiomas y ni pensar lo que sucedería con el español en el mundo".

"La ortografía es un elemento clave de unión de una misma lengua hablada en diferentes regiones del mundo, como sucede con el español".

Por otra parte, en relación con la enseñanza de la ortografía, los alumnos fundamentaron su posición a partir de considerar que

"La enseñanza de la ortografía tiene que ser diaria, tendría que ser en un horario independiente de las horas de la materia, donde también se enseñe algo de gramática".

Compartimos con los alumnos que se debe enseñar la ortografía en la escuela primaria a partir de las producciones que realicen los alumnos y que tengan un propósito comunicativo. Recuperamos con los alumnos, en tal sentido, la propuesta de construcción de una alternativa de trabajo en el aula superadora de las prácticas habituales y tradicionales de enseñanza y aprendizaje. En esta propuesta, considero importante incluir fuertemente las ideas de los alumnos y sus transformaciones sobre los objetos de conocimiento en la dirección de saberes socialmente válidos. Esto implica que las conceptualizaciones de los estudiantes sobre el objeto de conocimiento, junto con la organización de los medios necesarios que posibiliten su transformación en las situaciones escolares, se conviertan en un componente fundamental de las prácticas áulicas. En relación con la importancia de la ortografía, los alumnos de la formación docente consideraron que 
"Es importante conocer la ortografía, porque si uno comete faltas ortográficas se muestra que tiene muy poca preparación y un desconocimiento del lenguaje. En cambio, no cometer errores ortográficos demuestra la cultura de una persona".

Dado que los estudiantes construyen y reconstruyen el sistema de escritura durante los primeros años de aprendizaje en la escuela, es inevitable que haya errores y, por otra parte, son necesarios para poder aprender sobre la lengua siempre que se pueda reflexionar sobre ellos. Desde el punto de vista del objeto de conocimiento, es necesario respetar la lengua como una construcción social y cultural, que surge a partir de la necesidad de comunicarse de las personas. Tanto en el plano social como en el personal, el conocimiento de las convenciones ortográficas facilita la eficacia en la comunicación, ya que permite la eliminación de ambigüedades semánticas, léxicas y sintácticas. Además, este conocimiento es apreciado por la mayoría de los hablantes de la lengua y su carencia suele ser asociada con una dificultad en la formación y en la cultura de un individuo.

"Se tienen que plantear actividades que les permitan a los alumnos interactuar y discutir con sus compañeros, pero siempre en tareas comunicativas, que no queden los textos en el aula y para que los corrija la maestra".

Fue necesario recuperar con los alumnos de la formación docente la importancia que tiene la tríada didáctica, compuesta por el sujeto que enseña, el sujeto cognoscente y el objeto de enseñanza. Una vez más se consideró que la escritura es un sistema de notación que describe los fonemas del lenguaje, con propiedades particulares según el tipo de relación que establece con ellos. En el caso de nuestro sistema alfabético no se transcriben los fonemas uno por uno, sino que se analiza el lenguaje para identificarlos y así poder simbolizarlos notacionalmente. Así, la escritura permite que el lenguaje se convierta en objeto de análisis y se pueda reflexionar sobre él.

\section{c) Alumnos indecisos respecto de la simplificación ortográfica}

En relación con los alumnos que se mostraron indecisos, encontramos cierta coincidencia en los argumentos que esgrimieron en el debate. Pareciera ser que son los que más dificultades presentan en la comprensión de la naturaleza del sistema de escritura y, entonces, recurren a argumentos que suelen circular en la comunidad en general cuando se habla sobre la educación y la ortografía. Por ejemplo, el siguiente argumento sostiene una representación de personas mayores que creen que antes sí se 
estudiaba, pero que ahora los alumnos están más interesados en la tecnología que en el estudio:

"Los alumnos no se preocupan por estudiar y les da lo mismo superar sus deficiencias".

En el siguiente caso, podemos observar que se hace referencia a algo que también es cuestionado por nuestra sociedad: la formación inicial de los maestros. Generalmente, en nuestra zona se considera que los jóvenes con dificultades para estudiar se dedican al magisterio o a la policía, buscando una rápida salida laboral. En ambos casos, se cuestiona la formación de cada uno:

"Algunos maestros cometen errores graves de ortografía, lo cual contribuye a que los alumnos tengan también dificultades y no valoren la escritura".

Por otra parte, otro de los argumentos que presentaron los alumnos se relaciona con una idea que es frecuentemente comentada en la comunidad actual. Se trata de pensar que las nuevas tecnologías empeorarán la ortografía:

"La ortografía se ve alterada por el uso de los medios de comunicación y el uso de las nuevas tecnologías".

Los alumnos que están en contra de la simplificación ortográfica pusieron en consideración que todo cambio que se produzca en las tecnologías de la escritura produce consecuencias en las prácticas sociales. Además, señalaron estos alumnos, que postulan la comprensión de la naturaleza del sistema de escritura y están en contra de la reforma ortográfica, que lo que se debe considerar es la enseñanza de los distintos tipos de variedades de lenguaje de acuerdo con la situación comunicativa, con el propósito de comunicación y el objetivo didáctico, y con el texto que se produzca en relación con un destinatario real o imaginado.

Esto implicó que los alumnos que estaban argumentando sobre su indecisión respecto de la conveniencia de una reforma ortográfica plantearán que

"No es fácil aprender lengua. Hay que saber sobre las letras, los verbos, las oraciones, los textos. Al ser tan difícil su aprendizaje, es muy complicado enseñarla". 
Para explicar su posición, los alumnos que habían presentado el argumento anterior recurrieron a la lectura del prólogo del libro de Fontich, en el que Camps explica que hasta no hace mucho enseñar lengua parecía algo fácil: "copia, dictado, ejercicios de ortografía, análisis sintáctico y morfológico y alguna redacción de vez en cuando (...) De hecho cualquiera se atrevía a ser profesor de lengua" (2006: 11). A su vez plantearon que en el marco de la Didáctica de la Lengua, el espacio se concibe como una interacción entre prácticas pedagógicas y procesos de aprendizaje de una materia específica que es la lengua. En tal sentido, la complejidad de las disciplinas involucradas en la investigación de la enseñanza y el aprendizaje de la lengua, y las interrelaciones entre esas disciplinas hacen que sea necesario profundizar en una teoría de la acción didáctica que dé cuenta de las situaciones escolares en las que se enseña y se aprende lengua.

Frente a la complejidad de la enseñanza y el aprendizaje de la lengua, los alumnos propusieron que en su formación hubiese dos materias separadas, una para enseñar los contenidos de la lengua y las prácticas del lenguaje y otra para poder plantear las maneras de abordar la enseñanza de esos contenidos:

"Sería bueno tener dos materias separadas, que se junten después en el Ateneo de cuarto año. Se podría aprender sobre los contenidos y después pensar en la manera de enseñarlos".

Por último, después de la discusión que se generó sobre la conveniencia de separar las materias en dos para abordar los contenidos relacionados con el estudio de la lengua, por un lado, y su enseñanza por el otro, los alumnos reflexionaron sobre la importancia de su formación docente:

"La enseñanza debe garantizar que todos los alumnos puedan alfabetizarse. Ferreiro dice que, aunque en la escuela hay maestros mal pagos y con escasa formación, la escuela sigue siendo el lugar para alfabetizar. Lo que hace falta es una mejor formación para nosotros".

Como podemos observar en los argumentos presentados, existe influencia del sistema de creencias, representaciones y saberes de los futuros docentes sobre la práctica educativa. Es necesario considerar esta influencia sobre la enseñanza de la alfabetización para poder mejorar el proceso de aprendizaje, teniendo en cuenta lo que ha evolucionado la alfabetización y la didáctica de la lengua en estos últimos años. Se debe tomar conciencia de que la reforma propuesta en el último Diseño Curricular de la 
Provincia de Buenos Aires obedece a una forma determinada de abordar y entender la enseñanza y el aprendizaje, ya que se recupera el alumno como sujeto cognoscente, la naturaleza del objeto de conocimiento y la relación que se establece con el sujeto educador.

\section{- Síntesis del análisis del debate sobre la reforma ortográfica}

Los alumnos evaluaron la experiencia como algo muy positivo. Destacaron en la puesta en común que hicimos en el aula de formación docente que "más allá del miedo que nos dio al principio encarar la propuesta, pudimos darnos cuenta de qué dice la teoría de Ferreiro y cómo eso se ve en el aula". También resaltaron que los alumnos "reales, de verdad" de las escuelas primarias no son lo que ellos se imaginaban, puesto que esperaban encontrar "algo así como un alumno modelo, como el que se presenta en las teorías o en las lecturas que hemos hecho en las materias". Esto nos llevó a analizar con el grupo de alumnos de la formación docente que en el aula encontramos personas con procedencias lingüísticas diversas, y esto no se considera si se intenta enseñar lengua como algo estático, homogéneo e inamovible, en lugar de aprovechar la riqueza de los usos lingüísticos que son complejos y heterogéneos como los grupos humanos. Compartimos que, al no haber recetas para enseñar lengua, es necesario considerar las propuestas que se preguntan por los fenómenos lingüísticos, teniendo en cuenta la variación, su función social y la idea de que aprendemos lengua reflexionando sobre ella y tomando conocimiento sobre cómo funciona.

Por otra parte, comprender que las lenguas son sistemas de comunicación y que la escritura es un sistema de representación, cuyo vínculo con el lenguaje oral es mucho más complejo de lo que habitualmente se considera, es el punto de partida para acercarnos a un conjunto de fenómenos heteróclitos y variables. Esto fue algo que discutimos con los alumnos de la formación docente, a partir de la revisión de la bibliografía que ya habían estudiado sobre alfabetización, porque lo que surgió en el análisis de la experiencia con los alumnos de las escuelas primarias es el planteo de las dificultades lingüísticas que los alumnos tienen. Los alumnos de formación docente atribuyen diferencias socioculturales asociadas a los déficits lingüísticos y a problemáticas sociales como la falta de acompañamiento de la familia en el estudio, el abandono, la violencia familiar, etc. La evaluación diagnóstica que los futuros docentes habían realizado en las aulas de las escuelas primarias sugería una relación entre el proceso de alfabetización, las dificultades socio-culturales y familiares con el proceso de escolarización. 
Discutimos, además, sobre que hay alumnos de los sectores más desfavorecidos que pueden construir el sistema de escritura y ser lo que la sociedad considera "buenos" lectores y escritores cuando la escuela le ofrece oportunidades con buenas intervenciones docentes en el aprendizaje de la lengua y la práctica del lenguaje escrito. Por otra parte, fue necesario focalizar en que la escritura no es patrimonio de la escuela, sino que constituye un objeto cultural, que cumple diversas funciones y que tiene diferentes modos concretos de existencia, especialmente en los ámbitos urbanos. Observamos con los alumnos de la formación docente que la escritura se presenta frente a los niños que viven en las ciudades como un objeto que tiene propiedades específicas a través del cual se realizan acciones e intercambios sociales. Sin embargo, tanto la lectura como la escritura han sido consideradas, tradicionalmente, como objeto de una instrucción sistemática, como algo que debe ser 'enseñado' y cuyo 'aprendizaje' supondría la ejercitación de una serie de habilidades específicas.

Los alumnos de la formación docente compartieron que aprender lengua constituye un desafío y enseñarla mucho más. Llegaron a la conclusión de que uno de los mayores desafíos que tiene la escuela es enseñarles a leer y a escribir a los alumnos y que este aprendizaje supone uno de los mayores desafíos para los niños. Además, discutieron sobre la importancia que tiene la orientación didáctica que el docente tome para la enseñanza, ya que se practican en la escuela formas en las que se pretende que los alumnos hagan un trabajo de reconocimiento y segmentación de los fonemas como un conocimiento previo para aprender a leer y a escribir. En cambio, si se considera al alumno como un sujeto capaz de aprender y que llega a la escuela con una construcción previa de la escritura, se debe focalizar en que no se puede exigir una escritura convencional desde el inicio, sino que hay que respetar lo que el alumno considera que es escritura. Para propiciar la construcción del sistema de escritura se deben incluir diversos materiales escritos en el aula -diarios, revistas, enciclopedias, libros, calendarios, agenda semanal, listado de textos leídos y de textos para leer- y acompañar el momento en que los alumnos comienzan a relacionar lo escrito con el sonido, puesto que la segmentación de los fonemas surge naturalmente en el proceso de construcción del sistema de escritura. Se acordó que lo importante es respetar los tiempos y no apurar la construcción que vayan haciendo los alumnos.

\subsection{Análisis de las síntesis informativas}

La investigación para producir esta tesis, como ya anticipé, se basó en la implementación de una secuencia didáctica sobre la enseñanza y aprendizaje de la 
ortografía con alumnos que estaban en el anteúltimo año de la carrera Profesorado en Educación Primaria. En este contexto, en pequeños grupos debían rememorar lo trabajado y discutir qué información incluirían en las síntesis informativas. La actividad en pequeños grupos y la puesta en común en el grupo completo de clase permitió generar el feed-back necesario para iniciar la escritura de manera individual de las síntesis. Para la producción de las síntesis informativas solicité a los alumnos de la formación docente que tuvieran en cuenta todo lo que habíamos trabajado hasta el momento: las notas de clase, las lecturas, las secuencias didácticas, etc. Aunque la participación de la mayoría de los alumnos en la puesta en común oral había sido muy buena, cuando tuvieron que escribir y presentar los borradores era muy poco lo que escribían en clase.

\section{a) Producción de las síntesis informativas}

En el momento de producir las síntesis informativas, la mayoría recurrió a materiales sobre ortografía, sobre su enseñanza, sobre la reforma ortográfica y recurrieron a copiar conceptos e ideas más que a elaborar las propias. Justificaron esta práctica en que no tienen mucha experiencia en producir textos, en la falta de tiempo y en la superposición de muchas actividades -cierre de la práctica en las escuelas, parciales, producción de exposiciones orales, etc.-. Planteamos una revisión de los textos entre dos, respetando al principio los que constituían pareja pedagógica porque habían vivenciado la experiencia juntos $\mathrm{y}$, más tarde, hicimos un intercambio de los textos con otros participantes.

Fue necesario que se discutiera acerca de las contradicciones e inconsistencias que se presentaban en las síntesis. Aunque estaban de acuerdo con que se debe orientar la enseñanza de la ortografía al desarrollo de la reflexión metalingüística sobre los textos que han producido los alumnos, en algunas síntesis surgía "la necesidad de que conozcan las reglas ortográficas y comprobar su conocimiento a través del dictado" cuando nos habíamos planteado que se fueran construyendo en el aula con los estudiantes. En otro caso, se consideró que había que esperar que los alumnos tuviesen la madurez necesaria para aprender conocimientos gramaticales y que "el pensamiento abstracto llega en la adolescencia, con lo cual la escuela secundaria debe ocuparse de enseñar ortografía, análisis de palabras y oraciones”. Una tercera síntesis planteaba la necesidad de "controlar el griterío de los chicos en el aula porque no se escucha bien lo que dice la maestra o decimos las practicantes y escriben remal. Cuando hacen un poco 
de silencio, pueden pensar más en lo que van a escribir y escuchar mejor para no equivocarse tanto".

\section{b) Revisión de las síntesis informativas}

En función de mejorar los textos que habían producido les propuse que construyeran pautas de evaluación para revisar y modificar la escritura, en el caso de que se presentaran faltas ortográficas. La construcción de pautas era el motivo para que los alumnos de formación docente pudieran explicitar de qué manera corregir, focalizando en la evaluación formativa. Surgieron dos posturas diferentes: a) un grupo subrayó las palabras que presentaban faltas para que sus autores buscaran el origen de la dificultad y la corrigieran, y b) otro grupo corrigió encima de las palabras indicando la letra que correspondía. Compartimos y discutimos la propuesta de Camps et al. (1990) sobre la diferencia entre marcar el error cuantitativamente y hacerlo cualitativamente. En la discusión surgieron comentarios que discriminan los conocimientos previos y las actitudes de los chicos como "en la escuela donde estuve practicando es imposible enseñar ortografía desde este tipo de evaluación formativa... Los chicos no tienen disciplina y, si se les da una tarea que no comprenden, corren en el aula, se pelean entre ellos, se rompen las cosas. Hay un problema de base de la casa y del barrio" (R.B.). Es frecuente que sigan relacionando una "correcta oralidad para que puedan escribir bien. Hay maestras que no pronuncian las -s finales, entonces los chicos no las escriben. Yo pude hacer que en primer año, pronunciando pausadamente las palabras, los chicos escribieran muy bien. Para mí saben hacer corresponder los grafemas con los fonemas perfectamente" (D.L.).

Observé que, de una manera natural, lo primero que surge en muchos de los alumnos de la formación docente es que el conocimiento de la lengua oral y la pronunciación correcta son fundamentales para desarrollar una buena ortografía y, además, piensan que hay una relación biunívoca entre grafemas y fonemas. Aunque hayamos planteado las propuestas de Ferreiro $(1997,2013)$ y la necesidad de una evaluación formativa, que les permita a los alumnos construir regularidades a partir de escribir diccionarios de clase, fichas de consulta, etc. (Camps et al., 1990), varios futuros docentes persisten en la idea de que es más importante la lengua oral que la escrita.

Para discutir la relación de (in)dependencia entre la oralidad y la escritura, les dicté los poemas Epigramas de Boston y Nocturno en que nada se oye de Xavier Villaurrutia y compartimos los textos que habían escrito para observar sus escrituras. Después, los 
contrastamos con los originales y abordamos las figuras estilísticas que presentan los poemas. Por otra parte, volvimos a revisar las notas que habían tomado de clase y de la bibliografía leída. Discutir nuevamente sobre las experiencias propias escolares en cuanto al aprendizaje de la ortografía, lo que habíamos vivenciado en las aulas de las escuelas primarias y las recomendaciones de los autores sobre la enseñanza del conocimiento ortográfico, llevaron a que los alumnos pudieran hacer una revisión de sus informes a partir de analizar cuáles eran sus dificultades ortográficas y produjeran un cuadro con las faltas de ortografía. A continuación, pusimos en práctica los ejercicios propuestos por Camps et al. (1990), que se basan en la categorización de los errores y en la producción de fichas de consulta y de diccionarios con las palabras desconocidas.

Releímos y reflexionamos sobre la necesidad de explorar materiales gráficos, consultar diccionarios y analizar regularidades, junto con la importancia que tiene la información que provee el docente para desarrollar la conciencia (meta)lingüística. Al reflexionar sobre la importancia que tiene el lenguaje escrito en la construcción del aprendizaje, ya que permite registrar las ideas y volver sobre ellas para reformularlas, enriquecerlas, etc., los alumnos manifestaron la necesidad que tienen de aprender contenidos de lengua que después deberán enseñar y que en las etapas educativas anteriores no han aprendido. Compartimos la importancia que tiene la visión del error como un elemento necesario en la construcción del aprendizaje y la que tiene la reflexión metalingüística y el desarrollo del conocimiento metalingüístico.

\subsection{Análisis de las entrevistas}

En este apartado presentamos el resultado de la información obtenida en las entrevistas semiestructuradas, realizadas con tres alumnos participantes de la formación docente.

\section{a) Alumno 1}

El primero de los alumnos que seleccioné es escritor y tiene cinco libros publicados de manera artesanal, que ha producido él mismo. Además, coordina talleres de lectura y escritura creativa en dos bibliotecas populares, una está ubicada en Carmen de Patagones (Provincia de Buenos Aires) y la otra, en Viedma (Provincia de Río Negro). Se trata de un alumno que disfruta de la lectura y de la escritura, que está a favor de "defender la lengua escrita que nos une a los hispanohablantes del mundo" y que se preocupa por "llegar a ser un buen docente el día de mañana". Para complementar su formación, ha comenzado a cursar el Profesorado en Lengua y Comunicación Oral y 
Escrita y el Profesorado de Psicopedagogía, ambas carreras se dictan en el Centro Universitario Regional Zona Atlántica de la Universidad Nacional del Comahue.

\section{- Primera pregunta: ¿qué es la ortografía y cuál es su función?}

Reconoce la importancia que tiene "la ortografía como convención o norma para garantizar la comunicación por escrito en la lengua española, en nuestro caso".

- Segunda pregunta: ¿cómo construyeron la secuencia didáctica para enseñar ortografía? (Su propuesta de secuencia figura como SD6 en los ejemplos presentados.)

El alumno explicó que se sintieron perdidos con su compañera cuando tuvieron que pensar en construir una secuencia didáctica para enseñar ortografía. Primero consultaron en Internet qué había de novedoso para tomar como ejemplo, pero no encontraron nada. Después consultaron con la maestra guía -con quien hacen las prácticas en la escuela primaria- y ella les dio un material para trabajar ortografía. Así fue que reorganizaron algunos ejercicios para proponer a los alumnos de cuarto año.

Reconoció que, actualmente hay preocupación en la sociedad por cómo se escribe y por la ortografía. Sin embargo, en las escuelas se ha dejado de enseñar ortografía y, si se enseña, se lo hace a través de la presentación de las reglas ortográficas y de algunos ejercicios repetitivos que terminan con la evaluación de un dictado. No hay vinculación entre la enseñanza de la ortografía en el marco de la producción escrita real por parte de los alumnos. Generalmente, se emplean fotocopias de las actividades que proponen libros sobre ortografía o cuadernillos para aprender las reglas. La ortografía no constituye solamente un conjunto de normas y reglas, es un conocimiento que los alumnos deben construir para poder escribir y también porque influye en la comprensión de los textos escritos.

Recuperó la manera en que aprendió y cómo se sigue aprendiendo la ortografía, destacando el dictado para marcar los errores, la copia de varios renglones de una misma palabra para "fijar" su escritura y el recitado de reglas. Pero, a pesar de eso, también se ve que la ortografía sigue siendo un problema en el aprendizaje. Este problema tiene directa relación con la manera de enseñar. Señaló que haciendo toda esa práctica no hay enseñanza. Solamente sirve para marcar el error. Indicó que sería diferente si el dictado fuera de los alumnos al profesor, para que puedan ver de qué manera se realiza el 
proceso de escritura. Después, sí pensar y corregir entre todos los errores ortográficos, si es que se escribió preguntando a los niños cómo se escriben las palabras.

- Tercera pregunta: ¿cómo se puede enseñar ortografía en la escuela primaria?

Ante la pregunta de qué manera enseñar ortografía en la escuela primaria, el alumno destacó que tiene que haber lectura permanente. Además, es necesario pedirles que escriban para alguien, así se logra que la revisión del texto tenga sentido y que se entusiasmen con la corrección. Explicó que ha visto en la escuela que algunas maestras proponen realizar proyectos, que terminan siempre en la producción de un texto que tiene un destinatario porque se publica o se cuelga en la cartelera de la escuela y señaló que aprender a leer y escribir es uno de los principales objetivos de la escuela y desarrollar el conocimiento ortográfico es parte de este aprendizaje. Destacó que los alumnos en estos proyectos aprenden porque se involucran mucho más y al tener que publicarlos la revisión y corrección de los textos cobra sentido para ellos.

El alumno indicó que en sus experiencias en las bibliotecas, coordinando talleres de lectura y escritura, intenta que los alumnos se sientan libres y que puedan escribir con errores. Destacó que hay muchas deficiencias en las producciones escritas y que uno de los problemas de la escuela actual es que el error es sancionado. Para él, es importante acompañar al alumno, y hacerle sentir que la escritura es un recorrido que recién empieza con la primera escritura. Después hay que seguir trabajando para modelarla, pensando qué quiere uno que diga y a quién. Explicó que en la práctica que llevaron a cabo en la escuela, con su par pedagógico, atendieron las escrituras de los alumnos trabajándolas en grupos de cuatro alumnos, leyendo y releyendo entre todos los textos. Enfatizó que es necesario ver que los alumnos van elaborando hipótesis sobre cómo escribir y que, a veces, necesitan revisar y corregir esas hipótesis.

\section{- Cuarta pregunta: ¿qué te pareció la evaluación formativa?}

Consideró que la evaluación formativa constituye el momento esencial del proceso de enseñanza y aprendizaje de la lengua escrita porque permite recuperar lo que los alumnos produjeron para revisar y aprender desde sus errores. Afirmó que la enseñanza debe ser más estricta para la formación de un docente de primaria, especialmente para que pueda aprender cuestiones de gramática y de lingüística. Explicó que "si uno quiere explicarles a los alumnos de primaria, necesita conocimientos bien fundamentados, que 
no estén basados en las explicaciones que traen los manuales" y que, para ello, es necesario reforzar la enseñanza lingüística y desarrollar una capacidad metalingüística.

- Quinta pregunta: ¿qué pensás acerca de la simplificación ortográfica?

Respecto de la simplificación ortográfica, el alumno reconoció que al principio estaba en duda sobre qué significaba esto y le parecía una opción correcta, especialmente, porque uno de los que propuso la reforma es García Márquez. Pero, después de haber compartido en clase las características del español y de analizar el valor que tiene la ortografía en la comunicación, su postura se modificó. Se dio cuenta de que es importante para la unidad de la lengua escrita.

\section{b) Alumna 2}

La segunda alumna ha finalizado sus estudios en un secundario nocturno y planteó, desde el comienzo de esta investigación, que ella quería manifestar su proceso porque algo que la había marcado en el comienzo de su escolaridad era la discriminación que sentía al no aprender a leer y a escribir enseguida.

\section{- Primera pregunta: ¿qué es la ortografía y cuál es su función?}

La alumna explica que la ortografía se relaciona con "una escritura correcta de la lengua, que se basa en un conjunto de reglas y normas para escribir bien".

- Segunda pregunta: ¿cómo construyeron la secuencia didáctica para enseñar ortografía? (Su propuesta de secuencia figura como SD12 en los ejemplos presentados.)

Explicó que no sabían cómo planificar una secuencia para enseñar ortografía y que "le preguntamos a la maestra orientadora, con la que estábamos haciendo las prácticas para que nos diera materiales. La maestra nos prestó un libro que ella usa y lo escaneamos para armar la secuencia".

- Tercera pregunta: ¿cómo se puede enseñar ortografía en la escuela primaria?

Explicó que le parece difícil por la cantidad de conocimientos que se deben tener de la lengua. Agregó que al ver cómo planteamos el trabajo en la producción de las síntesis informativas, se dio cuenta de que no era una forma adecuada plantear la 
enseñanza de la ortografía desde las actividades propuestas en el libro. Indicó que le gustaría tener más práctica, especialmente en la escuela primaria destino de sus prácticas, para ver cómo funciona construir un diccionario de clase o fichas de dificultades ortográficas. Aunque todavía le cuesta procesarlo bien, señaló que encuentra sentido en que se aprenda a escribir desde el lenguaje escrito.

\section{- Cuarta pregunta: ¿qué te pareció la evaluación formativa?}

Destacó el valor que tiene la posibilidad de dialogar sobre los textos escritos, de poder discutir sobre qué iban a escribir en las síntesis informativas, por ejemplo. La alumna afirmó que el hecho de sacar la presión de la evaluación de la escritura porque se considera el aprendizaje, es realmente focalizar en el aprendizaje. Planteó que resignificar el error para considerarlo un elemento natural de la construcción de conocimientos es pensar en las necesidades que tienen los alumnos, en lo que les falta para aprender. Explicó que "lo que más me preocupa es la cantidad de conocimientos que no tenemos para abordar la enseñanza de la lengua escrita con los alumnos de primaria" y afirmó que esta materia -haciendo referencia a la Didáctica de Prácticas del Lenguaje y la Literaturadebería tener mayor carga horaria para poder aprender lo que necesitan los futuros docentes como conocimientos para guiar las discusiones entre los alumnos cuando se planteen situaciones de escritura.

\section{- Quinta pregunta: ¿qué pensás acerca de la simplificación ortográfica?}

La alumna señaló que en un principio estaba totalmente de acuerdo con realizar una reforma ortográfica. Le parecía lo mejor para que los alumnos no tuviesen más dificultades. Recordó que "no la pasaba nada bien en la escuela primaria cuando algunas maestras me retaban porque me costaba tanto escribir. También me pasó en la secundaria, por eso dejé. Después terminé de grande en una escuela nocturna porque quería progresar y ser un ejemplo para mis hijos". Agregó que, al observar que no se ha modificado la enseñanza de la ortografía en la escuela actual, ella veía una gran posibilidad de que se reformara o simplificara la ortografía. Pero, indicó que "cuando analizamos los materiales en clase y vimos que hay una relación muy particular entre las letras y la oralidad, cambié de opinión. No se trata de reformar la ortografía, sino de buscar formas adecuadas para poder enseñarla. Me gusta la evaluación formativa”. 


\section{c) Alumna 3}

Esta alumna es de las consideradas "una de las más estudiosas" por el cuerpo de profesores de la institución. Al principio de la investigación planteó que se debían leer todos los materiales "para llegar a tomar una postura sobre la reforma ortográfica".

- Primera pregunta: ¿qué es la ortografía y cuál es su función?

Considera que la ortografía es un conjunto de reglas ortográficas para que los alumnos aprendan a escribir correctamente las palabras de su lengua materna.

- Segunda pregunta: ¿cómo construyeron la secuencia didáctica para enseñar ortografía? (Su propuesta de enseñanza está ejemplificada como SD21.)

Explicó que la secuencia didáctica fue construida a partir de las dificultades que observaron en los alumnos de la escuela primaria, relacionadas con el uso mp, mb, nv, y agregaron el empleo de la letra $\mathrm{h}$. La base que emplearon con su par pedagógico para la secuencia fueron unas fotocopias que les dio la maestra guía y que ellas adaptaron para ofrecer actividades a los alumnos.

- Tercera pregunta: ¿cómo se puede enseñar ortografía en la escuela primaria?

Explicó que le parece difícil por la cantidad de conocimientos que se deben tener de la lengua. Agregó que al ver cómo planteamos el trabajo en la producción de las síntesis informativas, se dio cuenta de que no era una forma adecuada plantear la enseñanza de la ortografía desde las actividades propuestas en el libro. Indicó que le gustaría tener más práctica, especialmente en la escuela primaria destino de sus prácticas, para ver cómo funciona construir un diccionario de clase o fichas de dificultades ortográficas. Aunque todavía le cuesta procesarlo bien, señaló que encuentra sentido en que se aprenda a escribir desde el lenguaje escrito. Además, reflexionó sobre un episodio que le tocó vivir en una de las clases en la escuela primaria, cuando los alumnos se tiraron con papeles y la maestra guía les pidió que escribieran en las carpetas "Nos comprometemos a no tirar más bollos de papel". Mientras la maestra guía corregía unos cuadernos, ella como practicante se ocupó de recorrer el aula para que los chicos escribieran el acto de compromiso. Una de las nenas le preguntó cómo se escribía la palabra "bollo" -si con II o con y-. Le sugirió que consultara el diccionario. La alumna encontró "boyar", por lo que convinieron que escribiera "boyo". En el momento que 
compartió la experiencia en el aula de formación docente, le expliqué que debe considerar los significados que tienen las palabras en relación con el contexto de uso.

\section{- Cuarta pregunta: ¿qué te pareció la evaluación formativa?}

Afirmó que para poder enseñar a escribir y a enseñar es necesaria la evaluación formativa. Indicó que no entiende por qué no se aplica en la enseñanza de la lengua, ya que pudo observar en la escuela primaria que la evaluación siempre es para poner una nota de calificación. Señaló, además, que para poder hacer referencia al metalenguaje es imprescindible una sólida formación que los docentes ni los estudiantes del profesorado tienen. Rescató la importancia que tiene hablar y contrastar ideas con los compañeros y con el profesor para poder aprender cuando se está escribiendo. También manifestó que encuentra sentido que la enseñanza se realice a partir de los errores que los alumnos tienen y que no sean solo elementos para descalificar y bajar las notas de evaluación.

\section{- Quinta pregunta: ¿qué pensás acerca de la simplificación ortográfica?}

La alumna señaló que, en general, intentó mantenerse al margen de la disputa hasta que, cuando llegó el momento de debatir, le pareció más conveniente simplificar la ortografía. Justificó su postura tomando como ejemplo la propuesta de García Márquez pero, después, consideró que no solo puede quedarse con lo que uno piensa. Presentó ejemplos acerca de cómo los chicos en la escuela primaria discuten sobre qué letras pueden ser las que corresponden cuando la maestra les propone publicar los textos en la cartelera. Además, enfatizó la importancia que tuvo el trabajo que se hizo sobre la revisión y discusión de los materiales bibliográficos en el aula de formación docente.

Explicó que, posteriormente, con el análisis de la investigación que hicimos con todo el grupo, empezó a revisar sus argumentos y cambió de postura. Se da cuenta de por qué no es lo mismo enseñar a escribir desde los materiales escritos que hacerlo con la escalerita que usaba la maestra guía. Planteó que no sabía si la maestra guía, con quien hacía las prácticas, la entendió sobre la diferencia que hay entre usar todo tipo de texto escrito, en lugar de tomar una consonante y una vocal para aprender a escribir. Indicó que la maestra orientadora de prácticas le decía escalerita porque dibujaba escaloncitos en el pizarrón a partir de combinar una misma consonante con las diferentes vocales. Después los hacía repetir con ella a los chicos, en voz alta, la sílaba que tenía en cada escalón. Esta alumna señaló que, como dice Ferreiro, los chicos igual construyen el 
sistema de escritura, pero que el problema es que lo hacen con dificultades que, si no son trabajadas con la docente y el grupo, se arrastran para siempre.

\section{- Comentarios generales de las entrevistas}

Es necesario considerar que los alumnos que inician un proceso de formación docente llegan con creencias y representaciones profundamente arraigadas, que están ligadas a los aprendizajes que han tenido en su historia escolar. Uno de los problemas que ha enfrentado el sistema educativo argentino en los últimos años es la falta de enseñanza de los contenidos gramaticales, lo que contribuye al desconocimiento del objeto de estudio y el uso del lenguaje. Esto puede revertirse a partir de la explicación y del estudio de elementos específicos sobre la lengua. Los alumnos tuvieron la oportunidad de explicar que no tenían conocimientos previos ("Lo que vimos sobre ortografía, yo nunca lo había visto. Eso que explicó de morfología ni lo conocía, según Camila).

Pude observar en la primera entrevista que el alumno se interesa por la ortografía y la manera de enseñarla. En este caso, podemos observar que este estudiante valoriza el lenguaje escrito debido a su actividad como escritor y como tallerista en las bibliotecas populares. En general, otorga un papel central al alumno en la construcción del sistema de escritura sin perder de vista la importancia que tienen las intervenciones docentes para acompañar los procesos de enseñanza y aprendizaje.

En el caso de la segunda entrevista, es muy interesante poder observar el proceso que la alumna fue haciendo, ya que en un principio se manifestaba a favor de la reforma ortográfica convencida de que no era posible enseñar ortografía y destacaba su experiencia personal como muy negativa en el aprendizaje de la escritura. Me pareció relevante el proceso que fue haciendo a lo largo de la investigación y cómo fue cambiando de opinión sobre la simplificación de la ortografía a medida que íbamos discutiendo los materiales de lectura y que sus compañeros, que estaban en contra de la reforma ortográfica, planteaban sus puntos de vista. Aunque, al principio, los "errores" de ortografía le parecían algo incomprensible e imposible de solucionar, el conocimiento que se fue construyendo en la interacción del debate logró que modificara sus creencias y representaciones sobre la lengua escrita y su enseñanza. Además, pudo fundamentar por qué elegía ciertos materiales teóricos y criticaba la enseñanza que había observado en el aula de la escuela primaria donde llevó a cabo su experiencia. 
Por último, en la tercera entrevista, la alumna decidió leer todos los materiales para tomar posición respecto de la simplificación ortográfica. Después le pareció conveniente que podía reformarse la ortografía para lograr un aprendizaje de la lengua escrita sin dificultades. Pero, cuando pudo reflexionar sobre el contenido -a partir de profundizar su conocimiento sobre él- y vivenciar con los estudiantes de la escuela primaria el proceso de construcción de la lengua escrita, pudo cambiar su opinión y darse cuenta de lo que implicaría simplificar la ortografía para nuestra lengua y sistema de comunicación.

\section{Conclusiones}

He focalizado el análisis en poder inferir sobre a) las creencias sobre la ortografía y la simplificación ortográfica, b) las creencias relacionadas con la enseñanza y el aprendizaje de la ortografía, y c) las valoraciones asociadas a la evaluación formativa, explorando estos tres aspectos a la luz de la actividad metalingüística generada por los estudiantes.

\subsection{Conclusiones sobre la investigación}

En este apartado recupero las preguntas que formulé inicialmente: ¿Qué creencias tienen los alumnos de formación del profesorado -que están a punto de terminar su carrera- sobre la ortografía, su enseñanza y su aprendizaje en el marco de la implementación de una secuencia didáctica que tiene como objetivo promover la reflexión de los alumnos sobre esta temática?, y ¿Qué resultados se obtienen a partir de implementar la reflexión metalingüística sobre ortografía y su enseñanza?

En tal sentido, este trabajo es el resultado de un estudio sobre el conocimiento previo y las representaciones que los alumnos de dos grupos de tercer año del Profesorado en Educación Primaria tenían sobre la lengua escrita y la ortografía. He observado inicialmente que las propuestas y las maneras de enseñar la lengua escrita se basan en las concepciones que los futuros docentes -o los docentes- tienen sobre lo que es leer y escribir y sobre el lenguaje escrito en sí.

Las creencias y los saberes que tienen los alumnos de la formación docente sobre el contenido a enseñar constituyen un buen punto de partida para empezar a analizar el proceso de enseñanza y aprendizaje en el aula. Generalmente, aparecen como muy conservadores pero, si se les plantea una situación didáctica que les permita revisar esas creencias y saberes, se involucran con experiencias nuevas si les encuentran sentido. Se deben propiciar situaciones que permitan que el lenguaje se convierta en un objeto de 
reflexión. Las investigaciones realizadas por el GREAL como hemos visto resaltan la importancia que tiene incidir en el proceso de escritura y la necesidad de la interacción verbal con el adulto y con los compañeros en este proceso. La producción escrita es una actividad compleja que se inscribe en el entramado social de prácticas comunicativorepresentativas.

Considero que la implementación de la secuencia didáctica me permitió analizar con los futuros docentes que las maneras de enseñar la lengua escrita responden a concepciones de lo que es leer y escribir. Les expliqué que la escritura puede ser conceptualizada de dos formas muy diferentes y, de acuerdo con la manera como se la considere, las consecuencias pedagógicas también serán muy diferentes. Pudieron darse cuenta en la medida en que participaron en las actividades en la escuela primaria y, posteriormente, en una relectura y discusión de los materiales teóricos. Les resulta difícil comprender la diferencia entre concebir la escritura como un código de transcripción gráfico del habla, o que la escritura constituye una representación del lenguaje. La alfabetización no es una adquisición natural del lenguaje escrito, sino que implica la construcción y el aprendizaje del sistema de la lengua junto con las estrategias de uso del lenguaje escrito. Es necesario incorporar a este aprendizaje la dimensión plural y social, dado que la práctica del lenguaje escrito se produce en una comunidad concreta, entre personas que comparten o no un mismo dialecto, con formas expresivas que son el resultado de intercambios previos a lo largo de la humanidad.

En tal sentido, valoro que la propuesta de construir una secuencia didáctica para reflexionar sobre las creencias iniciales de los futuros docentes, e implementar actividades de lectura de materiales bibliográficos con el fin de desarrollar la conciencia metalingüística, es una base para generar un contexto orientado a preguntar, reflexionar, generar preguntas, discutir y poner en común las reflexiones. Constituye también una manera de activar los conocimientos que los alumnos tienen de manera inconsciente para que puedan analizar conscientemente el funcionamiento de la lengua a través de la incorporación de los niveles de funcionamiento de su uso. Los cuestionarios iniciales permitieron que comenzaran a pensar sobre lo que consideraban que es la ortografía, la revisión de las secuencias didácticas que construyeron inicialmente permitieron reflexionar sobre lo que sabían, la autoevaluación constituyó un momento especial para revisar los materiales teóricos y discutirlos en función de que emergiera la conciencia metalingüística, el debate contribuyó a discutir las ideas sobre la simplificación ortográfica y la producción de las síntesis informativas posibilitó pensar lo trabajado. 
Me parece que una cuestión central para comenzar a enseñar la ortografía es que los docentes enseñen a los alumnos las regularidades y las irregularidades de las normas a través de actividades o secuencias didácticas diseñadas para el descubrimiento, la comprensión y la construcción de las reglas. En este marco, el error debe dejar de ser una muestra de la falta o de lo que no se sabe, sino que debe ser fuente de información sobre lo que falta aprender o sobre las hipótesis que los alumnos construyen sobre el objeto de conocimiento. Es necesario que en la formación docente se produzca una articulación entre los saberes o conocimientos disciplinares y los avances que se producen en relación con la didáctica. Si bien muchas veces los futuros docentes solicitan la "receta mágica" o la intervención magistral, las investigaciones que se han realizado en el marco de la Didáctica de la Lengua indican que no existen recetas ni soluciones mágicas y que el docente debe estar preparado para saber qué hacer en un momento determinado. Por otra parte, es imprescindible que el docente también investigue sobre su propia práctica para enriquecer los procesos de enseñanza y aprendizaje.

\subsection{Conclusiones sobre las creencias de los alumnos}

\section{- Sobre el concepto de ortografía y la simplificación ortográfica}

En relación con el significado de ortografía, en un principio los estudiantes señalaron cuestiones vinculadas a la norma para una escritura correcta, sin errores. A medida que fueron reflexionando sobre las acciones realizadas, especialmente en la producción de las síntesis informativas, como hemos visto comenzaron a escucharse vinculaciones de la ortografía con la necesidad de garantizar la comunicación en un diasistema como el español y la perdurabilidad de la lengua española. Al respecto, he podido observar una evolución en la forma de pensar de muchos alumnos sobre la necesidad de incorporar una evaluación formativa, que revea el error como un elemento necesario para construir aprendizaje.

Antes de leer materiales, de discutir y poder reflexionar sobre la importancia que tiene la ortografía en la comunicación y en la perdurabilidad de una lengua, varios alumnos se inclinaban por simplificar la ortografía. Pero, después del debate, algunos iniciaron un proceso de comprensión de la importancia que tiene la convención ortográfica.

\section{- Sobre la enseñanza y el aprendizaje de la ortografía}

Las primeras ideas que sostienen los alumnos cuando se trata de pensar en la enseñanza de la ortografía es la relevancia que tiene la oralidad sobre la escritura. 
Pareciera que lo primero que surge naturalmente es que la lengua oral es la unidad básica de la comunicación y que la escritura implica poner en papel lo que se ha dicho. En el Nivel Superior -e incluso en la tradición escolar - se piensa que la escritura es una reproducción del lenguaje oral. Esto implica que muchos docentes comiencen la enseñanza de las primeras letras asociándolas y repitiendo los sonidos, o bien a partir de la escritura y pronunciación de ciertas sílabas, como si los alumnos pudiesen reconocer desde el principio los sonidos de las consonantes y vocales que están aprendiendo. Posteriormente, cuando ya pueden escribir palabras aisladas, se enfatiza que atiendan a la pronunciación de las palabras en el enunciado para poder separarlas y escribirlas. Debemos considerar que hay numerosas investigaciones que muestran cómo los niños pre-alfabetizados o que están iniciándose en la alfabetización presentan dificultades para segmentar las palabras y las sílabas en los sonidos vocálicos y consonánticos. Uno de los descubrimientos más importantes ha sido que la capacidad de segmentar los sonidos de las consonantes y vocales no es una actividad que precede al aprendizaje de la lectura y la escritura, sino que guarda una estrecha relación con la forma en que va evolucionando este aprendizaje.

En la producción de las síntesis informativas, lo primero que expresaban algunos alumnos era la necesidad de pronunciar bien las palabras para que hubiese una mejora en la ortografía de los alumnos. En este punto discutimos una cuestión central que se relaciona con la cultura escrita. Nos planteamos qué es la escritura y cómo desarrollar el input de lo escrito con los niños en la edad de la escritura. Además, reflexionamos sobre dos modelos que presentan una visión muy diferente de la enseñanza de la ortografía española. Por un lado, están los que se basan en una ortografía transparente y que se proponen enseñar desde el establecimiento de la relación fonema-grafema, argumentando que los mecanismos fonológicos son fundamentales en la primera etapa de aprendizaje de la escritura. Por otro lado, se plantea que la ortografía española no tiene tal transparencia y que se debe reflexionar con el alumno sobre las regularidades e irregularidades para que vaya construyendo un conocimiento gráfico, dado que no se puede separar la enseñanza de la ortografía de la enseñanza de la lengua escrita.

Es necesario tener conciencia de la importancia que tiene la alfabetización inicial como la única solución posible de fondo al problema de la alfabetización de adolescentes y adultos. Tradicionalmente, el planteo de la alfabetización se ha hecho en función de cuál es el método que se utilizará y el estado de "madurez" o de inteligencia del niño. Se consideran, así, dos de los polos del proceso de aprendizaje, el que enseña y el que 
aprende pero se deja de lado el tercer elemento de la tríada didáctica: la naturaleza del objeto de conocimiento involucrado en este aprendizaje.

\subsection{Conclusiones sobre la reflexión metalingüística}

Esta investigación ha sido relevante dado que se ha presentado un problema para que, tanto para mí -en mi rol de docente investigadora- como para los alumnos de formación docente, reconsideráramos la enseñanza de la ortografía. La relevancia está dada en el hecho de que se propició que los futuros docentes pudieran aprender a partir de la experiencia, en la que se cuestionaron conceptos teóricos y se aplicaron en el aula para conocer sus resultados. Así, se pudieron articular dos ejes: (i) la enseñanza de la ortografía en el marco de situaciones reales de escritura y a través de la reflexión metalingüística; y (ii) la reflexión sobre las creencias de los alumnos de formación inicial del profesorado.

En algunos pequeños grupos, se rescató la oposición entre el conocimiento inconsciente y el consciente del lenguaje. Los alumnos señalaron que es importante pensar sobre lo que uno tiene de manera inconsciente, pero explicaron que el problema es que es difícil si no le enseñan a pensar. Por eso destacaron la importancia que tiene que el profesor conozca esto para poder hacerlo con los alumnos. Además, valoraron la evaluación formativa y la importancia que tiene que el error no sea un elemento negativo, sino que sirva para construir conocimiento. De acuerdo con sus vivencias, afirmaron que actualmente se sigue tomando en la escuela el dictado nada más que para marcar los errores que tienen los alumnos. No se hace un aprendizaje de eso, solamente se marca que comete faltas de ortografía.

En tal sentido, pude observar es que no alcanza con brindarle teorías y sugerirles cambios y nuevos marcos teóricos para que los futuros docentes construyan el objeto de conocimiento. También es necesario darles la oportunidad de llevarlos al aula de la escuela primaria para poder vivenciar lo que explican los marcos teóricos y que puedan reconocer y legitimar, a partir de la propia experiencia, cuáles son las ideas que facilitan los procesos de innovación que se pretenden llevar a la práctica.

El conocimiento ortográfico está constituido por diversas facetas que deben ser consideradas en el proceso de enseñanza y aprendizaje, por lo cual no basta con la presentación de las reglas. Las normas que deben construir los alumnos a partir de participar en discusiones con el grupo y el docente, de leer y consultar materiales escritos y de consulta, pueden ser agrupadas en cuatro categorías: a) las que tienen relación con la correspondencia letra-sonido; b) las que tienen relación con usos específicos de las 
letras para indicar el sonido según el contexto de uso; c) las que especifican la escritura de los morfemas; y d) las que se basan en la escritura de las familias de palabras. Por lo expuesto, el docente debe estar capacitado para reconocer que la ortografía cumple diversas funciones:

- En el plano lingüístico y comunicativo constituye un dique de contención del lenguaje oral por su convencionalismo y favorece la transmisión integra de los enunciados.

- En el plano sociolingüístico es un elemento unificador de las diferentes variedades del lenguaje oral, dado que la ortografía señala los signos gráficos que deben representar los sonidos y forma un sistema coherente, con convenciones que perduran en el espacio y el tiempo.

- En el plano académico y escolar el conocimiento ortográfico representa el nivel cultural del alumnado.

- En el plano pedagógico se debe garantizar que la enseñanza de la ortografía sea motivadora y que se integre a la experiencia global de los alumnos.

El análisis de las interacciones verbales me permitió observar que los alumnos pueden analizar ciertas cuestiones y que, para resolver otras, necesitan saberes específicos. Por ejemplo, me refiero a profundizar en conocimientos sobre la vinculación de la ortografía con la gramática y, específicamente, con los niveles de la organización y el funcionamiento de la lengua en contexto. Para los alumnos futuros docentes que participaron en esta experiencia de investigación, en la escuela primaria hace falta que haya estrategias adecuadas de enseñanza de la ortografía y no que sean un mero conjunto de reglas ortográficas que hay que memorizar. En el proceso de la investigación se pudo observar que, al comienzo, algunos se acercaban con cierta desconfianza a un objeto de estudio que les generaba temores, vergüenza e inseguridad. Después, a medida que íbamos explicando los materiales, focalizando en la ortografía como un elemento que ha sido históricamente problemático por la manera en que se ha propuesto su abordaje, muchos comentaron que se sentían más cómodos con el trabajo que habíamos iniciado.

Por otra parte, el análisis de las situaciones didácticas que se proponen en los libros destinados a la ortografía y la revisión de los materiales sobre la construcción y reconstrucción de la lengua escrita generó que hubiese una apertura a considerar el conocimiento ortográfico como un elemento que debe ser abordado en el proceso de escritura. A veces, no se toma conciencia de que los alumnos leen la bibliografía y la 
reproducen en las evaluaciones parciales sin que hayan comprendido totalmente la teoría. Por ello, es importante el trabajo en el aula con alumnos de escolaridad primaria y una nueva reflexión y análisis de los materiales teóricos en el aula de la formación docente. Comprobar que reflexionar sobre los rasgos contextuales de la escritura genera necesariamente un trabajo metalingüístico sobre el producto escrito es un aprendizaje para los alumnos de la formación docente. En tal sentido, los futuros docentes pudieron observar que se deben propiciar las condiciones en el aula para que haya una reflexión metalingüística y que esto incluye el contenido a enseñar, cómo lo concebimos, las actividades que propongamos, el trabajo en pequeños grupos y el colectivo y una diversidad de situaciones que exijan que los alumnos puedan explicar, pensar, repensar y volver a explicar.

\subsection{Conclusiones sobre la evaluación formativa}

La evaluación formativa para enseñar y aprender a escribir es fundamental porque permite que, tanto el docente como los alumnos, puedan focalizar en la enseñanza y en el aprendizaje, en lugar de la evaluación con intenciones de calificar. Este tipo de evaluación me ha permitido reflexionar acerca de las prácticas habituales donde el lenguaje escrito es objeto permanente de evaluación y se pierde la posibilidad de enfocar su enseñanza. Además, la evaluación formativa posibilita considerar las características que tienen los alumnos para adaptar los procedimientos que se utilizan en la clase en función de que sea mayor el número de alumnos que alcanza aprender.

Por otra parte, la evaluación formativa permite incluir progresivamente a los alumnos en una comunidad de discurso a partir de que puedan hablar y escuchar, leer y escribir para poner en común las ideas que tienen y construyen sobre el objeto de conocimiento. Pudimos partir de las creencias e ideas iniciales que los alumnos tenían y, a través del diálogo que se generó en el aula de formación inicial de docentes, construir conocimientos en la interacción, mientras se apropiaban de información necesaria para reflexionar sobre el objeto de conocimiento y su enseñanza. Estos alumnos se han formado en los niveles primario y secundario sin enseñanza de contenidos gramaticales, por lo que les faltan conocimientos para que puedan reflexionar sobre las categorías gramaticales de la lengua y vincularlas con el uso. En algunos casos han tenido enseñanza de la ortografía de una manera tradicional, sin que haya una reflexión de las dificultades que presenta la construcción del conocimiento ortográfico y se focalizaban el error y el aprendizaje de reglas. En otros, ni siquiera han tenido un acercamiento a la ortografía porque se fue dejando de lado su enseñanza en la escuela. 


\subsection{Implicaciones de esta investigación hacia el futuro}

Considero que el proceso de formación de un docente es un proceso de aprendizaje que se articula de manera significativa sobre el conocimiento previo que tiene el estudiante, que está moldeado por su propia experiencia como alumno. En función de que el sistema de creencias y representaciones de los futuros docentes funciona como un filtro que orienta las prácticas del aula, para mí fue relevante analizar los argumentos que expusieron sobre la reforma ortográfica. Mi trabajo se basó en considerar las creencias de los estudiantes y la necesidad de desarrollarlas y matizarlas en un proceso de implicación en reflexiones conjuntas, de elaboración de material, de contraste con la teoría y la práctica, con el propósito de desarrollar con los alumnos un proceso de actividad metalingüística.

Reconceptualizar la escritura implica que los alumnos futuros docentes aprendan que, además de considerar el papel comunicativo que tiene el uso de la lengua, es necesario que los alumnos puedan participar de las actividades y decisiones que el productor textual debe realizar y tomar cuando escribe. Esto significa tener en cuenta el problema retórico, el contenido, el tipo de léxico que se emplea y las estructuras lingüístico-discursivas que caracterizan un texto, la organización y disposición de las partes textuales en un determinado soporte, etc. La otra cuestión es que puedan observar que la corrección no es solamente ortográfica y que es importante que los alumnos puedan discutir entre ellos y con el docente qué forma es más adecuada y tengan a disposición libros, diccionarios, manuales para consultar. En otras palabras, es necesario que los alumnos puedan comprender las tareas que realiza un escritor al producir y publicar un texto.

Recupero como relevante el papel que pude asumir como docente-investigadora en promover una situación de andamiaje que permitiera recuperar los conocimientos previos de los alumnos futuros docentes y que con la implementación de la secuencia didáctica los alumnos pudiesen hacerse responsables de su aprendizaje y que, después de la discusión de los materiales en un espacio de taller, haya podido promover la autonomía de estos dos grupos de estudiantes. Rescato la necesidad de la figura del docente como el encargado de producir una situación de andamiaje en la recuperación de creencias iniciales de los alumnos y en la promoción de la reflexión metalingüística para que los alumnos construyan el conocimiento. El habla exploratoria es una herramienta fundamental en la construcción de este conocimiento. 
Esta posibilidad de desdoblamiento entre los roles de docente e investigadora logró que pudiese analizar que lo importante no es la formación entendida como la aprehensión de estrategias de enseñanza a partir de la práctica áulica, ni como la aplicación de recetas provenientes de la teoría, sino como la progresiva incorporación de los alumnos a una comunidad de discurso, donde puedan reflexionar sobre la enseñanza y el aprendizaje de los alumnos cuando se trata de enseñar y aprender ortografía. De manera progresiva los materiales bibliográficos explorados fueron incorporándose al discurso de los futuros docentes y reelaborando las ideas iniciales que tenían sobre la ortografía y su enseñanza

\section{Referencias bibliográficas}

Alegría Izcoa, J. \& Carrillo Gallego, M.S. (2014). "Mecanismos implicados en la escritura de palabras del castellano". En Aula, 20, pp.45-64.

Arnoux, E.; Nogueira, S. y Silvestri, A. (2007). "Habilidades metacomprensivas en estudiantes de profesorado: la formulación de preguntas". En Folios, 25, Bogotá: Universidad Pedagógica Nacional, pp. 81-96.

Borg, S. (2003). "Teacher cognition in language teaching: A review of research on what language teachers think, know, believe, and do". En Language Teaching, 36(2), pp. 81-109.

Borg, S. \& Burns, A. (2008). "Integrating Grammar in Adult TESOL Classrooms". En Applied Linguistics, 29(3), pp. 456-482.

Borzone de Manrique, A.M. (1999). "Conocimientos y estrategias en el aprendizaje inicial del sistema de escritura”. En Lingüística en el Aula, 3, pp. 7-29.

Borzone de Manrique, A.M. \& Diuk, B. (2001). "El aprendizaje de la escritura en español: Un estudio comparativo entre niños de distinta procedencia social". En Interdisciplinaria, 18(1), pp. 35-63.

Borzone, A.M. \& Diuk, B. (2003). "La escritura de textos en niños pequeños: Conocimiento ortográfico y producción textual”. En Cultura y Educación, 15, pp. 17-27.

Braithwaite, J. (1999). "Does it matter what I think? - an exploration of teachers constructions of literacy and their classroom practices". Paper presented at the European Conference on Educational Research, Lahti, Finland, 22-25 September 1999.

Calderhead, J. (1987). "Developing a Framework for the Elicitation and Analysis of Teachers' Verbal Reports". En Oxford Review of Education, 13(2), pp. 183-189. (1996). "Teachers: Beliefs and knowledge". En Berliner, D.C. \& Calfee, R.C. (eds.). Handbook of Educational Psychology. New York: Macmillan, pp. 709725.

Calsamiglia Blancafort, H. y Tusón Valls, A. ([1999] 2001, $1^{\text {a }}$ reimpresión). Las cosas del decir. Manual de análisis del discurso. Barcelona: Editorial Ariel.

Cambra, M. (2003). Une approche ethnographique de la classe de langue. París: Didier.

Cambra, M.; Fons, M.; Palou, J. \& Civera, I. (2008). "Los procesos de reflexión de los docentes y la innovación en las aulas plurilingües". En Camps, A. \& Milian, M. 
(coords.). Miradas y voces. Investigación sobre la educación lingüística y literaria en entornos plurilingües. Barcelona: Graó, pp. 45-60.

Camps, A. et al. (1990). La enseñanza de la ortografía. Barcelona: Graó.

Camps, A. \& Milian, M. (2000). El papel de la actividad metalingüística en el aprendizaje de la escritura. Rosario: Homo Sapiens.

Camps, A. \& Ribas, T. (2000). La evaluación del aprendizaje de la composición escrita en situación escolar. Madrid: Ministerio de Educación, Cultura y Deporte, Secretaría General de Educación y Formación Profesional, Centro de Investigación y Documentación Educativa.

Camps, A. (Coord.). (2001). El aula como espacio de investigación y reflexión: investigaciones en didáctica de la lengua. Barcelona: Graó.

Camps, A. \& Zayas, F. (coords.). (2006). Secuencias didácticas para aprender gramática. Barcelona: Graó.

Camps, A. (2009). "Actividad metalingüística y aprendizaje de la gramática: hacia un modelo de enseñanza basado en la actividad reflexiva". En Cultura y Educación, 21, pp. 199-213.

(2012). "La investigación en didáctica de la lengua en la encrucijada de muchos caminos". En Revista Iberoamericana de Educación, № 59, pp. 23-41.

(2014). "Hacia una renovación de la enseñanza de la gramática". En Lenguaje y textos, 40, pp. 7-18.

Carratalá Teruel, F. (2013). Tratado de didáctica de la ortografía de la lengua española. La competencia ortográfica. Barcelona: Ediciones Octaedro.

Clandinin, D.J. (1985). "Personal Practical Knowledge: A study of teachers' classroom images". En Curriculum Inquiry, 15(4), pp. 361-385.

Connelly, F.M. \& Clandinin, D.J. (1985)."Personal practical knowledge and the modes of Knowing". En Eisner, E. (ed.). Learning and Teaching the Ways of Knowing, 84th Yearbook of the National Society for the Study of Education, Part II. Chigago: University of Chicago Press, pp. 174-198.

Cuetos, F. (1989). "Lectura y escritura de palabras a través de la ruta fonológica". En Infancia y Aprendizaje, 45, pp. 71-84.

De Ketele, J.M. (1984). Observar para educar. Observación y evaluación en la práctica educativa. Madrid: Editorial Visor.

(2003). "La formación didáctica y pedagógica de los profesores universitarios: luces y sombras". En Revista de Educación, 331, pp. 143-169.

Díaz Argüero, C. (2004). "El aprendizaje de la ortografía. Un viejo problema, una nueva perspectiva". En Pellicer, A. \& Vernon, S. (Coord.). Aprender y enseñar la lengua escrita en el aula. México: SM Editores, pp. 97-123.

Dirección General de Cultura y Educación de la Provincia de Buenos Aires (2008). Diseño Curricular para la Educación Primaria. La Plata: Gobierno de la Provincia de Buenos Aires.

Diuk, B.; Borzone, A. M.; Sánchez Abchi, V. \& Ferroni, M. (2009). "La Adquisición de Conocimiento Ortográfico en Niños de 1er a 3er Año de Educación Básica”. En Psykhe, 18(1), pp. 61-71.

Dolz, J. (2009). "Los cinco grandes retos de la formación del profesorado de lenguas". En V SIGET. Simpósio Internacional de Estudos de Gèneros Textuais. Caxias do Sul, Brasil. 
Elbaz, F. (1983). Teacher Thinking: a study of practical knowledge. London: Croom Helm.

Engeström, Y. (1987). Learning by Expanding: An Activity-Theoretical Approach to Developmental Research. Helsinki: Orienta-Konsultit.

Esteve Serrano, A. (1982). Estudios de teoría ortográfica del español. Murcia: Publicaciones del Departamento de Lingüística General y Crítica Literaria, Universidad de Murcia.

Fang, Z. (1996). "A review of research on teacher beliefs and practices". En Educational Research, 38(1), pp. 47-65.

Ferreiro, E. (1997). Alfabetización. Teoría y práctica. México: Siglo XXI Editores. - (2013). "No todo es ortográfico en la adquisición de la ortografía". En El ingreso a la escritura y a las culturas de lo escrito. México: Siglo XXI Editores, pp. 169-186.

Ferroni, M.; Sánchez Abchi, V.; Diuk, B. \& Borzone, A. M. (2008). "La adquisición de la ortografía en español: un estudio comparativo entre niños de distinto sector social de procedencia". Ponencia presentada en las XV Jornadas de Investigación y Cuarto Encuentro de Investigadores en Psicología del Mercosur. Facultad de Psicología - Universidad de Buenos Aires, Buenos Aires.

Ferroni, M.; Diuk, B. \& Mena, M. (2015). "Desarrollo de la lectura y la escritura de palabras con ortografía compleja: sus predictores". En Avances en Psicología Latinoamericana.

Florit, A.M. y Alochis, I.M. (2007). “¿Qué demandan los alumnos de primer año de la universidad?" Ponencia presentada en la Universidad Nacional de Córdoba. Disponible en http://www.fundlitterae.org.ar/images/archivos/13.\%C2\%AA\%20PONENCIA\%20\% 20ALOCHIS-FLORIT\%20Jornadas\%202007.pdf [Sitio consultado el 18/11/2015].

Fontich, X. (2006). Hablar y escribir para aprender gramática. Barcelona: ICE-Horsori. - (2010). "Formación inicial del profesorado y el estudio de caso". En I Congreso Internacional Virtual de Formación del Profesorado. La formación del profesorado en el siglo XXI: propuestas ante los cambios económicos, sociales y culturales. Murcia: Universidad de Murcia.

--- (2011). "La enseñanza de la gramática en primaria y secundaria: algunas reflexiones y propuestas. En $D a$ Investigação às Práticas. CIED-Centro Interdisciplinar de Estudos Educacionais. Escola Superior de Educaçao de Lisboa, 1(2), pp. 39-58.

Fontich, X. \& Camps, A. (2015). "Gramática y escritura en la educación secundaria: estudio de caso sobre los conceptos de los profesores". En Tejuelo. Didáctica de la Lengua y la Literatura, $\mathrm{N}^{\circ} 22$, pp. 11-27.

Frausin, P.; Samoluk, M. y Salas, P. (2012). “La alfabetización académica en la educación superior. Los problemas de lectura y escritura en los alumnos del profesorado de Educación Física de la ciudad de Santa Fe. Una mirada desde los actores". En Boletín Electrónico REDAF, Red Nacional Actividad Física y Desarrollo Humano, Año II, $\mathrm{N}^{\circ}$ 23. Disponible en http://www.redaf.gob.ar/articulos/alfabetizacionacademica-educacion-superior 4a5d.pdf [Sitio consultado el 18/11/2015].

Frías Conde, X. (2001). Introducción a la ortografía iberorrománica medieval. lanua. Revista Philologica Romanica. Suplemento 02.

García Márquez, G. (1997). "Botella al mar para el Dios de las palabras". Ponencia presentada en el I Congreso de la Lengua Española, Zacatecas. 
Grande, E (h) y Jiménez Grotter, V. (2008). "Dificultades en lecto-escritura de los ingresantes universitarios". Trabajo para el módulo V "El docente investigador de su práctica", Posgrado de Especialización en Educación Superior, Universidad Católica de Cuyo.

Harris, R. (1999). Signos de escritura. Barcelona: Gedisa Editorial.

Jakobson, R. (1963). Essais de linguistique genérale. París: Minuit, 1963.

Jiménez Ruiz, J.L. (2013). Lingüística General II. Guía docente. Alicante: Editorial Club Universitario.

Kagan, D. (1990). "Ways of Evaluating Teacher Cognition: inferences concerning the goldilocks principle". En Review of Educational Research, 60(3), pp. 419-469.

Katz, L. \& Frost, R. (1992). "Orthography, phonology, morphology, and meaning: An overview". En Frost, R. \& Katz, L. (Eds.). Orthography, Phonology, Morphology, and Meaning. Amsterdam: Elsevier North Holland Press, pp. 1-8.

Kaufman, A. M. (2005). "Cómo enseñar, corregir y evaluar la ortografía de nuestros alumnos... y no morir en el intento". En Lectura y Vida, Año 26, № 3, pp. 6-20.

Kaufman, A.M. y Rodriguez, M.E. (2008). La calidad de las escrituras infantiles. Cuentos y resúmenes. Ortografía y gramática. Buenos Aires: Editorial Santillana, Aula XXI.

Marín, J.; Cuadro, A. \& Pagán, A. (2007). "Léxico ortográfico y competencia lectora". En Ciencias PsicológicasK, I(1), pp. 15-26.

Martínez Alcalde, M. J. (ed.). (1999). Textos clásicos sobre historia de la ortografía castellana (compilación y estudio introductorio). Madrid: Digibis-Fundación Histórica Tavera.

Martínez de Sousa, J. (1996). Diccionario de ortografía de la lengua española. Madrid: Paraninfo.

Martínez Marín, J. (1992). “La ortografía española: perspectiva historiográfica”. En Cauce, 14-15, pp. 125-134.

Narvaja de Arnoux, E. (2006). "Marcar la nación en la lengua: la reforma ortográfica chilena". En Ámbitos. Revista de Estudios de Ciencias Sociales y Humanidades, núm. 16. Córdoba, España, pp. 41-54.

(2008). Los discursos sobre la nación y el lenguaje en la formación del Estado chileno (1842-1862). Estudio glotopolítico. Buenos Aires: Santiago Arcos.

Nespor, J. (1987). "The Role of Beliefs in the Practice of Teaching". En Journal of Curriculum Studies, 19(4), pp. 317-328.

Olson, D. (1999). El mundo sobre el papel. El impacto de la escritura y la lectura en la estructura del conocimiento. Barcelona: Editorial Gedisa.

Padilla de Zerdán, C. (2003). "Metadiscurso y producción escrita en estudiantes universitarios". En Educación, Lenguaje y Sociedad, Vol. I No 1, pp. 221-236.

Pajares, F. (1992). "Teachers' Beliefs and Educational Research: Cleaning up a Messy Construct". En Review of Educational Research, 62(3), pp. 307-332.

Piacente, T. y Tittarelli, A.M. (2006). "Comprensión y producción de textos en alumnos universitarios: la reformulación textual”. En Orientación y sociedad, v.6, La Plata.

Pujol Llop, M. (2001). "Hacia una visión integrada de la ortografía: comunicativa, cognitiva y lingüística (II)”. En Tabanque: Revista pedagógica, 16, pp. 193-215.

Quinteros, G. (2004). "La libertad de las letras". En Pellicer, A. \& Vernon, S. (Coord.). Aprender y enseñar la lengua escrita en el aula. México: SM Editores, pp. 41-70. 
Real Academia Española (1999). Ortografía de la lengua española. Edición revisada por las Academias de la Lengua Española. Disponible en: http://reec.uvigo.es/varios/Ortografia lengua espanola.pdf [Sitio consultado el 23/10/2015].

Real Academia Española y Asociación de Academias de la Lengua Española (2011). Ortografía de la lengua española. Buenos Aires: Espasa.

Rondelli, F.M. y Di Masso, R.J. (2014). "Consulta a ingresantes 2014 a la Carrera de Medicina Veterinaria acerca de dificultades con la ortografía en la escritura de la lengua castellana". En XV Jornadas de Divulgación Técnico Científicas 2014 - II Jornada Latinoamericana. Facultad de Ciencias Veterinarias, Universidad Nacional de Rosario.

Ruiz Bikandi, U. (2006). "La salida del topo: caminos de transformación práctica en un proceso formativo. Análisis de una entrevista". En Camps, A. (Coord.). Diálogo e investigación en las aulas. Investigaciones en didáctica de la lengua. Barcelona: Graó.

Signorini, A. \& Piacente, T. (2001). "Adquisición de la lectura en español: Las habilidades de procesamiento de palabras en lectores iniciales". En Revista IRICE, 15, pp. 529.

Stake, R. (1999). Investigación con estudio de casos. Madrid: Morata.

Strong-Wilson, T. (2008). "Changing literacies, changing formations: the role of elicitation in teacher action research with new technologies". En Teachers and Teaching: Theory and Practice, 14(5), pp. 447-463.

Taylor, S.J. y Bogdan, R. (1998). Introducción a los métodos cualitativos de investigación. Barcelona: Paidós.

Teberosky, A. (1998). "Enseñar a escribir en la edad de la escritura". En Textos. Didáctica de la Lengua y la Literatura, $N^{\circ} 17$, Lectura y escritura: primeros pasos. Barcelona: Graó.

(2011). "Programar la leitura e la escrita: os textos as actividades, a criança e os professores”. En Da Investigação às Práticas. CIED-Centro Interdisciplinar de Estudos Educacionais. Escola Superior de Educaçao de Lisboa, 1(I), pp. 6-23.

Teobaldo, M. y Melgar, S. (2009). "Competencias en la comprensión lectora y producción escrita. Alumnos de Institutos Superiores de Formación Docente: Dificultades de los estudiantes de 1er. Año". En Informes de investigación de la Dirección de Investigación y Estadística del Ministerio de Educación del GCBA. Disponible en http://www.buenosaires.gob.ar/sites/gcaba/files/2009 competencias en la compr ension lectora y produccion escrita.pdf [Sitio consultado el 18/11/2015].

Van Dijk, T. (1999). Ideología. Una aproximación multidisciplinaria. Barcelona: Gedisa Editorial.

Vázquez, A. (2010). “¿Qué dicen que hacen los estudiantes universitarios cuando escriben desde fuentes?". En Vázquez, A.; Novo, M.; Jakob, I.; Pelliza, L. (compiladoras). Jornadas sobre lectura, escritura y aprendizaje disciplinar. Facultad de Ciencias Humanas, Universidad Nacional de Río Cuarto, pp. 153-174.

Watson, A. (2015). “Conceptualisations of 'grammar teaching': L1 English teachers' beliefs about teaching grammar for writing". En Language Awareness, Volume 24, Issue 1, January 2015, pp. 1-14.

Vernon, S. (2004). “¿Qué tanto es un pedacito?”. ?”. En Pellicer, A. \& Vernon, S. (Coord.). Aprender y enseñar la lengua escrita en el aula. México: SM Editores, pp. 19-40. 
Zamudio Mesa, C. (2004). “¿Por qué aprender a leer y escribir es complicado?”. En Pellicer, A. \& Vernon, S. (Coord.). Aprender y enseñar la lengua escrita en el aula. México: SM Editores, pp. 163-193. 


\section{Anexo}

\section{- Propuesta para trabajar en sexto año de primaria}

\section{SD6, (Alumno 1 en la entrevista semiestructurada)}

\section{Actividad .El docente dictará este discurso al grupo total}

Queridísimos compañeros:

Hoy es el día que hemos elegidos para celebrar este hermoso momento en que empiezan las vacaciones. No importa la lluvia ni algunas fallas organizativas. Lo que importa es que hayamos llegado juntos a esta época del año.

Ya hace un par de semanas que, en los pasillos de nuestra escuela, no se habla de otra cosa, no se huele más que el olorcillo a despedida y a futura pausa.

Es una maravilla que podamos irnos hoy sabiendo que vamos a volver dentro de unos pocos meses, quizá algo más grandes a esta nuestra escuela, nuestra casa, nuestro hogar.

Ahora quiero que dediquemos un aplauso hipercaluroso a nuestros compañeros y compañeras que egresan, para que sientan que los acompañamos con el corazón en sus próximos pasos.

Muchas gracias y felices vacaciones

\section{2 actividad}

Corregir el dictado por pareja.

Hacer un listado de las palabras que están incorrectas.

\section{Actividad}

Hacer una segunda corrección. (Aquí cada uno deberá corregir su propia escritura) a partir de la lista de las palabras incorrectas marcadas por sus parejas

\section{Actividad}

El docente hará un listado en el pizarrón o en afiche de cada una de las palabras escritas como erróneas por los alumnos.

\section{Actividad.}

Se analizará cada una de las palabras, la docente les dirá a los alumnos que busquen en el diccionario u otros medios de información, las palabras que ellos creen que están escritas erróneamente.

\section{Actividad}

Se analizara aquellas palabras que llevan "Il" y "h" 
Llevan "Il” Iluvia-fallas-llegado-pasillos-olorcillo-maravilla-

Llevan "h": hemos-hermoso-hayamos-habla-hogar-hipercaluroso.

Institucionalización. La docente le presentará las siguientes reglas.

Llevan II las palabras que empiezan con Ila-,Ile-,Ilo-,Ilu- fa-,fo-,fu. Por ejemplo, llave, Ileno, llorar, lluvias, fallar, follaje.

Hay algunas pocas excepciones: yacer, yate, yegua, yodo.
Llevan II las palabras que terminan en illo,-illa.Ejemplo,cuchillo rodilla Las palabras que terminan en -alle,-elle,ello, por ejemplo calle, muelle, sello excepto plebeyo.

Se escriben con $\mathbf{h}$ Las formas de los verbos haber, hacer, hallar, hablar, habitar,huir, por ejemplo, habíamos, hicimos, hallo, hablaste, huimos.

Las palabras que comienzan con las sílabas herm-,hog- y el prefijo hiper-,por ejemplo , hermandad, hogareño, hipermercado.

Algunas formas conjugadas del verbo oler, por ejemplo, huelo, huellas. Muchas interjecciones, por ejemplo, ioh!,iuh!, ibah! 
- Propuesta para trabajar en tercer año de primaria

\section{SD12 (Alumna 2 en la entrevista semiestructurada)}

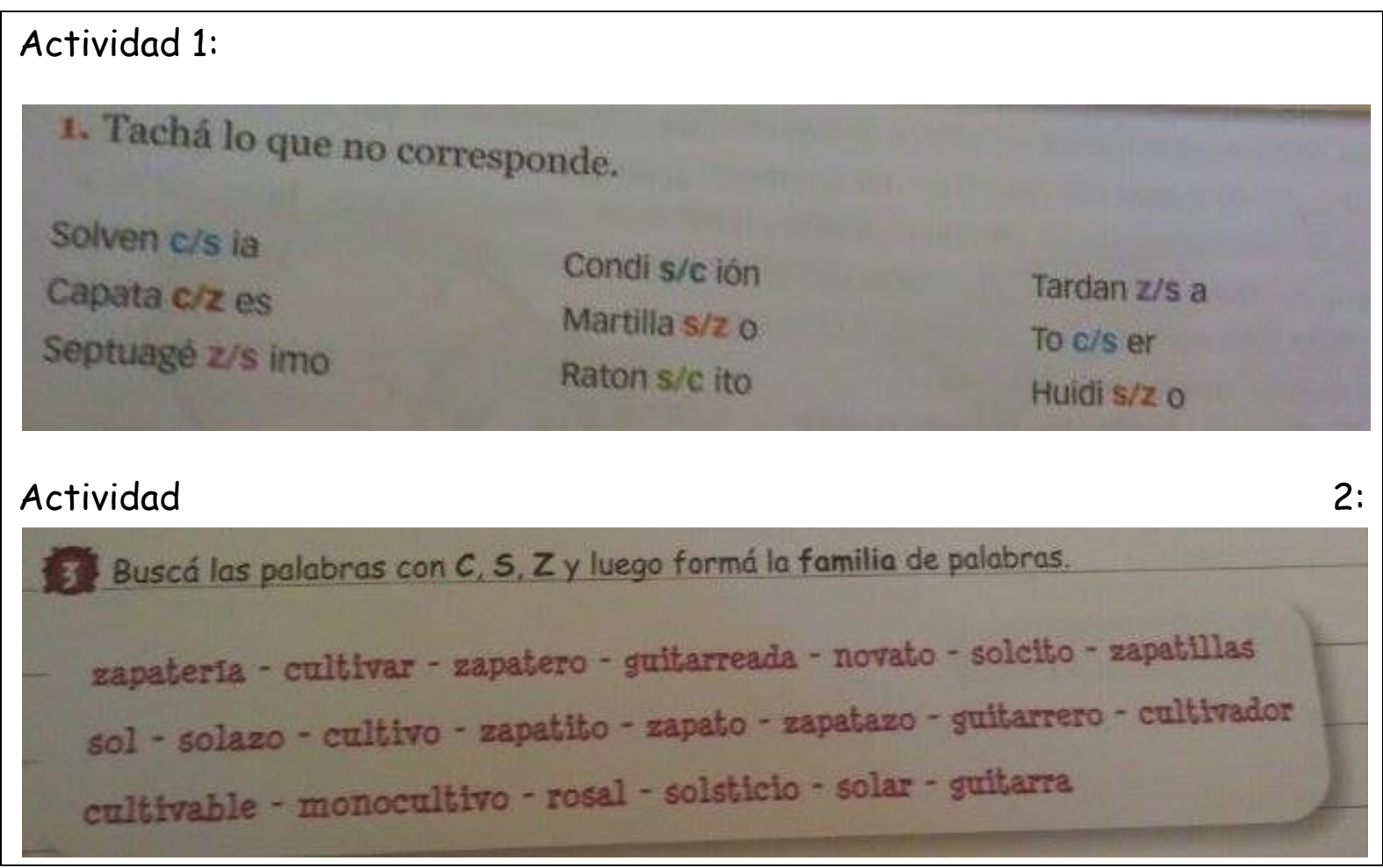

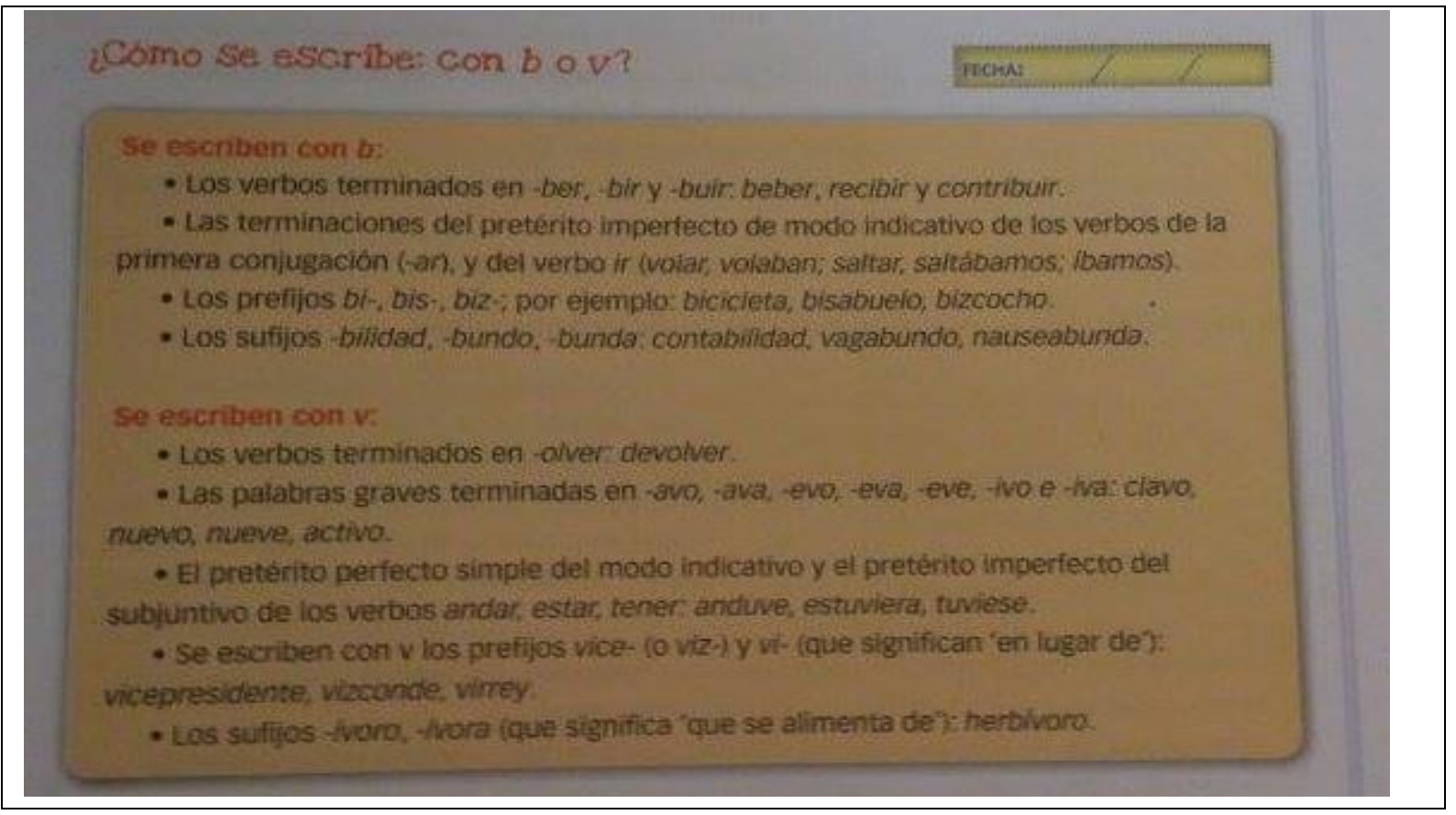




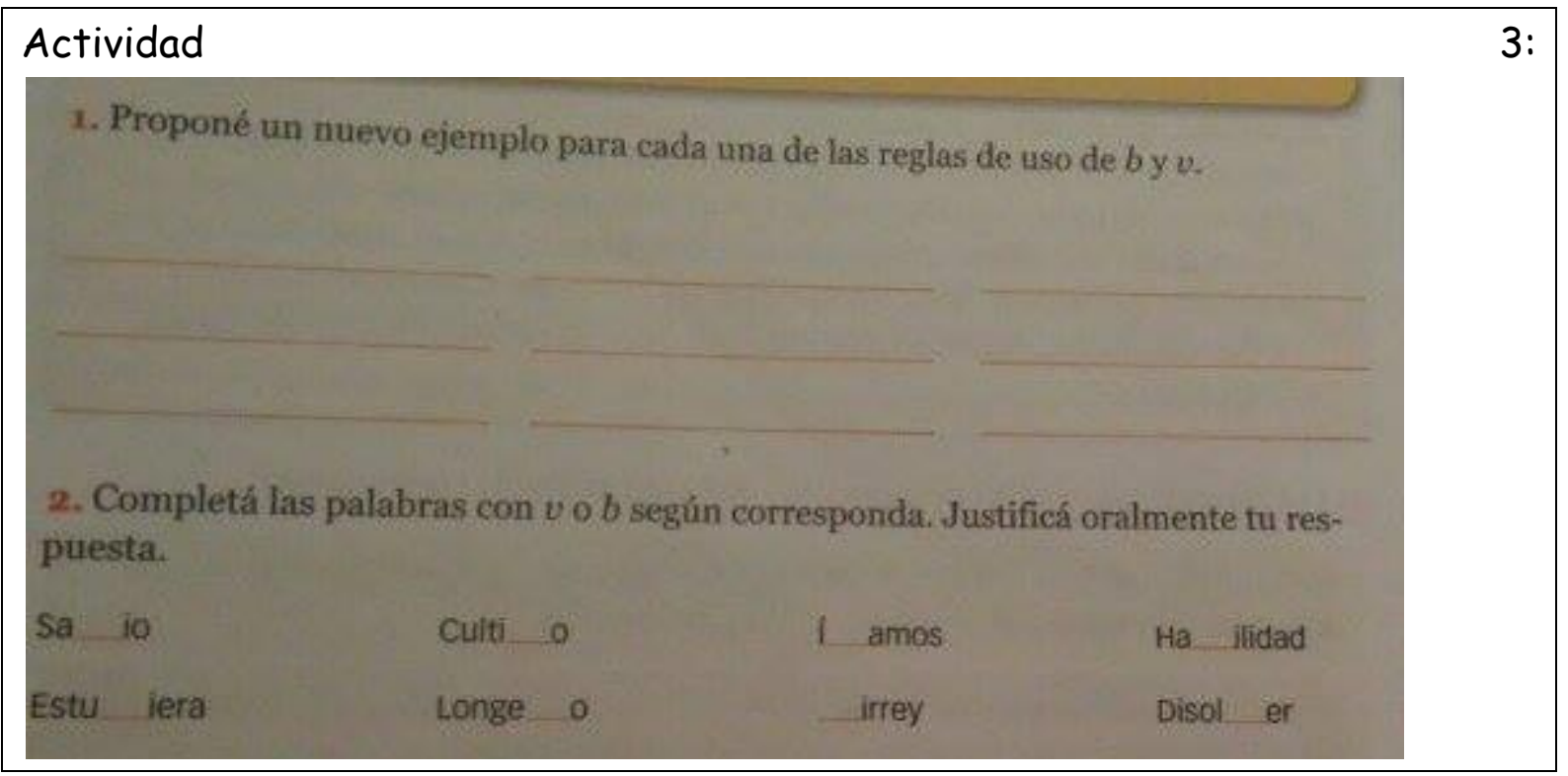




\section{- Propuesta para trabajar en tercer año de primaria}

\section{SD21, (Alumna 3 en la entrevista semiestructurada).}

\section{ACTIVIDAD 1:}

\section{INICIO.}

\section{PALABRAS CON MB Y MP}

Se escribe con $m$ delante de $b$. Se escribe con $m$ delante de $p$.

\section{DESARROLLO.}

1.- Clasifica estas palabras, según si se escriben con mb o con mp.

Ciempiés biombo bambú gambas

Sombra emperador campo champú

Palabras con mb Palabras con $\mathrm{mp}$

2.- Completa las palabras con $\mathrm{mb}$ o $\mathrm{mp}$ y completa estas oraciones.

- La ca__ana sonaba en el alto del ca__anario.

- Aquel ca__esino tocaba bien el ta__or.

- La bo__ billa de la la__ ara se ha fundido.

3.- Completa con $\mathrm{m}$ o $\mathrm{n}$.

e__vío

a__bulancia

cha__iñón

i_vento.

\section{ACTIVIDAD 2}

\section{ALGUNOS SECRETOS DE LA H.}

1)__Lean los siguientes titulares y observen las palabras destacadas.

- Siguen las huellas del famoso ladrón de joyas.

- Discuten el problema de los hielos continentales.

- Encontró la gallina de los huevos de oro.

2) _ transcriban y separen en las sílabas las palabras destacadas. Subrayen los diptongos que reconozcan. 


\section{PALABRAS QUE COMIENZAN CON LOS DIPTONGOS CON UE Y UI SE ESCRIBEN CON H.}

3) - relacionen una sílaba del conjunto $A$ con otra del conjunto $B$ para formar palabras que correspondan a las definiciones. UNA ADVERTENCIA: el redactor de las definiciones atravesaba un mal momento debido a un desengaño amoroso y por eso las escribió destacadas en el medio de los mensajes para su enamorada.
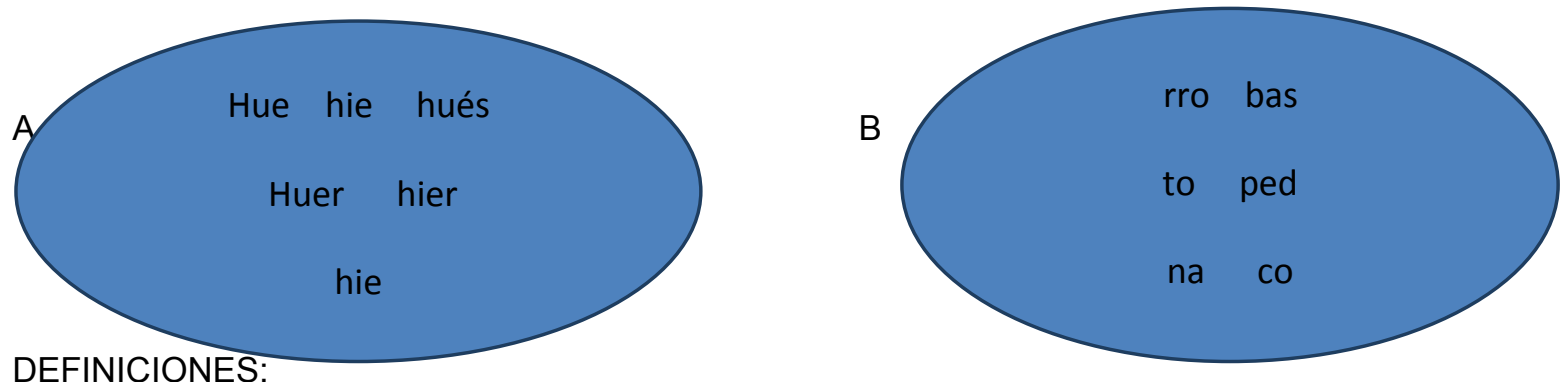

- Cuando te fuiste sentí un vacío difícil de llenar en el corazón.

- Tu risa ya no suena suave y cristalina, sino como de mamífero carnicero que se alimenta de cadáveres.

- Me haces sentir como un individuo que se aloja en casa ajena en tu vida.

- Tu abandono marchitó todas las flores de mi campo o jardín.

- Quisiera arrancarte de mis pensamientos como se arrancan las plantas blandas en el jardín.

- Desde que me dejaste siento un metal de color gris azulado clavado en mi pecho. 